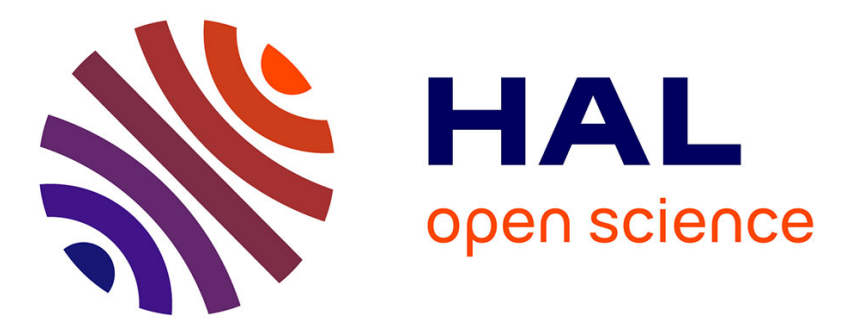

\title{
Économie du bois de feu et sociétés néolithiques: analyses anthracologiques appliquées aux sites d'ambiance humide des lacs de Chalain et Clairvaux (Jura, France)
}

Alexa Dufraisse

\section{To cite this version:}

Alexa Dufraisse. Économie du bois de feu et sociétés néolithiques: analyses anthracologiques appliquées aux sites d'ambiance humide des lacs de Chalain et Clairvaux (Jura, France). Gallia Préhistoire - Archéologie de la France préhistorique, 2005, 47, pp.187-233. 10.3406/galip.2005.2050 . halshs-02338057

\section{HAL Id: halshs-02338057 \\ https://shs.hal.science/halshs-02338057}

Submitted on 21 Jan 2020

HAL is a multi-disciplinary open access archive for the deposit and dissemination of scientific research documents, whether they are published or not. The documents may come from teaching and research institutions in France or abroad, or from public or private research centers.
L'archive ouverte pluridisciplinaire HAL, est destinée au dépôt et à la diffusion de documents scientifiques de niveau recherche, publiés ou non, émanant des établissements d'enseignement et de recherche français ou étrangers, des laboratoires publics ou privés.

\section{(1) (1) $\$$}

Distributed under a Creative Commons Attribution - NonCommercial - NoDerivatives 44.0 


\title{
ÉCONOMIE DU BOIS DE FEU ET SOCIÉTÉS NÉOLITHIQUES
}

\section{Analyses anthracologiques appliquées aux sites d'ambiance humide des lacs de Chalain et de Clairvaux (Jura, France)}

\author{
Alexa DufraissE*
}

Mots-clés. Néolithique, bois de chauffage, modes de collecte, usage et technique, écosystème forestier, stratégies d'exploitation, approche systémique du territoire.

Résumé. Celte étude repose sur l'analyse anthracologique de six sites d'habitat littoraux implantés sur les rives des lacs de Chalain et de Clairvaux. La séquence chronologique débute au Néolithique moyen II avec le Néolithique moyen bourguignon (NMB), vers 3700 av. J.-C., et s'achève au Néolithique final I avec le groupe de Clairvaux, vers 2800 av. J.-C. La problématique de cet article a été axée sur l'étude de l'exploitation du bois de feu destiné aux activités domestiques, en cherchant à démontrer l'existence ou non d'interactions entre, d'une part, les modalités d'exploitation et, d'autre part, l'organisation sociale, le contexte économique et l'environnement. Au cours de la première phase d'analyse, nous avons pu démontrer la qualité et la validité paléoécologique des charbons de bois prélevés en milieu lacustre, moyennant une méthode d'échantillonnage rigoureuse qui diffère parfois de celle appliquée en milieu terrestre sec. Il a été possible de caractériser les modalités d'exploitation du bois de feu, tant du point de vue des modes de collecte que de la gestion de l'espace forestier. Parce que le feu joue un rôle fondamental dans la vie quotidienne, ces communautés agropastorales ont mis en place une véritable économie du bois de feu conditionnée par un certain nombre de variables telles que la société et ses modes de vie, le contexte économique et l'état du milieu transformé, des résultats qui permettent de souligner la performance de l'anthracologie en milieu humide dans l'étude des relations homme/territoire.

Key-words. Neolithic, fire-wood, collect methods, custom and technique, forest ecosystem, exploitation strategy, systemic approach of the territory.

Abstract. This study is based on the anthracological analysis of six littoral dwelling sites of the Chalain and Clairvaux lakes. The chronological sequence starts at the Middle Neolithic II with the Middle Burgundian Neolithic culture (NMB), around 3700 BC, and ends at the I.ate Neolithic I with the group of Clairvaux (around 2800 BC). The topic of this study is the question of the exploitation of fire-wood for household activities, searching to make evident the existence or not of interactions between, at first, the exploitation modalities, then the spatial organization, the economic context and environment. During the first stage of study, it has been possible to make evident the quality and validity of charcoal collected in lake dwellings, by means of a rigorous sampling method which sometimes differs from the one applied in dry lands. The modalities of fire-wood exploitation have been characterized, from the point of view of the collect methods and of the woodland management. Since fire plays a fundamental part in everyday life, these agropastoral communities set up a real economy of fire-wood conditioned with a certain amount of variables such as society and its way of life, and the way it changes and ecomic context, with results that enable us to emphasize the performance of anthracology in wetlands for the study of relationship between man and territory: * LMR 6565 "Laboratoire de Chrono-écologie ", CNRS - Université de Franche-Comté, UFR Sciences et techniques, 16 route de Gray,
F-25030 Besançon. 
Schlagwörter. Feuerholz, Neolithikum, Arten der Holzgewinnung, Methode und Technik, Ökosystem Wald, Strategien der Rohstoffnutzung, Systemischer Ansatz zur Erforschung des Lebensraums.

Zusammenfassung. Diese Untersuchung beruht auf der anthrakologischen Analyse zon sechs Seeufersiedlungen am Lac de Chalain und am Lac de Clairvaux. Die chronologische Abfolge setzl gegen 3700 v. Chr. im Mittelneolithikum (Néolithique moyen II) ein mil dem Burgundischen Mittelneolithikum (Néolithique moyen bourguignon, "NMB ") und endet gegen 2800 v. Chr. im Spätneoltihikum (Néolithique final I) mit der Clairvaux-Gruppe (groupe de Clairvaux). Die hier untersuchte Problematik kreist um die Frage der Gewinnung von Feuerholz für den häuslichen Bedarf. Es sollte den möglichen Wechselwirkungen zwischen der Art und Weise der Holzgewinnung einerseits und der Organisation des Sozialverbandes, dem ökonomischen Kontext und der Umwelt andererseits nachgegangen werden. In der ersten Phase unserer Untersuchung konnte aufgezeigt werden, in welchem Maße im Bereich von Seeufersiedlungen gewonnene Holzkohleproben aussagekräftig und paläoökologisch relevant sind, sofern eine gründliche Methode der Probenentnahme zur Anwendung kommt, die sich mitunter von der bei Landsiedlungen auf Mineralböden praktizierten unterscheidet. Schließlich ließen sich, was die Art und Weise der Rohstoffgewinnung und die Frage der Bewirtschaftung der Waldflächen angeht, die Modalitäten der prähistorischen Brennholzbeschaffung näher charakterisieren. Da das Feuer eine fundamentale Rolle im täglichen Leben spielt, besaßen diese Ackerbau und Viehzucht treibenden Siedelgemeinschaften eine regelrechte Brennholzzirtschaft, die durch eine Reihe von Faktoren wie die Gesellschaftsform und ihre Lebenswelt, den ökonomischen Kontext und den jeweiligen Zustand der durch menschliche Eingriffe gestalleten Umwelt konditioniert war. Die hier erzielbaren Ergebnisse zeigen, wie leistungsfähig die Anthrakologie im Feuchtbodenmilieu für die Untersuchung der Wechselbeziehungen sein kann, die zwischen dem Menschen und seinem Lebensraum bestehen.

Überselzung: Stefan WIRTH

Les questions que soulèvent les rapports entre les hommes et la forêt peuvent être explorées par différentes approches, archéologique, historique ou environnementale. L'organisation et la gestion du milieu dans les stratégies alimentaires (végétale ou animale) reflètent, dans une certaine mesure, l'organisation d'une société, ses modes de vie, sa perception de l'environnement et le milieu dans lequel elle vit. Cependant, pour qu'une société s'approprie un espace, pour que des relations s'établissent entre les villageois et leur milieu, il faut que l'utilisation des ressources soit ancrée dans la vie quotidienne des populations.

La collecte du bois de feu fait l'objet d'une activité fréquente, répétée, quasi quotidienne, et joue de ce fait un rôle fondamental dans les relations que développent les membres d'une même communauté, entre eux et avec leur milieu. Cette collecte peut être réalisée suivant de nombreux critères: certains dépendent des propriétés physiques du bois, d'autres sont clairement déterminés par les traditions. Toutefois, la collecte reste déterminée par le milieu puisqu'elle dépend tout d'abord de la biomasse disponible, de la proximité des ressources ou encore de la diversité spécifique. Les charbons de bois constituent donc d'excellents marqueurs des milieux parcourus et des formations végétales qui s'y développent; c'est d'ailleurs pourquoi, en raison de l'absence de sélection apparente du bois de feu, les diagrammes anthracologiques provenant de contexte domestique sont le plus souvent décrits et inter- prétés en termes d'évolution des peuplements forestiers exploités (Chabal el al., 1999). Néanmoins, ces charbons de bois, résidus émanant du bois de feu sélectionné et transporté par l'homme, sont aussi le reflet des usages, des techniques et des modes de gestion de l'espace forestier.

I es sites d'ambiance humide (lacs, tourbières, paléochenaux) sont particulièrement propices, de par leur richesse documentaire, à l'étude des relations sociétés/environnement. Les excellentes conditions de conservation permettent, en effet, à de nombreuses disciplines d'intervenir et d'appréhender les relations entre l'homme et son milieu avec une perception différente de l'espace et des modes de gestion. Cependant, l'anthracologie en milieu humide a, jusqu'à présent, rarement été considérée comme une discipline à part entière (probablement parce que la conservation des charbons de bois n'est pas spécifique à ce milieu); elle est le plus souvent réduite à une liste de taxons ${ }^{\prime}$ associée à l'analyse des autres restes végétaux (Lundstrom-Baudais, 1986 ; Jacquat, 1988 ; Jacomet $e t$ al., 1989). Pourtant, la dilatation des séquences sédimentaires et la haute résolution chronologique - de l'ordre de la génération - qu'offrent les sites d'ambiance humide permettent d'appréhender, en intégrant les aspects sociaux et environnementaux, l'économie du bois de feu dans sa globalité.

1. Toutes unités de classification des êtres vivants (espèce, genre, famille). 
L'anthracologie appliquée au milieu humide s'avère donc une discipline particulièrement prometteuse pour l'étude des relations des hommes avec leur milieu et le territoire exploité. Précisons d'ores et déjà qu'il s'agit de territoires " journaliers ", c'est-à-dire fréquentés quotidiennement et dont l'étendue peut être estimée à une journée de marche, parfois plus. Ce territoire est typiquement un anthroposystème où interagissent les contextes socioéconomiques et environnementaux. Or, si pour les périodes historiques le territoire est un espace organisé en ager, saltus et silva, cette organisation doit être reconsidérée pour les communautés d'agriculteurs-éleveurs (Néolithique et âge des Métaux), où toute portion de l'espace forestier est susceptible d'être un jour cultivée, puis de retourner à la forêt. À l'intérieur de ce territoire, différentes activités prennent place comme les cultures, la cueillette mais aussi l'élevage, activités qui interagissent et forment un système complexe.

La problématique de cette étude vise donc à caractériser l'économie du bois de feu destiné aux activités domestiques en cherchant à démontrer l'existence (ou l'absence) d'interactions entre, d'une part, les modalités d'exploitation (modes de collecte, gestion des aires d'exploitation) et, d'autre part, l'organisation sociale, le système technique, le contexte économique et l'état de l'environnement transformé. Les habitats littoraux des lacs de Chalain et dc Clairvaux (Jura, France) sont un parfait terrain d'application, grâce aux trente années de recherches dirigées par P. Pétrequin, qui ont permis de restituer les évolutions sociales, techniques, culturelles, démographiques et environnementales.

Pour répondre à cette problématique, et après vérification de la bonne représentativité paléoécologique des charbons de bois (démontrée en milieu terrestre sec), nous caractériserons tout d'abord les formations végétales des boisements exploités dans une dynamique temporelle et spatiale (et leurs modifications, qu'clles soient d'origine climatique, anthropique ou liées à une dynamique naturelle de la végétation), puis nous proposerons des hypothèses sur les aires potentielles d'exploitation. Nous discuterons ensuite des modalités d'acquisition du bois de feu au sein du territoire et des interactions pouvant exister entre l'exploitation du bois de feu et les autres activités pratiquées; une démarche rendue possible grâce à la conservation de la plupart des vestiges organiques non carbonisés. Cette démarche, qui s'appuie sur des témoins archéologiques « mesurables ", rejoint de façon pratique et démontrable les approches théoriques de site-catchment analysis (Higgs, VitaFinzi, 1972) en fournissant des hypothèses sur l'économie du combustible, sa place au sein des ressources alimentaires et énergétiques ainsi quc sur l'organisation d'unc communauté, sa perception du milieu, ses modes de vie, autant d'informations qui fondent aujourd'hui l'archéologie.

\section{LES HABITATS LITTORAUX DES LACS DE CHALAIN ET DE CLAIRVAUX}

\section{APERÇU GÉOGRAPHIQUE, MORPHOLOGIQUE ET CLIMATIQUE}

Les lacs de Chalain et de Clairvaux sont situés dans le massif jurassien, plus prćcisćment dans la Combe d'Ain, à $500 \mathrm{~m}$ d'altitude (fig. 1). La Combe d'Ain est une dépression allongée dans le sens nord-est - sud-ouest, creusée par

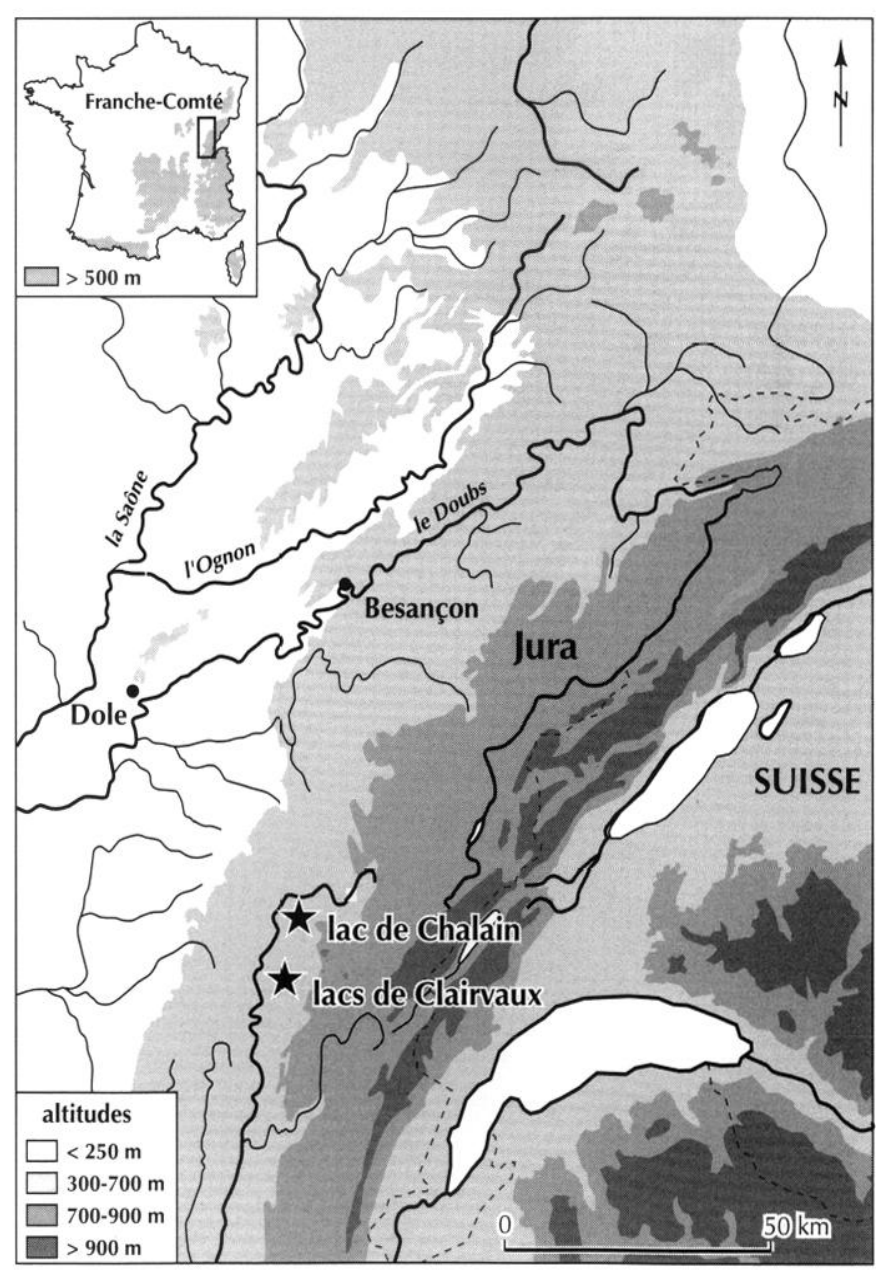

Fig. 1 - Localisation des lacs de Chalain et de Clairvaux dans le massif jurassien. 


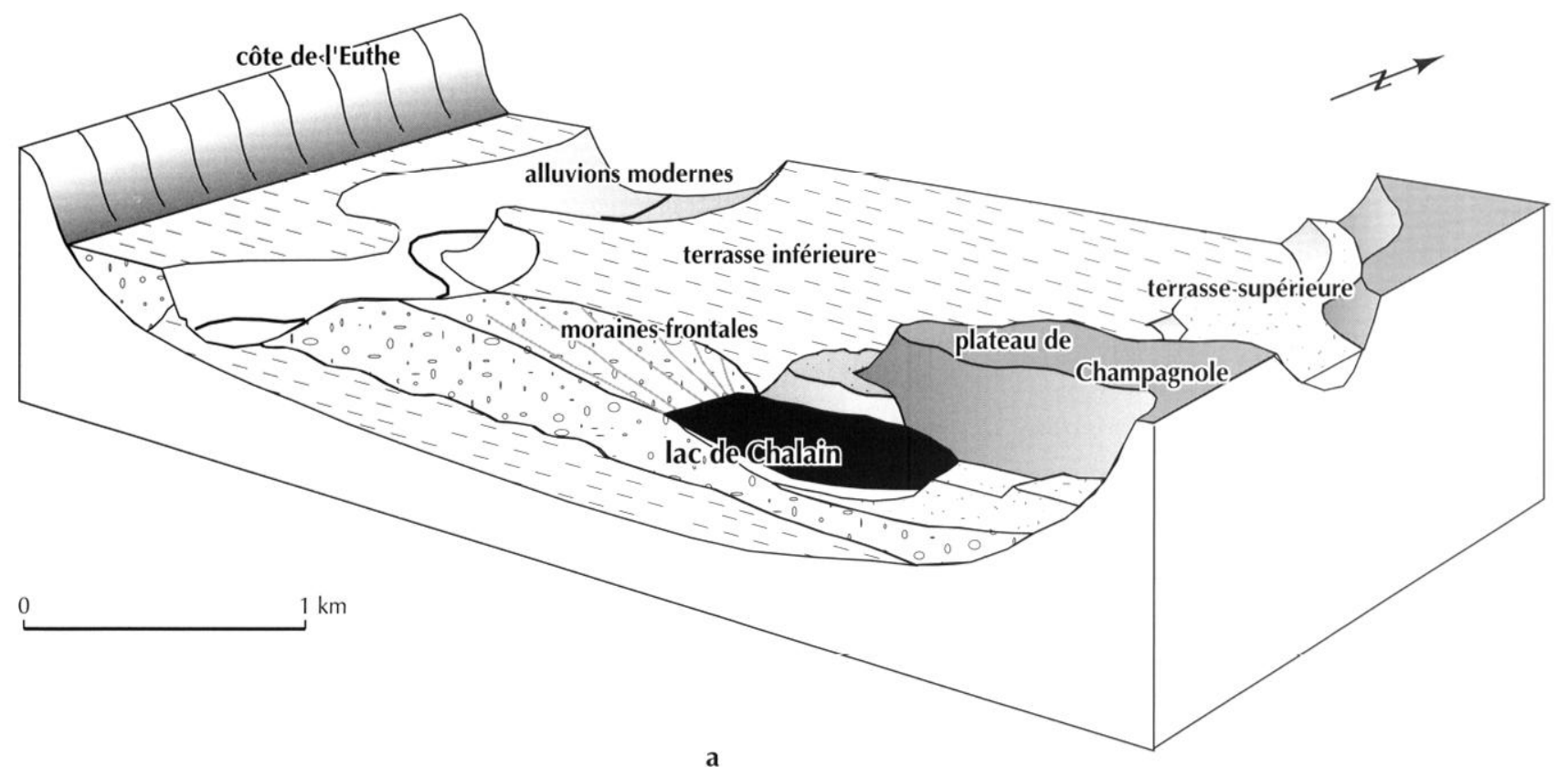

a

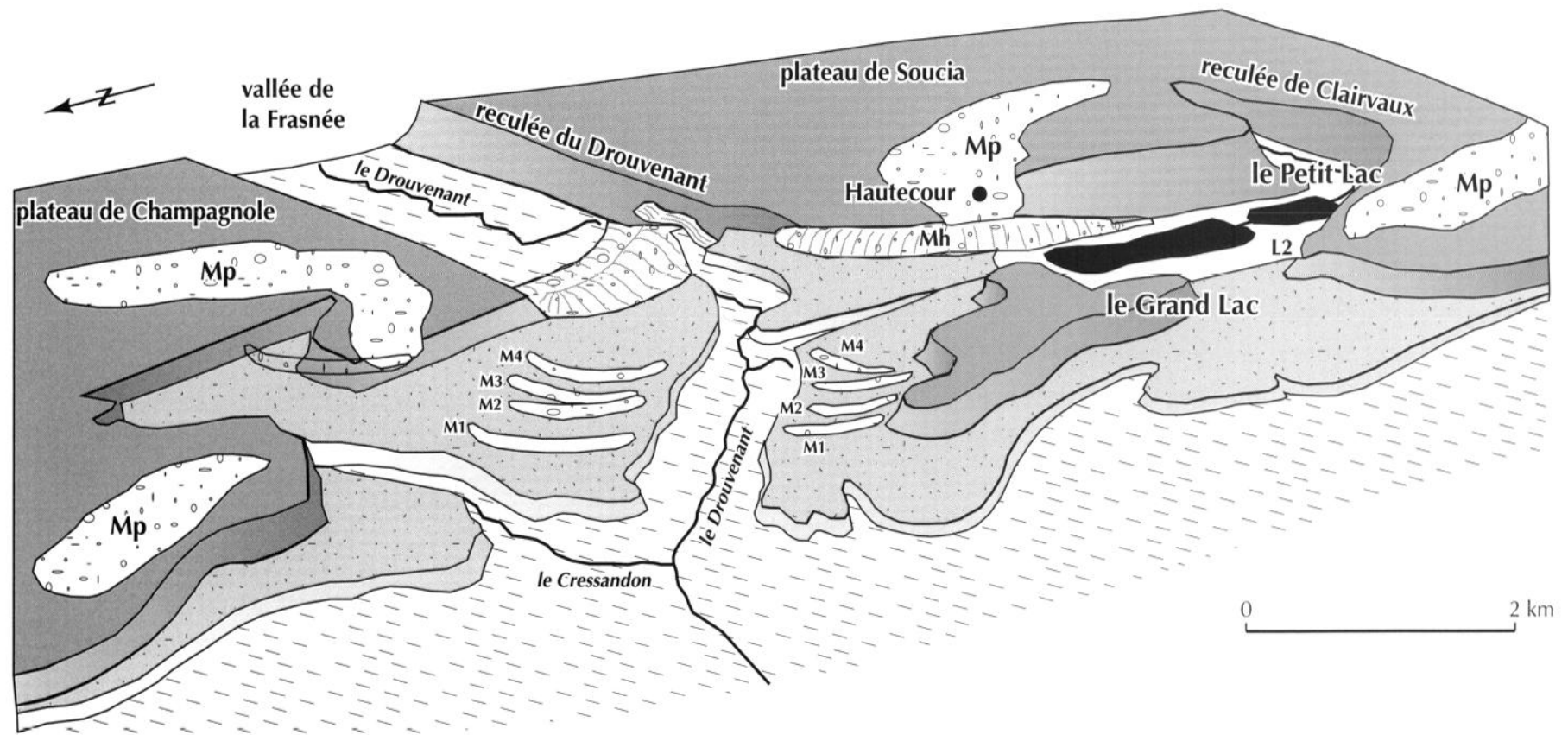

b

M1, M2, M3, M4 : Rides morainiques de Clairvaux

Mc : Moraine de Cogna ₹ double crête

Mh : Moraine de Hautecour ₹ flanc de plateau

Mp : Moraine de plateau

L2 : dépôts lacustres de retrait lacs et craies lacustres

plateaux calcaires du Jura plissé (700 ₹ 1000 m)

terrasse supérieure (525-530 m) : dépôts de progradation

(dépôts grossiers ₹ graviers alternant avec des couches sableuses)

- terrasse inférieure (490-500 m) :

laminite silteuse (varves) ₹ blocs calcaires isolés

[. moraines : argiles $\neq$ blocs

Fig. 2 - Bloc diagramme schématique de la vallée de l'Ain:

a, au débouché de la moraine terminale de Chalain ; b, au débouché de la reculée de Clairvaux (d'après Campy, 1982). 
l'érosion fluviatile. Elle est encadrée à l'ouest par les premiers plateaux du Jura (plateau de Lons-le-Saunier) et à l'est par les plateaux supérieurs (plateau de (hampagnole). Ces derniers sont entaillés par plusieurs reculées dont certaines sont encore occupées par des lacs, comme ceux de Chalain et de Clairvaux, formés par l'avancée des langues glaciaires du Würm dans la vallée de l'Ain. L'altitude varie dans cette région entre $450 \mathrm{~m}$ dans le fond de la vallée, $650 \mathrm{~m}$ sur la côte de l'Euthe et $750-800 \mathrm{~m}$ sur le plateau de Champagnole. Les températures moyennes annuelles sont de l'ordre de $10{ }^{\circ} \mathrm{C}$ dans la Combe d'Ain et varient en fonction du gradient altitudinal $\left(9^{\circ} \mathrm{C}\right.$ sur le premier plateau, $7{ }^{\circ} \mathrm{C}$ sur les plateaux supérieurs et $6{ }^{\circ} \mathrm{C}$ dans la Haute-Chaîne) (Campy, 1982). La Combe d'Ain, protégée par la côte de l'Euthe des vents d'ouest, bénéficie néanmoins d'une situation privilégiée, notamment en ce qui concerne le minimum pluviométrique qui se situent entre 1300 et $1400 \mathrm{~mm}$ au lieu de $1400-1500 \mathrm{~mm}$ pour les régions voisines. Les gels tardifs y sont tempérés par la fréquence des brouillards (Beaufils, 1983).

Le lac de Chalain (commune de Fontenu), orienté estouest, se situe dans la reculée de Chalain (fig. 2a). Seule la rive occidentale - où sont concentrés les habitats littoraux donne sur la terrasse inférieure, précédée d'un front morainique. L'absence de terrasse supérieure - transition entre les moraines et la terrasse inférieure - le distingue morphologiquement des lacs de Clairvaux. Ces derniers (commune de Clairvaux-les-Lacs) sont orientés nord-sud et séparés par un arc morainique surbaissé (fig. 2b). Situés au débouché de la reculée de Clairvaux qui entaille le plateau calcaire de Soucia, ils sont bordés à l'est par le versant pentu de Hautecour, où calcaires et moraines affleurent (terres actuellement utilisées pour les pâturages), puis par le plateau de Soucia, entre 600 et $1000 \mathrm{~m}$ d'altitude (les $800 \mathrm{~m}$ d'altitude sont atteints à $4 \mathrm{~km}$ à vol d'oiseau). Au nord et à l'ouest, ils sont délimités par une terrasse supérieure formée d'alluvions grossières (sols à vocation cćrćalic̀rc au $\mathrm{XIX}^{\mathrm{e}}$ siècle), puis par une terrasse inférieure formée de varves glaciaires imperméables, à forte rétention d'eau terres vouées aux prés et pâturages au XIX ${ }^{\mathrm{e}}$ siècle (Campy, 1982)

\section{VÉGÉTATION ACTUELLE, RÉGIONALE ET LOCALE}

À l'échelle du massif jurassien, les températures et la pluviométrie régissent la répartition de la flore sur plusieurs étages, caractérisés par des séries de végétation qui leur sont propres. Toutefois, au sein de chaque étage, la topographie comme la nature des substrats (limons, calcaires, marnes, cailloutis fluvio-glaciaires, etc.) sont à l'origine d'une grande variété floristiquc (fig. 3) (Ramcau et al., 1980).

On distingue l'étage collinéen, jusqu'à $650 \mathrm{~m}$ d'altitude (plaines, avant-monts et premiers plateaux). Les séries des chênaies caducifoliées (chêne sessile: Quercus sessiliflora; chêne pédonculé : Quercus pedunculata; chêne pubescent : Quercus pubescens) à charme (Carpinus betulus) et à hêtre (Fagus sylvatica), acidiphiles, calcicoles ou mésotrophes dominent cet étage, accompagnés du frêne (Fraxinus excelsior), des tilleuls à petites feuilles et à grandes feuilles (respectivement Tilia cordata et Tilia platyphyllos), des érables champêtre et plane (respectivement Acer campestre et Acer platanoides). En bord dc rivière, les séries des aulnaies avec l'aulne glutineux (Alnus glutinosa), des saulaies avec les saules blanc et pourpre (respectivement Salix alba et Salix purpurea), des aulnaies-frênaies et des ormaies-frênaies investissent les lieux.

Vient ensuite l'étage submontagnard, entre 650 et $800 \mathrm{~m}$ d'altitude, recouvert par des hêtraies, puis l'étage montagnard (de 800 à $1500 \mathrm{~m}$ ) qui est caractérisé par une raréfaction des forêts de feuillus au profit du sapin (Abies alba) en fonction de l'altitude. Le sapin et l'épicéa (Picea abies) deviennent ensuite les essences dominantes accompagnées du pin sylvcstre (Pinus sylvestris) et du pin à crochets (Pinus uncinata). Dans l'étage subalpin, au-delà de $1300 \mathrm{~m}$, où les conditions n'autorisent qu'une croissance réduite du couvert forestier, on peut également voir des hêtraies subalpines, des érablaies, des pessières et des pinèdes dites à lycopodes. Enfin, la pelouse, formée d'herbacées, se substitue progressivement à la forêt.

La situation de la Combe d'Ain, à la transition entre l'étage collinéen et l'étage montagnard, est à l'origine d'une grande variété floristique (fig. 4). Actuellement déboisée, il n'en reste que des friches inexploitables essentiellement constituées de frênes. Cependant, les relevés phytosociologiques actuels, confrontés aux associations déjà décrites dans les régions voisines encore boisées (Côte de l'Euthe, plateau lédonien, plateau de Champagnole), ont permis de restituer la végétation potentielle ${ }^{2}$ (Rameau et al., 1980, Beaufils, 1983) : selon une coupe ouest-est, de l'Ain vers le plateau de Champagnole, les groupements forestiers se

2. Végétation susceptible de se développer indépendamment de l'homme sur un sol donné sous un climat déterminé à l'échelle d'une station. 


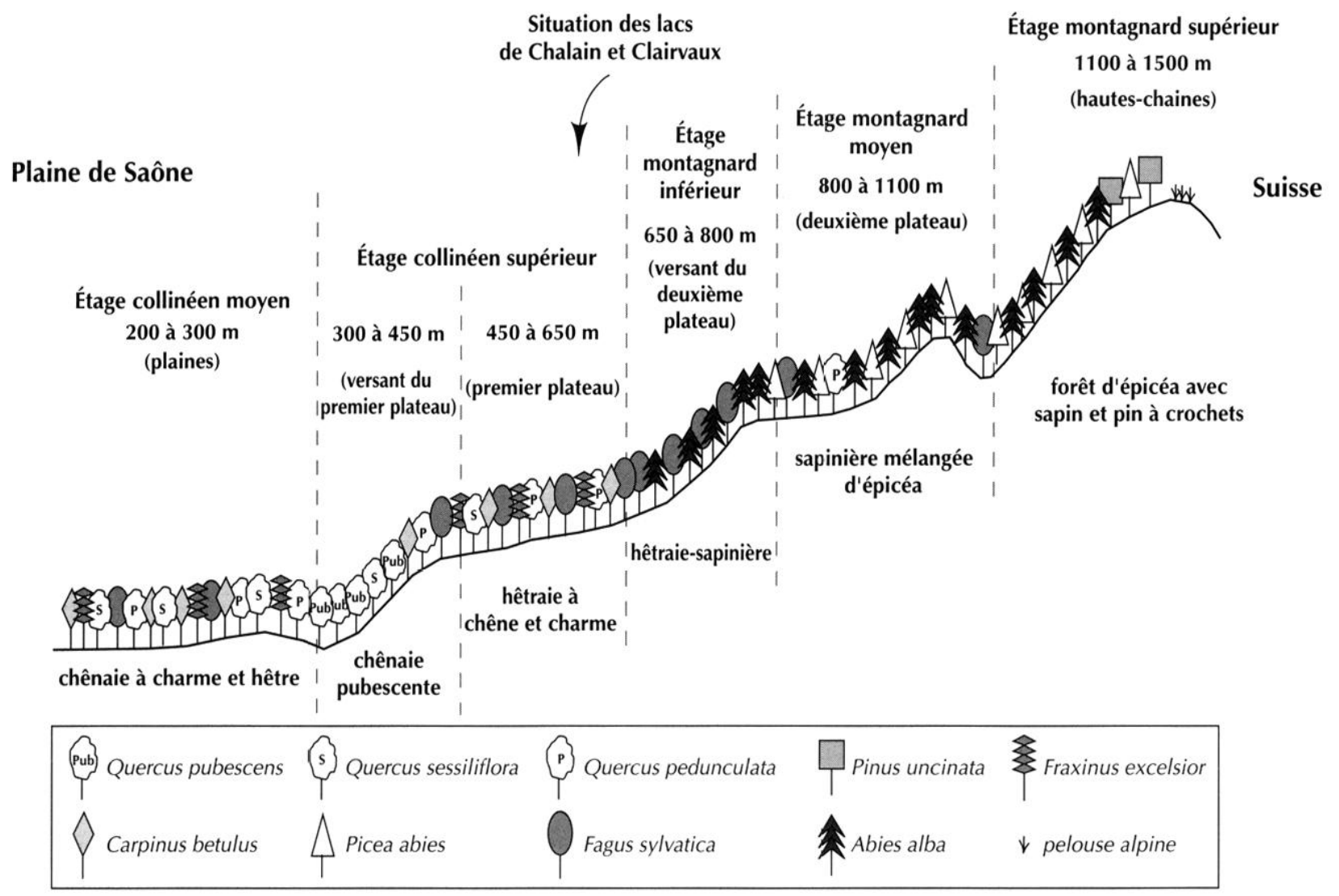

Fig. 3 - Répartition de la végétation climacique en fonction de l'altitude selon une coupe est-ouest dans le massif jurassien (d'après les données de Rameau et al., 1980).

Côte de l'Euthe

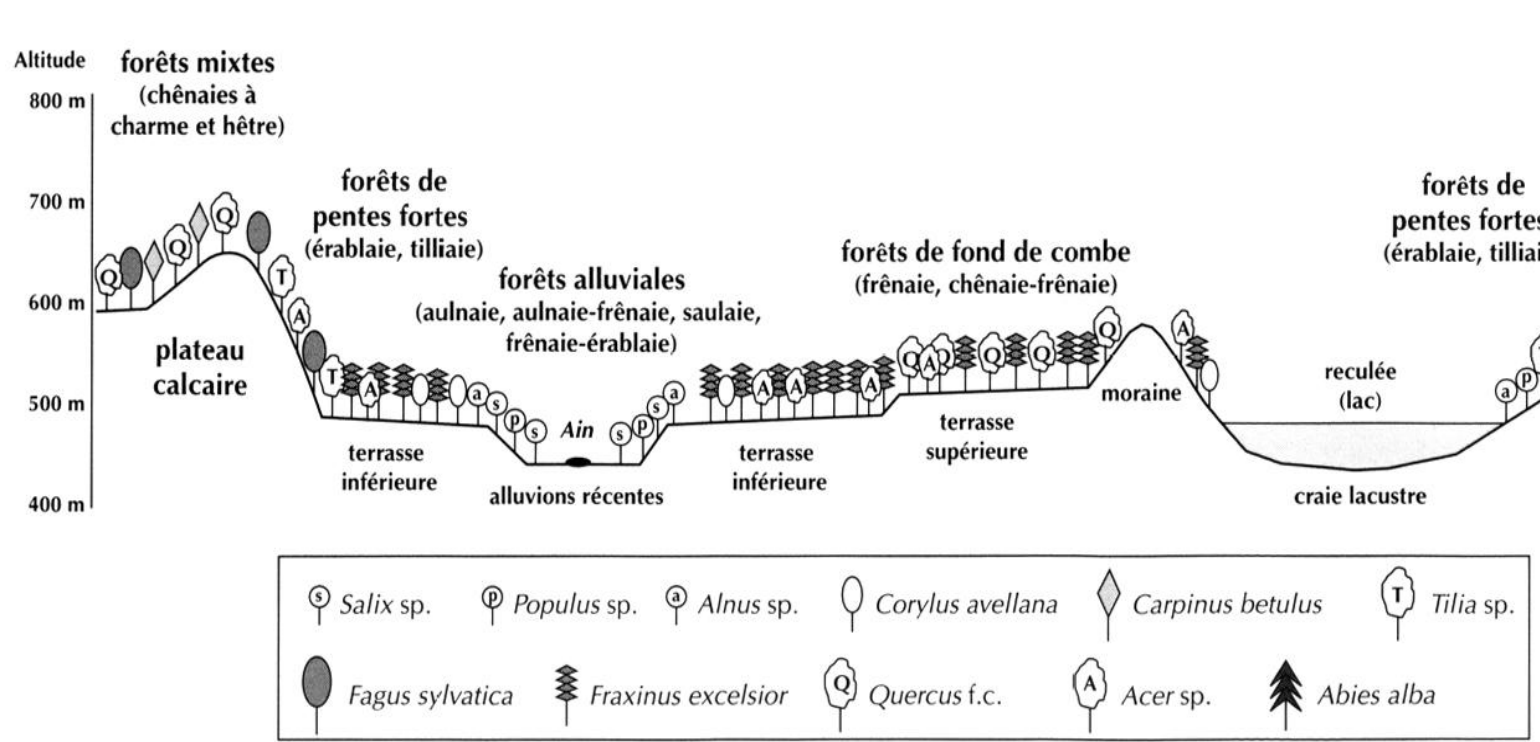

forêts mixtes

(hêtraies à

chênes et charme)

Fig. 4 - Coupe morphologique de la Combe d'Ain selon un axe ouest-est et répartition de la végétation potentielle (d'après les données de Beaufils, 1983). 
succèdent en fonction du degré d'hydromorphie du sol et l'altitude. Ainsi, les bords de lacs et de rivières sont occupés par des forêts riveraines (ou ripisylves) caractérisées par les saules (Salix sp.), les aulnes (Alnus sp.), le frêne (Fraxinus sp.), les érables (Acer sp.). La végétation des premiers plateaux (entre 450 et $650 \mathrm{~m}$ d'altitude) est, quant à elle, principalement composée des chênaies caducifoliées, tandis que les hêtraies (et la hêtraie-sapinière) dominent sur les plateaux supérieurs (650-800 m d'altitude).

Pour terminer, précisons que les lacs de Clairvaux sont plus engagés dans les plateaux supérieurs du Jura que celui de Chalain : l'étage submontagnard (entre l'étage collinéen supérieur et l'étage montagnard inférieur) se situe à $500 \mathrm{~m}$ à vol d'oiseau des lacs de Clairvaux et à $2 \mathrm{~km}$ du lac de Chalain. Quant à l'étage montagnard inférieur, il est à $4 \mathrm{~km}$ à vol d'oiseau des lacs de Clairvaux et à $6 \mathrm{~km}$ du lac de Chalain. De plus, les versants de la reculée de Clairvaux et ceux de la vallée de la Frasnée, très étroite et située à $2 \mathrm{~km}$ de Clairvaux, sont actuellement recouverts par des plants naturels de sapin, dont la dispersion des semis a certainement été favorisée par l'inclinaison importante des versants et par une exposition ombragée.

La végétation actuelle que nous venons de décrire constitue une base d'interprétation essentielle pour les spectres anthracologiques. Cependant, les facteurs historiques ont eu une importance fondamentale dans la composition dendrologique actuelle des massifs jurassiens, une situation qui semble bien éloignée des potentialités climaciques ${ }^{3}$ réelles, et dont il faut tenir compte lors de l'interprétation. Ainsi, les chênaies-charmaies-hêtraies calcicoles actuelles de la Combe d'Ain étaient certainement aux environ du $\mathrm{III}^{\mathrm{e}}$ millénaire av. J.-C. des forêts de hêtre accompagnées du chêne (Beaufils, 1983; Dufraisse, Gauthier, 2002).

\section{LES OCCUPATIONS LACUSTRES DU JURA AU NÉOLITHIQUE}

Les trente années de recherches menées sur les habitats littoraux de Chalain et de Clairvaux ont permis, grâce à la contribution de nombreuses disciplines, de suivre les évolutions sociales, techniques, culturelles et environnementales des communautés agropastorales entre 3700 et 2500 av. J.-C.

3. Climax : état d'une végétation en équilibre avec les facteurs écologiques naturels, or l'activité humaine change les rapports de compétition et d'équilibre entre les espèces et empêche ainsi l'installation d'un climax.
Le calendrier d'abattage des bois de construction, établi à partir des études dendrochronologiques (Lavier, 1996; Viellet, 2002) autorise par ailleurs un calage précis, particulièrement détaillé entre 3200 et 2900 av. J.-C., qui permet d'appréhender les relations entre densité de population, organisations sociales, systèmes techno-économiques et état de l'environnement transformé par l'homme (Arbogast et al., 1995).

Parmi les nombreux habitats reconnus sur les rives des lacs, le choix des sites a été réalisé en privilégiant tout d'abord les périodes pour lesquelles un certain nombre de données archéologiques et paléoenvironnementales étaient acquises, c'est-à-dire le Néolithique moyen avec le NMB (Néolithique moyen bourguignon) et la première partie du Néolithique final avec le Horgen et le groupe de Clairvaux, soit une séquence chronologique comprise entre 3700 et 2800 av. J.-C. Nous avons ensuite cherché, dans la mesure du possible, à analyser des sites contemporains (au sein d'un même bassin lacustre et entre les deux bassins) de manière à établir des comparaisons sur les modalités de collecte et les zones d'approvisionnement.

Finalement, cette étude repose sur les analyses de six sites d'habitat, parmi lesquelles celles de Chalain 3 et Clairvaux III ont été réalisées par $\mathrm{K}$. Lundstrom-Baudais (1986, 1997) (fig. 5) :

- le $36^{\mathrm{e}}$ siècle av. J.-C. (Néolithique moyen bourguignon) avec la couche $\mathrm{V}$ de Clairvaux La Motte-aux-Magnins et le site de Clairvaux XIV;

- la fin du $32^{\mathrm{e}}$ siècle et le début du $31^{\mathrm{e}}$ siècle (groupe de Horgen) avec la couche VIII de Chalain 3 et la couche $O$ de Chalain 19 ;

- la fin du $31^{\mathrm{e}}$ siècle (Clairvaux ancien) avec le site de Chalain 4 (phases 1 à 4) et les couches HK de Chalain 19 ; - le début du $30^{e}$ siècle (Clairvaux moyen) avec les couches ABC de Clairvaux La Motte-aux-Magnins ;

- les $29^{\mathrm{e}}$ et $28^{\mathrm{e}}$ siècles (Clairvaux récent) avec le site de Clairvaux III et les couches D à G de La Motte-auxMagnins.

La période étudiée, du Néolithique moyen au Néolithique final, couvre donc la transition Atlantique récent/Subboréal, une période marquée par le début d'une lente péjoration du climat qui s'accentue à la transition Subboréal/Subatlantique. Comme pour les autres périodes climatiques, cette tendance n'est pas linéaire et montre des oscillations avec des alternances entre des phases d'amélioration et de détérioration climatiques. Au cours de cette période, l'étude des fluctuations des lacs de Chalain et de 

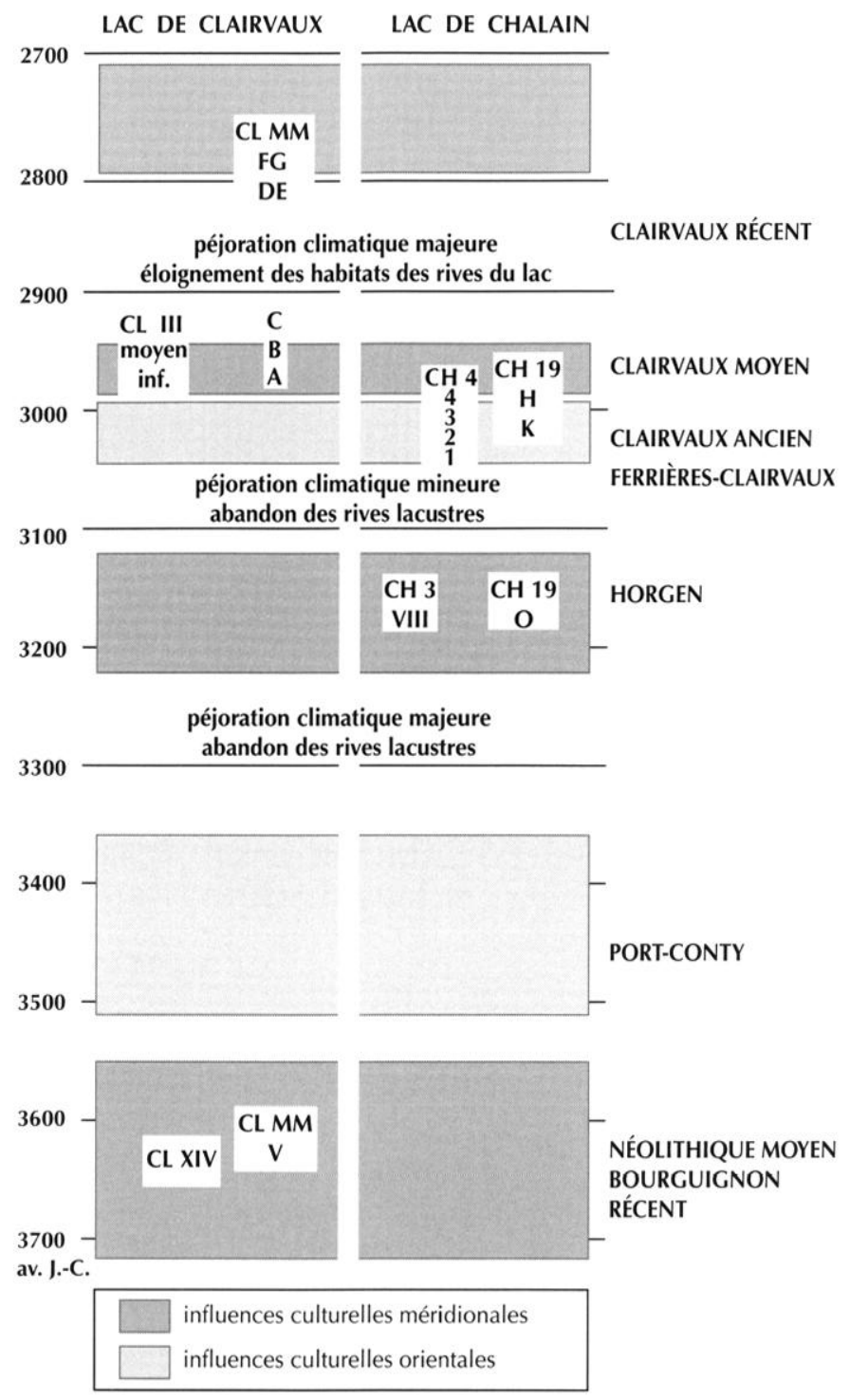

Fig. 5 - Chronologie des sites néolithiques des lacs de Chalain et de Clairvaux analysés.

Clairvaux met en évidence des phases transgressives majeures entre 3550 et 3250 av. J.-C. et entre 2900 et 2800 av. J.-C., intercalées de phases globalement régressives (Magny, 1995). Il apparaît également des épisodes transgressifs et régressifs secondaires, notamment entre 3100 et 2942 av. J.C. Ces oscillations climatiques ont été corrélées aux rythmes des habitats lacustres: les périodes de bas niveaux lacustres, phases d'amélioration climatique, ont été favorables aux implantations villageoises, tandis que les périodes d'instabilité et de crues répétées ont conduit au déplacement des habitats et à leur raréfaction (transgressions lacustres du $35^{\circ}$ siècle et du $29^{\circ}$ siècle) ou à l'abandon total du littoral caractérisé par l'absence de marqueurs polliniques d'activités agropastorales (transgression lacustre de la première moitié du $31^{\mathrm{C}}$ siècle) (Magny, 1995, 1997).

Chaque bassin lacustre a connu une dynamique culturelle spécifique. F.n d'autres termes, à Clairvaux, la forte densité des villages concerne le Néolithique moyen bourguignon $\left(37^{\circ}\right.$ siècle et $36^{c}$ siècle) et le Clairvaux récent ( $30^{\mathrm{e}}$ siècle) ; à Chalain, les groupes du Horgen ( $32^{\mathrm{e}}$ siècle), Clairvaux ancien $\left(31^{\mathrm{e}}\right.$ siècle) et Chalain $\left(27^{\mathrm{e}}\right.$ siècle) sont particulièrement développés. Ce déplacement d'un bassin lacustre à l'autre, qui va dans le sens d'un déplacement de population selon un rythme de l'ordre de deux siècles, est interprété comme une solution pour régler les crises sociales et environnementales (Pétrequin, Pétrequin dir., 2001).

Enfin, le Néolithique moyen et le Néolithique final du Jura se distinguent par un basculement des axes d'influences culturelles, d'abord est-ouest puis sud-nord. Les distances de transfert s'en trouvent modifiées, à courte ou moyenne distance avant 3300 av. J.-C. (80 km entre la Combe d'Ain et Neuchâtel), puis sur des distances plus longues à $300 \mathrm{~km}$ (distance entre la Combe d'Ain et l'Ardèche ou les plateaux caussenards) après $3300 \mathrm{av}$. J.C. Au Néolithique moyen, on suppose que le déplacement des communautés agricoles se faisait par petits groupes. Au Néolithique final, cette situation change : le passage entre le Horgen et le Ferrières (fin du $31^{e}$ siècle et du $30^{e}$ siècle) se caractérise par une augmentation très rapide de la densité de population (démontrée par le nombre élevé de villages contemporains), ce qui suggère un véritable transfert de population depuis le couloir rhodanien, mouvement qui aboutit à la formation d'un groupe original : le groupe de Clairvaux. On assiste alors à une nouvelle conception de l'architecture domestique: le plan de fondation des maisons (quatre rangées longitudinales) trouverait ses origines dans la vallée du Rhône ou plus au sud en Languedoc, tandis que le plan des villages reste de type nord-oriental (Arbogast et al., 1998 ; Pétrequin et al., 1999 ; Pétrequin dir., 2000).

\section{MATÉRIEL ET MÉTHODES \\ ÉCHANTILLONNAGE DES CHARBONS DE BOIS EN MILIEU LACUSTRE}

Les charbons de bois analysés dans cette étude proviennent tous des couches de litières végétales décomposées (plus couramment appelées fumier). Les niveaux d'incendie, où les restes ligneux carbonisés sont les résidus du bois 
d'architecture mais aussi du bois de feu, ou encore des ustensiles en bois ont été écartés. Il est en effet impossible dans ce type de dépots de restituer pour chaque fragment de charbon sa fonction d'origine.

Différentes études de répartition des artefacts archéologiques entre charbons de bois, lentilles d'argile et pierres chauffées, montrent que la présence de charbons dans les fumiers résulterait du nettoyage épisodique des foyers à usage domestique (chauffage, éclairage, cuisson des aliments, etc.) situés dans les foyers d'habitation (Pétrequin, Pétrequin, 1989; Arbogast el al., 1997). Par ailleurs, aucune trace d'activités artisanales comme la cuisson des céramiques (dont on sait par des exemples ethnologiques que le bois recherché n'est pas forcément le même que le bois de chauffage) n'a été attestée au sein des maisonnées ou du village. Les charbons de bois issus des fumiers sont donc très certainement les résidus du bois de feu destiné aux activités domestiques.

Si la bomne représentativité paléoécologique des charbons de bois en contexte domestique a été démontrée en milieu terrestre sec, movennant des conditions d'échantillomage rigoureuses qui tiennent compte à la fois de l'usage fait du bois, de la durée des dépôts échantillonnés et des modes de dispersion des charbons de bois (Chabal, 1997), cette étape méthodologique n'a jamais été reconsidérée en contexte d'habitat lacustre où l'eau est un paramètre essentiel dont il faut tenir compte. Elle agit, en effet, de manière très complexe sur les modes de sédimentation aussi bien pendant la formation des couches archéologiques qu'après l'abandon des villages (Pétrequin, Pétrequin, 1984; Nicoud, 1992). Dans la répartition des restes végétaux, on distingue ainsi les zones de battement des lacs et les \%ones d'eau calme (zone aquatique, inondable ou émergée à l'étiage). Dans les zones de battements des lacs, le ressac opère un tri des restes organiques en fonction de leur taille et de leur densité. Or, ces deux phénomènes peuvent être à l'origine de distorsions importantes (qui fausseraient les interprétations) ; c'est pourquoi il est préférable d'éviter les prélèvements dans ces zones. Dans les zones d'eau calme, c'est le phénomène de flottage qui intervient: les variations du niveau des lacs remettent régulièrement en suspension les éléments organiques les plus légers tombés à l'eau. Répartis cette fois-ci sous forme d'une nappe de flottage, les débris végétaux, parmi lesquels les charbons de bois, flottent dans les ruelles et sous les maisons. Ce flottage ne concerne ni les éléments organiques déjà sédimentés (dans les zones émergées à l'étiage ou inondables), ni ceux piégés par des apports massifs anthropiques lourds tel que dans les dépotoirs. Une analyse de la répartition spatiale des charbons de bois sur le site de Chalain 19 confirme cette dispersion sous forme de nappe de flottage ; aucun tri granulométrique ou densimétrique n'y a été mis en évidence. La liste floristique et ses fréquences révèlent au contraire un dépôt très homogène, certainement lié au phénomène de brassage de l'eau (Dufraisse, 2002a).

L'eau joue également un rôle déterminant dans les modes de gestion des déchets d'un village. Un modèle ethnologique établi sur des situations actuelles sur le lac Nokoué au Bénin montre, en effet, que l'organisation des déchets dans un village n'est pas la même selon que l'on se trouve dans un village de terre ferme ou aquatique (Pétrequin, Pétrequin, 1984). Alors que, dans un village de terre ferme, le sol des habitats et des rues est régulièrement balayé et les déchets repoussés entre les maisons ou en direction du lac, dans les villages installés en zone amphibie, les déchets sont directement rejetés à l'eau, sous les planchers rehaussés (existence de trappes) et/ou organisés sous forme de dépotoirs collectifs. Les déchets sont alors régulièrement remis en suspension et se dispersent sous forme de nappes de flottage. Si ce modèle ethnologique permet d'étendre le champ des possibilités explicatives, il ne peut toutefois pas être généralisé ; comme le montre l'étude. de la répartition des témoins archéologiques, la gestion des déchets et leur aire de répartition présentent une grande variabilité, et peuvent même être conditionnées par la position du foyer par rapport à l'entrée de la maison (Arbogast et al., 1997).

Ces remarques permettent de souligner la diversité des modes de sédimentation en fonction de la position du village et des différentes unités domestiques par rapport à la rive du lac. Il est donc essentiel de pouvoir adapter les modes d'échantillonnage au cas par cas, de manière à ce que les différents modes de dépôt des charbons de bois en fonction des zones littorales et/ou des modes de gestion des déchets soient au mieux représentés. Cependant, cette technique n'est possible que sur les sites en cours de fouille. Nous avons donc utilisé une méthode d'échantillonnage complémentaire pour les autres sites, sous forme de transects perpendiculaires à la rive des lacs. Ce type de transect, réalisé à la tarière palynologique et/ou pédologique avec un pas pouvant varier de 1 à $5 \mathrm{~m}$, est notamment utilisé lors des campagnes de prospections sur les rives des lacs (Pétrequin dir., 2000 ; Pétrequin, Pétrequin 
dir., 2001). Cette méthode permet de repérer les différentes zones littorales et donne une bonne représentation des différents modes de dépôts. Elle a été testée sur le site de Chalain 19 et validée par des résultats très proches de ceux acquis par un échantillonnage systématique (sous forme d'échiquier) au sein des nappes de flottage (Dufraisse, 2002a).

Enfin, la totalité des sédiments a été tamisée à l'eau avec une maille de $2 \mathrm{~mm}$. La détermination des charbons de bois (le plus souvent au rang de l'espèce) repose sur les différentes caractéristiques anatomiques spécifiques au bois qui se conservent lors de la carbonisation. L'observation se fait sur des cassures fraîches au microscope optique à réflexion (grossissement $\times 50 \mathrm{a} \times 400$ ) selon les trois plans naturels du bois : le plan transversal (perpendiculaire à l'axe du tronc), le plan longitudinal tangentiel (perpendiculaire au rayon du bois) et le plan longitudinal radial passant par l'axe de la tige dans le tracé du rayon. Des atlas anatomiques tels ceux de F. H. Schweingruber (1990) et des collections de référence de charbons de bois actuels permettent par analogie de déterminer les taxons en présence.

\section{ÉCOSYSTÈME FORESTIER ET GESTION DES TERRITOIRES}

S'il existe une véritable économie du bois de feu, une ressource nécessaire en abondance, la collecte reste de manière générale déterminée par le milieu. Les spectres anthracologiques en contexte domestique fournissent donc le plus souvent une bonne image des groupements ligneux exploités à l'échelle de la station forestière (unité élémentaire du paysage, homogène dans ses composantes physiques et biotiques); ils informent sur la composition des boisements, leur variété spécifique et les conditions de croissance des peuplements, autant d'indicateurs permettant de caractériser l'écosystème forestier à une période donnée. L'anthracologie aborde également les transformations de cet écosystème à moyen terme (à l'échelle d'une dizaine d'année) et à long terme (à l'échelle de quelques siècles) en fonction des perturbations internes (exemple des successions de végétation vers le climax) et externes (incendies, inondations, activités humaines) que suppose l'effet des facteurs naturels et anthropiques dans une dynamique temporelle.

Lorsque les zones d'étude sont suffisamment contrastées, il est également possible de localiser précisément les aires d'exploitation par analogie avec l'écologie actuelle des essences forestières, d'évaluer leur emprise spatiale et leur évolution dans le temps.

Cependant, si les charbons de bois révèlent la nature des essences et leurs proportions, ils contiennent également d'autres informations; ainsi, l'observation des cernes annuels de croissance apporte des données supplémentaires sur les conditions de croissance de l'arbre, qui dépendent des facteurs génétiques (propres à chaque espèce), de la physiologie de l'arbre (âge, partie anatomique, etc.), du milieu (sol, climat, inclinaison de pente, structure des peuplements, etc.) et des pratiques humaines (traitements sylvicoles, défrichements, etc.). Au vu de ce potentiel, nous avons cherché à développer une nouvelle approche fondée sur la mesure des largeurs de cerne réalisée à l'aide d'un microscope optique à réflexion muni d'un micromètre. Ces mesures, couplées à celle des rayons de courbure (voir p. 11-12), permettent d'établir pour chaque espèce des courbes de croissance diamétrale (fig. 6 ; Dufraisse, 2002b). Ces courbes, issues de la mesure d'un grand nombre de fragments provenant eux-même d'un grand nombre d'individus exploités sur une durée de 10 à 15 ans, sont représentatives des conditions de croissance des peuplements exploités; toute variation individuelle existant au sein d'un arbre ou d'un arbre à l'autre de la même espèce tend donc à être gommée. Toutefois, s'il est possible d'interpréter les événements majeurs, le manque de référentiel actuel dans des forêts peu transformées par l'homme (et théoriquement proches de celles exploitées au Néolithique dans le Jura) ne permet pas d'interpréter toutes les variations. Par ailleurs, étant donné le retrait radial du bois au cours de la combustion, les mesures réalisées sur des bois frais archéologiques ou actuels ne sont pas comparables à celles réalisées sur des charbons de bois. Il n'en demeure pas moins que cette méthode - dont l'interprétation est basée sur l'évolution relative des courbes entre elles et qui intègre les listes floristiques et leurs proportions - est un outil particulièrement performant pour restituer l'évolution des conditions de croissance des peuplements forestiers exploités.

Ainsi, en intégrant des hypothèses à la fois d'ordre anthropique et écologique, les tentatives d'interprétation de la sylvigénèse gagnent en finesse, notamment dans l'attribution des causes à l'origine des modifications observées, un domaine de recherche où de nombreuses questions demeurent sans réponse. Cette approche présente en outre l'intérêt de pouvoir préciser la signification écologique des modalités de collecte dans des zones boisées, où les modifi- 


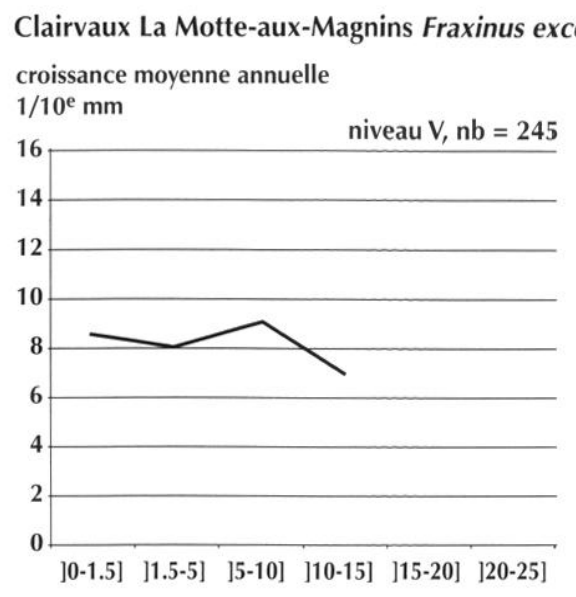

$\mathrm{nb}=$ nombre de cernes mesurés

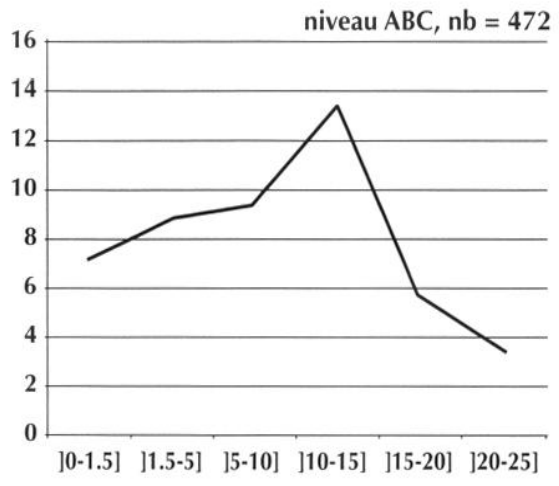

[0-1.5] [1.5-5] [5-10] ]10-15] [15-20] ]20-25]

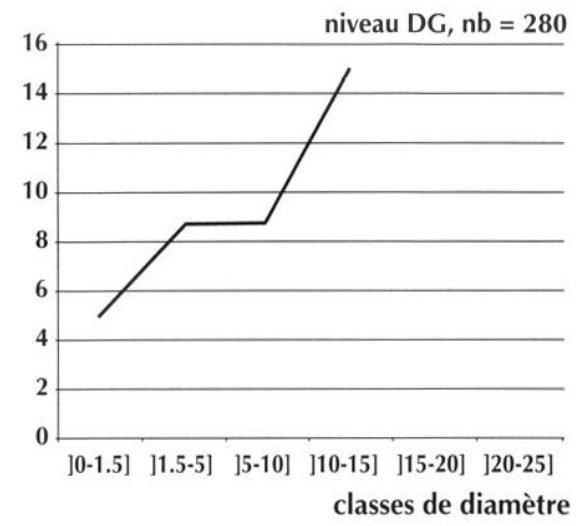

Fig. 6 - Exemples de courbes de croissance diamétrale fondées sur la mesure des largeurs de cerne. des charbons de bois de frêne couplée à celle des rayons de courbure; Clairvaux La Motte-aux-Magnins.

cations du couvert végétal peuvent être générées tout à la fois par le climat, par la compétition entre les espèces forestières et par l'homme.

\section{ÉTUDE DES MODES DE COLLECTE}

L'ethnologie rend compte de la diversité des critères de sélection du bois de feu et de la variabilité des pratiques souvent conditionnées par les traditions et le cadre environnemental (Smart, Hoffman, 1987). Ainsi, l'espèce, l'état du bois (sec, vert, altéré) ou encore la morphologie (taille et diamètre) sont des facteurs qui peuvent intervenir individuellement ou de manière combinée dans la collecte.

L'essence est un des critères de choix du bois, puisque des caractéristiques physiques du bois vont dépendre les propriétés combustibles (inflammabilité, température de combustion, pouvoir calorifique, persistance de la flamme, durée de calcination). Ce critère est également important pour apprécier les connaissances d'une communauté sur son propre environnement, même s'il ne faut pas perdre de vue la possibilité d'une sélection des espèces qui ne repose pas toujours sur des critères objectifs.

Outre ce critère de sélection lié à l'espèce, l'état physiologique (sec, vert) et phénologique du bois (sain, altéré) sont des paramètres au moins aussi importants puisqu'ils agissent directement sur le comportement d'une essence au feu en faisant varier de manière très significative ses propriétés combustibles. Ainsi, la sélection du bois en fonction des essences n'est justifiée que si le bois présente un état physiologique comparable (exemple du ramassage de bois mort). Ces caractères peuvent désormais être pris en compte, puisqu'un catalogue de signatures anatomiques caractéristiques des états du bois a récemment été établi sur la base d'expérimentations (Théry-Parisot, 2001).

Enfin, un dernier critère de sélection du bois joue un rôle fondamental dans les choix de collecte et permet, à lui seul, de gérer un feu en fonction des usages du foyer (éclairage, chauffage, cuisine, etc.) : il s'agit de la morphologie, c'est-à-dire des dimensions et du diamètre du bois. Associé à l'étude des outils d'abattage, ce critère permet en outre d'apprécier le niveau technique des populations. Paradoxalement, rares sont les études qui le prennent en compte (Marguerie, 1992 ; Ludemann, Nelle, 2002). La détermination des calibres repose sur la mesure des rayons de courbure de cernes. Cette mesure est effectuée sous une loupe binoculaire en superposant le plan transversal du charbon et une cible imprimée sur un transparent. La valeur lue indique la distance du fragment par rapport au cœur ; les proportions obtenues ne reflètent donc en aucun cas les diamètres exploités. Nous avons donc élaboré un modèle théorique, fondé sur des notions simples de mathématiques et de géométrie, qui permet d'estimer les proportions de diamètres exploités correspondant aux proportions lues dans l'échantillon (fig. 7 ; Dufraisse, 2002b). Ce modèle est actuellement testé sur la base d'expérimentations en fonction des essences, de la morphologie du bois mis au feu (bûches, éclisses) et des types de foyers, pour en définir les limites d'application et instaurer des facteurs correctifs si nécessaire. Pour ce qui est de l'interprétation, si les histogrammes donnent une bonne estimation des calibres de 

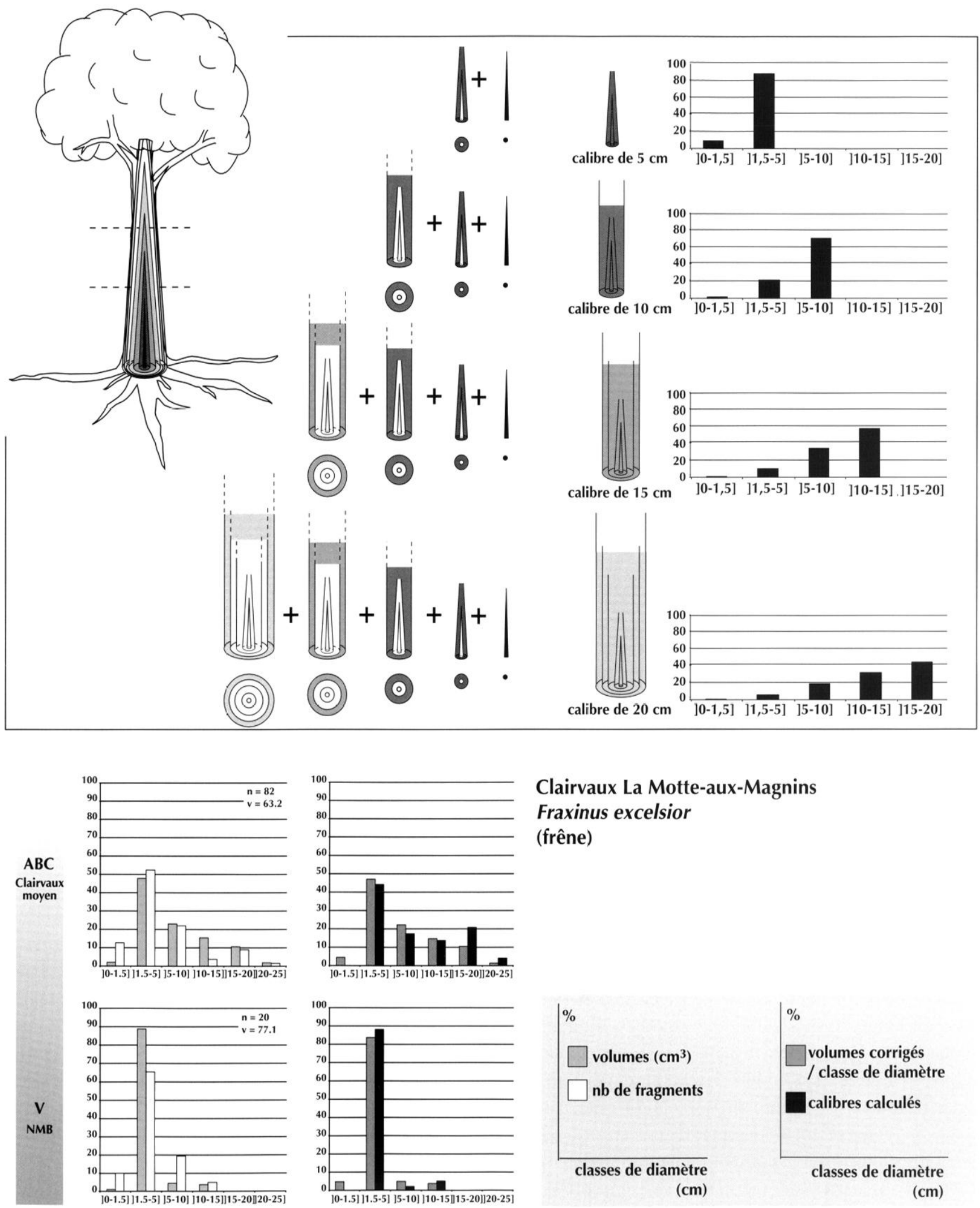

\section{Clairvaux La Motte-aux-Magnins} Fraxinus excelsior (frêne)
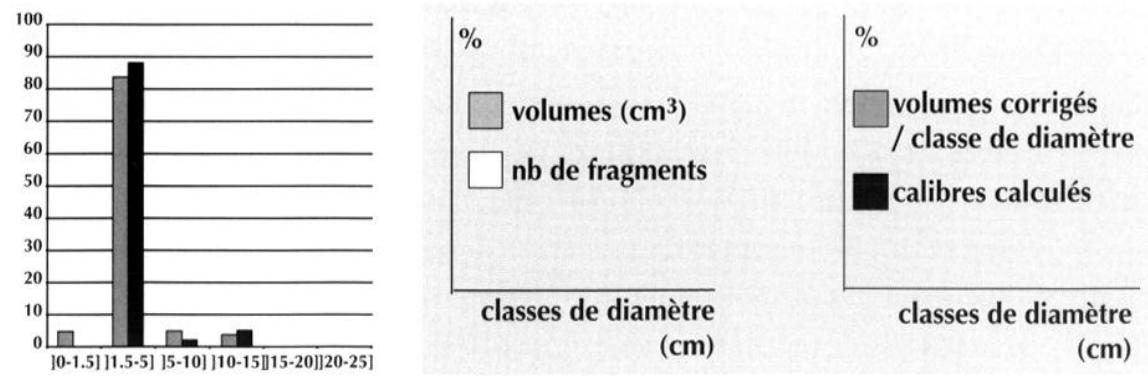

Fig. 7 - Étude des calibres de bois : schéma de la démarche suivie pour l'élaboration d'un modèle théorique et exemple d'application ; Clairvaux La Motte-aux-Magnins ; frêne. 
bois exploités par l'homme, l'interprétation en termes de structure des peuplements (qui dépend de la composition floristique, de l'arrangement spatial des arbres, etc.) est beaucoup plus délicate, notamment en raison du biais humain introduit au moment de la collecte.

\section{ANALYSES ANTHRACOLOGIQUES}

Pour l'exposé des résultats et des premières interprétations (boisements exploités, aires d'approvisionnement), les bassins de Clairvaux et de Chalain ont été traités indépendamment, d'une part, en raison de la topographie, le bassin de Clairvaux étant plus engagé dans les pentes du deuxième plateau du Jura que celui de Chalain et, d'autre part, parce que les aires d'approvisionnement en matières premières exploitées en accès direct diffèrent d'un lac à l'autre, au nord pour Chalain et au sud pour Clairvaux (Pétrequin, comm. pers.).

\section{LE BASSIN DE CLAIRVAUX}

\section{ClairvauX La Motte-auX-Magnins}

Située à l'extrémité d'une presqu'île sur la rive nord du Grand Lac, La Motte-aux-Magnins a été occupée à plusieurs reprises, d'abord pendant le NMB (niveaux VIb, V et IVb, entre 3700 et 3600 av. J.-C.), puis le Clairvaux moyen (ensemble $\mathrm{ABC}$, entre 2980 et 2960 av. J.-C.), le Clairvaux récent (ensemble DE et FG, entre 2900 et 2700 av. J.-C.), et enfin le groupe de Chalain (ensemble HK, 2700 et postérieur) qui ne sera pas présenté ici (Pétrequin dir., 1989).

La fouille a rapidement permis de mettre en évidence une organisation des restes végétaux en nappe de flottage répartie selon les tracés des courbes de niveaux. Nous avons donc réalisé les prélèvements à la tarière pédologique sur environ huit mètres de longueur, selon une ligne nord-sud perpendiculaire à la rive du lac. Cette première série a essentiellement permis l'échantillonnage des niveaux $\mathrm{V}$ et $A B C$. Celui des niveaux supérieurs a été complété par l'analyse de trois colonnes PVC (de $10 \mathrm{~cm}$ de diamètre chacune) laissées en place lors des fouilles (campagne 1983).

\section{Résultats}

L'analyse du NMB repose sur la détermination de 290 fragments et 17 taxons. Il est caractérisé par l'exploitation
CLAIRVAUX

LA MOTTE-AUX-MAGNINS

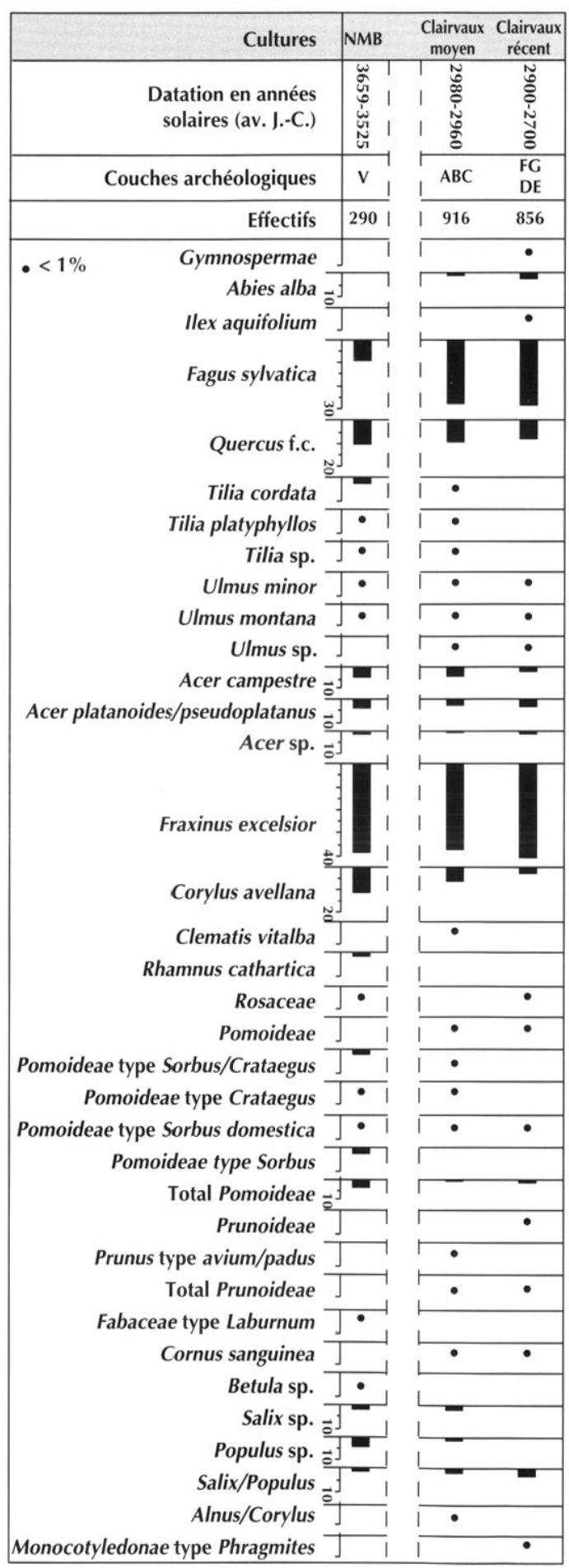

Fig. 8 - Diagramme anthracologique du site de Clairvaux La Motte-aux-Magnins. 
Tabl. I - Dénombrements et pourcentages des taxons reconnus par l'identification des charbons de bois de Clairvaux La Motte-aux-Magnins.

\begin{tabular}{|c|c|c|c|c|c|c|c|c|c|c|c|c|}
\hline \multicolumn{13}{|c|}{ CLAIRVAUX LA MOTTE-AUX-MAGNINS } \\
\hline \multirow{2}{*}{ Essences $\quad$ Unités stratigraphiques } & \multicolumn{2}{|c|}{$\mathrm{v}$} & \multicolumn{2}{|c|}{$A B C$} & \multicolumn{2}{|c|}{ DE } & \multicolumn{2}{|c|}{ DG } & \multicolumn{2}{|c|}{ FG } & \multicolumn{2}{|c|}{ Total D à G } \\
\hline & $\mathrm{Nb}$ & $\%$ & $\mathrm{Nb}$ & $\%$ & $\mathrm{Nb}$ & $\%$ & $\mathrm{Nb}$ & $\%$ & $\mathrm{Nb}$ & $\%$ & $\mathrm{Nb}$ & $\%$ \\
\hline Abies alba & & & 10 & 1,1 & 5 & 2 & 19 & 6,1 & 1 & 0,3 & 25 & 2,8 \\
\hline Acer campestre & 14 & 4,8 & 34 & 3,7 & 5 & 2 & 4 & 1,3 & 7 & 2,4 & 16 & 1,9 \\
\hline \begin{tabular}{|l|} 
Acer platanoides/pseudoplatanus \\
\end{tabular} & 10 & 3,5 & 23 & 2,5 & 6 & 2,4 & 4 & 1,3 & 20 & 6,7 & 30 & 3,5 \\
\hline Acer sp. & 3 & 1 & 8 & 0,9 & 2 & 0,8 & 4 & 1,3 & 9 & 3 & 15 & 1,7 \\
\hline Alnus/Corylus & & & & & 1 & 0,4 & & & & & 1 & 0,1 \\
\hline Angiospermae & 4 & 1,4 & 11 & 1,2 & 4 & 1,6 & 6 & 1,9 & 2 & 0,7 & 12 & 1,4 \\
\hline Betula sp. & 2 & 0,7 & & & & & & & & & & \\
\hline Clematis vitalba & & & 2 & 0,2 & & & & & & & & \\
\hline \begin{tabular}{|l|} 
Cornus sanguinea \\
\end{tabular} & & & 1 & 0,1 & & & 1 & 0,3 & & & 1 & 0,1 \\
\hline Corylus avellana & 32 & 11 & 58 & 6,3 & 15 & 6 & 6 & 1,9 & 4 & 1,3 & 25 & 3,1 \\
\hline Fabaceae type Laburnum & 2 & 0,7 & & & & & & & & & & \\
\hline Fagus sylvatica & 27 & 9,3 & 256 & 27,9 & 71 & 28,4 & 105 & 34 & 67 & 22,6 & 243 & 28,3 \\
\hline \begin{tabular}{|l} 
Fraxinus excelsior \\
\end{tabular} & 113 & 39 & 341 & 37,2 & 99 & 39,6 & 98 & 31,7 & 153 & 51,5 & 350 & 40,9 \\
\hline Gymnospermae & & & & & & & 1 & 0,3 & 1 & 0,3 & 2 & 0,2 \\
\hline Ilex aquifolium & & & & & & & & & 8 & 2,7 & 8 & 0,9 \\
\hline Monocotyledonae type Phragmites & & & & & & & 2 & 0,6 & & & 2 & 0,2 \\
\hline Pomoideae & & & 1 & 0,1 & 2 & 0,8 & & & & & 2 & 0,3 \\
\hline Pomoideae type Crataegus & 1 & 0,3 & 2 & 0,2 & & & & & & & & \\
\hline Pomoideae type Sorbus & 5 & 1,7 & 4 & 0,4 & 4 & 1,6 & 2 & 0,6 & 3 & 1 & 9 & 1,1 \\
\hline Pomoideae type Sorbus domestica & 1 & 0,3 & & & & & & & & & & \\
\hline Pomoideae typeSorbus/Crataegus & 5 & 1,7 & 4 & 0,4 & & & & & & & & \\
\hline Populus sp. & 13 & 4,5 & 11 & 1,2 & 2 & 0,8 & & & 1 & 0,3 & 3 & 0,4 \\
\hline Prunoideae & & & & & & & & & 1 & 0,3 & 1 & 0,1 \\
\hline Prunus type avium/padus & & & 2 & 0,2 & & & & & & & & \\
\hline Quercusf.c. & 31 & 10,7 & 89 & 9,7 & 30 & 12 & 28 & 9,1 & 7 & 2,4 & 65 & 7,8 \\
\hline Rhamnus cathartica & 3 & 1 & & & & & & & & & & \\
\hline Rosaceae & 1 & 0,3 & & & & & & & 1 & 0,3 & 1 & 0,1 \\
\hline Salix sp. & 6 & 2,1 & 17 & 1,9 & & & & & 1 & 0,3 & 1 & 0,1 \\
\hline Salix/Populus & 4 & 1,4 & 16 & 1,7 & 4 & 1,6 & 14 & 4,5 & 9 & 3 & 27 & 3,1 \\
\hline \begin{tabular}{|l|} 
Tilia cordata \\
\end{tabular} & 7 & 2,4 & 2 & 0,2 & & & & & & & & \\
\hline Tilia platyphyllos & 1 & 0,3 & 1 & 0,1 & & & & & & & & \\
\hline Tilia sp. & 2 & 0,7 & 3 & 0,3 & & & & & & & & \\
\hline Ulmus minor & 1 & 0,3 & 5 & 0,5 & & & 2 & 0,6 & & & 2 & 0,2 \\
\hline Ulmus montana & 2 & 0,7 & 8 & 0,9 & & & 7 & 2,3 & 2 & 0,7 & 9 & 1 \\
\hline Ulmus sp. & & & 7 & 0,8 & & & 6 & 1,9 & & & 6 & 0,6 \\
\hline Nombre de charbons déterminés & 290 & & 916 & & 250 & & 309 & & 297 & & 856 & \\
\hline Nombre de taxons & 17 & & 18 & & 12 & & 13 & & 13 & & 17 & \\
\hline Écorce/ Phloème & 6 & & 15 & & 0 & & 1 & & 1 & & 2 & \\
\hline Indéterminables & 3 & & 8 & & 0 & & 2 & & 2 & & 4 & \\
\hline
\end{tabular}

majoritaire du frêne (Fraxinus excelsior, $39 \%$ ) accompagné du noisetier (Corylus avellana, $11 \%$ ), des chênes à feuillage caduc (Quercus f.c., 10,7\%), du hêtre (Fagus sylvatica, 9,3\%) et des érables (Acer campestre et platanoides/pseudoplatanus, 9,3\% au total) (tabl. I ; fig. 8). On note la présence d'essences compagnes avec des postpionnières nomades de demi-ombre telles que les tilleuls à petites feuilles et à grandes feuilles (Tilia cordata et platayphyllos), l'orme champêtre et l'orme des montagnes (Ulmus minor et montana), des pionnières héliophiles telles que le nerprun purgatif (Rhamnus cathartica), la famille des Pomoïdées (qui totalise $4 \%$ ) représentée par les sorbiers et les aubépines (Pomoideae type Crataegus et Sorbus) et des pionnières ripicoles telles que les peupliers et les saules (Populus sp. et Salix sp., qui totalisent $8 \%$ ) et les bouleaux (Betula sp.).

Pendant le Clairvaux moyen (ensemble $\mathrm{ABC}$ ), niveau fondé sur la détermination de 916 fragments et 18 taxons, le frêne $(37,2 \%)$ prédomine toujours accompagné des chênes caducifoliés $(9,7 \%)$. Ce niveau est marqué par une augmentation significative des taux de hêtre $(27,9 \%)$ et l'apparition du sapin $(1,1 \%)$, espèce dryade exigeant une humidité atmosphérique élevée, à affinités submontagnarde et montagnarde. Concernant les essences compagnes, tandis que les ormes se maintiennent, ce niveau est carac- 
térisé par une baisse globale des pourcentages des essences compagnes telles que les érables champêtre et plane/ sycomore $(7,1 \%)$, les tilleuls à petites feuilles et à grandes feuilles, mais aussi des essences héliophiles, de lisières et/ou ripicoles telles que le noisetier $(6,3 \%)$, les Pomoïdées (qui totalisent $1 \%$ ), les saules et les peupliers (qui totalisent $4,8 \%$ ). D'un point de vue qualitatif, on peut remarquer la disparition du nerprun purgatif et des bouleaux ainsi que l'apparition du merisier (Prunus avium/padus), du cornouiller sanguin (Cornus sanguinea), essences de demiombre, postpionnières, souvent associées aux chênaieshêtraies et aux forêts ripicoles.

Pendant le Clairvaux récent (ensemble D à G, 856 charbons de bois déterminés et 17 taxons), le frêne et le hêtre restent majoritaires mais avec des pourcentages plus élevés que précédemment $(39,6 \%$ et $28,4 \%)$. Les proportions du sapin (2\%) augmentent également, tandis que les érables et les ormes se maintiennent ; précisons que l'érable plane/sycomore $(3,5 \%)$ et l'orme des montagnes $(1 \%)$ sont mieux représentés que l'érable champêtre $(1,9 \%)$ et l'orme champêtre $(0,2 \%)$. Il faut également signaler l'apparition du houx (Ilex aquifolium), espèce dryade, sciaphile, appréciant les sols frais, et le recul des chênes à feuillage caduc $(7,8 \%)$, du noisetier $(3,1 \%)$, de la famille des Pomoïdées $(1,4 \%)$, des saules et des peupliers $(3.6 \%)$ ainsi que la disparition des tilleuls.

Considérons maintenant les courbes de croissance diamétrale des essences dominantes (fig. 9). Le frêne, tout d'abord, présente des évolutions bien distinctes entre, d'une part, les ensembles stratigraphiques $\mathrm{V}$ et $\mathrm{ABC}$ et, d'autre part, l'ensemble $D$ à $G$. Ainsi, la croissance du frêne se décompose en deux phases dans les deux premiers ensembles. Tandis que la première phase, dite phase juvénile, est caractérisée par une croissance rapide, la seconde phase est caractérisée par une diminution de la croissance en fonction des classes de diamètre; l'âge de maturité semble atteint. Les taux d'accroissement semblent cependant plus importants dans l'ensemble ABC. Dans l'ensemble $\mathrm{D}$ à $\mathrm{G}$, la croissance du frêne présente des taux d'accroissement encore plus importants et ne semble pas marquée par l'effet de l'âge. Or, le frêne dont la longévité est de 70 à 200 ans, est une essence postpionnière, au tempérament héliophile dès son jeune âge et affectionnant plus particulièrement les milieux humides. Cette évolution pourrait refléter une ouverture du milieu (concurrence moins forte et apport de lumière) favorisant ainsi la croissance des peuplements de frêne.
Pour ce qui est du hêtre, la croissance n'est représentée que pour les petits diamètres (voir p. 17). La croissance augmente rapidement en fonction de l'âge et représente la phase juvénile. Un seul ensemble, $A B C$, permet d'apprécier l'âge de maturité, qui se situerait entre 10 et $15 \mathrm{~cm}$ de diamètre. Dans les ensembles suivants, notons qu'à ces mêmes classes de diamètre, l'âge de maturité ne semble pas atteint. Or, le hêtre, dont la longévité est de l'ordre de 100 à 300 ans, est une espèce d'ombre, exigeant une humidité atmosphérique élevée. Ces courbes indiquent donc des conditions de croissance favorables : en milieu fermé et probablement en altitude, où l'humidité atmosphérique comme les précipitations annuelles sont suffisamment importantes.

Parmi les autres essences, le chêne, l'érable et les Pomoïdées ne sont représentées que dans un ensemble $(A B C)$, deux pour le noisetier (V et $A B C$ ), ce qui rend les interprétations plus délicates, aucune comparaison n'étant possible. Considérant l'écologie de ces essences, postpionnières, nomades et héliophiles, notons toutefois que l'évolution de leurs courbes de croissance, qui diminuent rapidement en fonction du diamètre, traduirait un développement plutôt en milieu fermé.

L'étude des calibres indique pour le NMB l'exploitation d'une strate sous-arbustive avec une nette préférence pour les calibres compris entre $5 \mathrm{~cm}$ et $10 \mathrm{~cm}$ de diamètre. Cette exploitation concerne le frêne, le hêtre, les érables, le noisetier et les Pomoïdées. La période du Clairvaux récent se démarque par l'utilisation d'une gamme de calibres plus large, pouvant atteindre des diamètres de $25 \mathrm{~cm}$ pour le frêne et le hêtre. Il existe en outre un certain équilibre entre les différentes classes exploitées. Puis l'étude des diamètres du frêne indique dès le Clairvaux récent un retour progressif vers l'exploitation de petits calibres tels ceux des érables, du noisetier et des Pomoïdées. Il faut attendre le groupe de Chalain pour constater une retour vers l'exploitation de petits calibres de hêtre (fig. 10).

Pour ce qui est de l'état physiologique du bois collecté, les signatures anatomiques ne permettent de réfuter ni l'utilisation ni la collecte de bois vert pendant le NMB et le Clairvaux moyen. En revanche, le Clairvaux récent se distingue par une nette prédominance de l'utilisation et donc de la collecte de bois vert : $13 \%$ des charbons de bois présentent des zones de collapse or, selon les travaux d'I. Théry-Parisot (2001), pour $100 \%$ de bois vert brûlé, $15 \%$ à $20 \%$ de fragments présentent des zones de collapse (Dufraisse, 2002b, p. 148-149). 

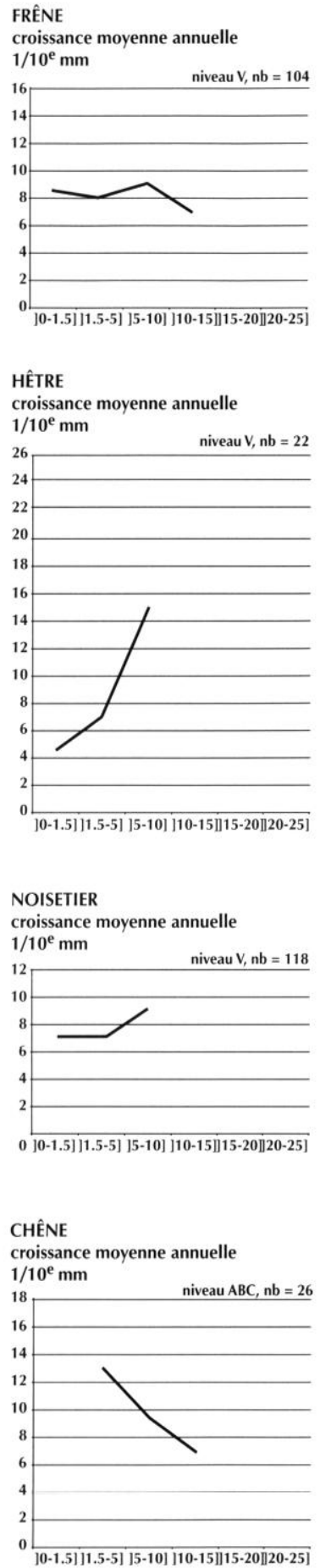

Fig. 9 - Evolution de la croissance moyenne annuelle par classes de diamètres des principaux taxons à Clairvaux La Motle-aux-Magnins.
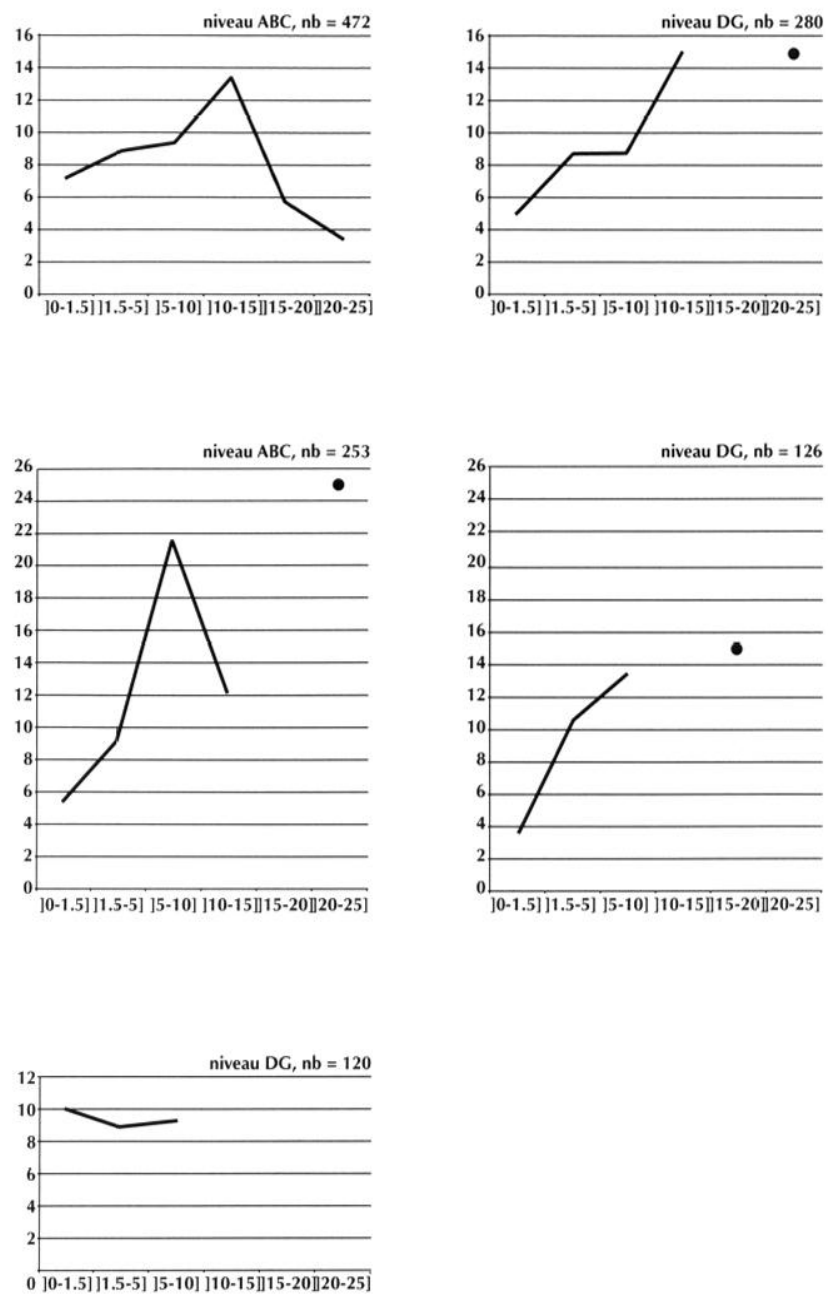

POMOÏDÉES

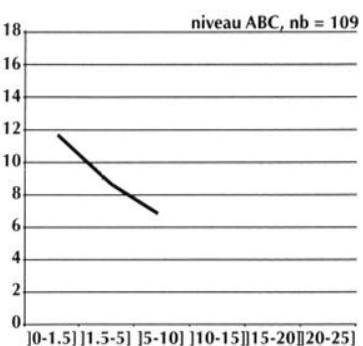

\section{ÉRABLE CHAMPÊTRE}

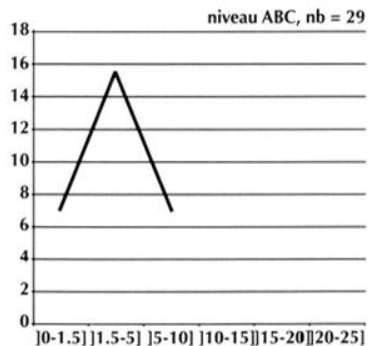

\section{Représentativité paléoécologique et zones potentielles d'approvisionnement}

Le diagramme anthracologique de La Motte-auxMagnins (fig. 8) montre une richesse taxonomique importante dont les proportions, par analogie avec la végétation actuelle et le spectre pollinique réalisé sur le Petit Lac de
Clairvaux (Richard, 1989a) - caractérisé par une nette prédominance du hêtre à partir de l'Atlantique récent -, paraissent cohérentes et représentatives du milieu. Ces résultats peuvent donc être interprétés comme l'exploitation d'au moins trois biotopes: la hêtraie accompagnée du sapin et d'autres conifères, la frênaie alluviale accompagnée d'essences postpionnières héliophiles telles que le 

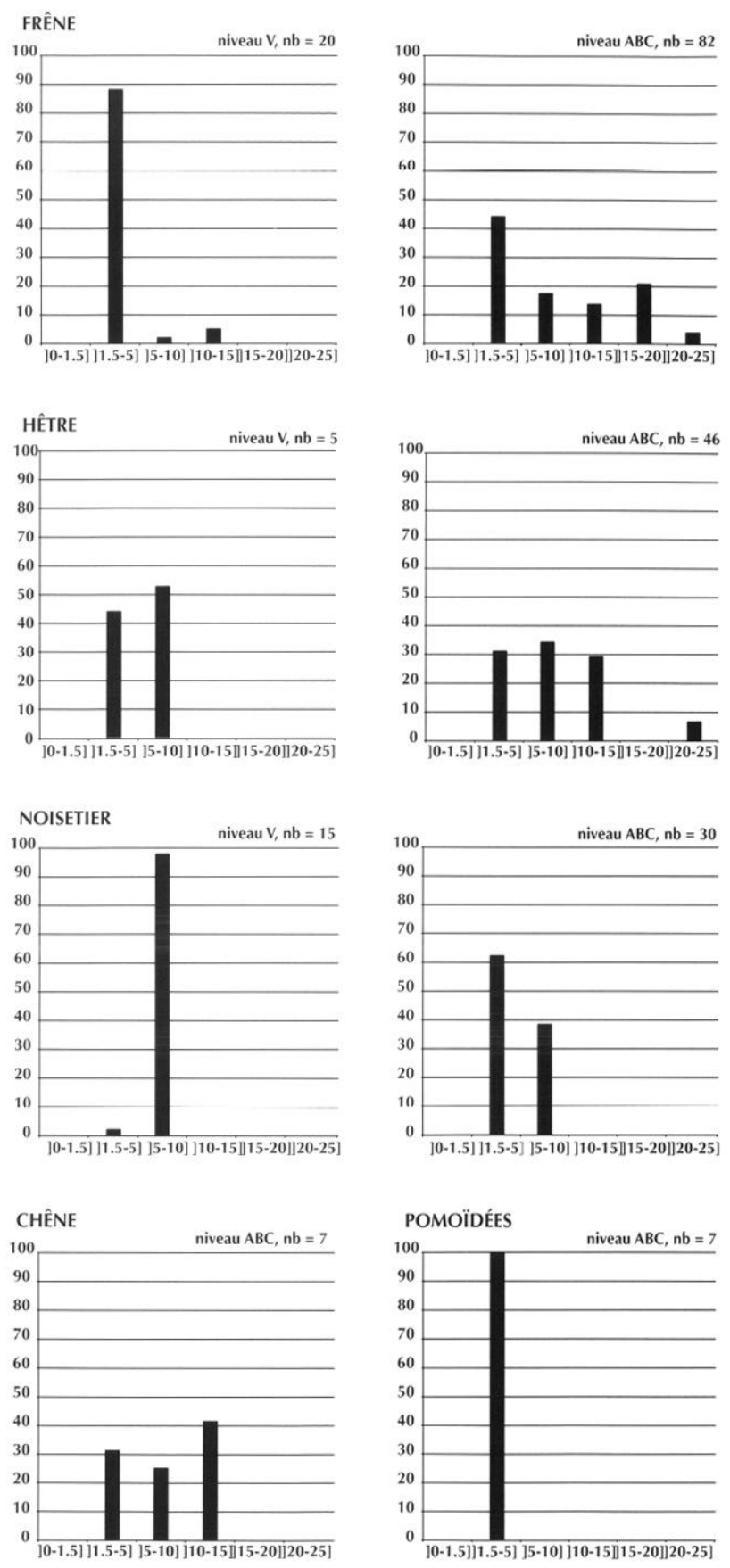
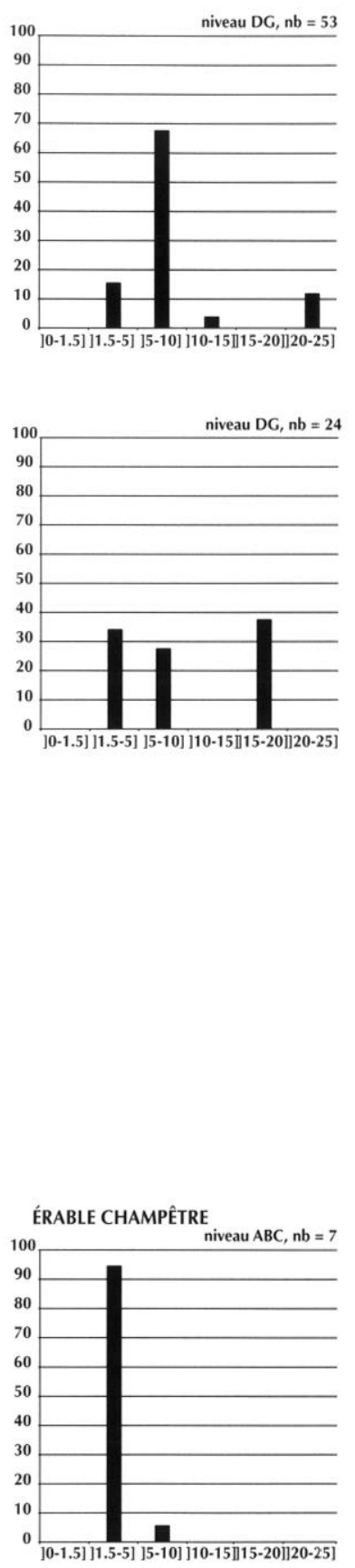

Fig. 10 - Estimations des proportions de diamètres exploités à Clairvaux La. Motte-aux-Magnins. chêne et le noisetier. Enfin, la ripisylve est principalement représentée par les saules et les peupliers.

Au NMB, le frêne (essence postpionnière héliophile et appréciant les sols humides) se développe sur les terrasses supérieure et inférieure de l'Ain où le degré d'hydromorphie du sol bloque le développement du chêne (Rameau, 1987). La ripisylve est également présente, composée des saules et des peupliers et du tremble. Le cortège de la hêtraie, uniquement représenté par le hêtre, est quasiment absent. Les aires d'exploitation semblent donc limitées aux terrasses glacio-lacustres de la Combe d'Ain, à proximité des rives du lac, ce qui est cohérent avec la faible densité d'habitat. Enfin, les petits diamètres pourraient refléter l'exploitation d'une strate sous-arbustive et arbustive, relativement dense, comme le laissent supposer les courbes de croissance (fig. 1la). 


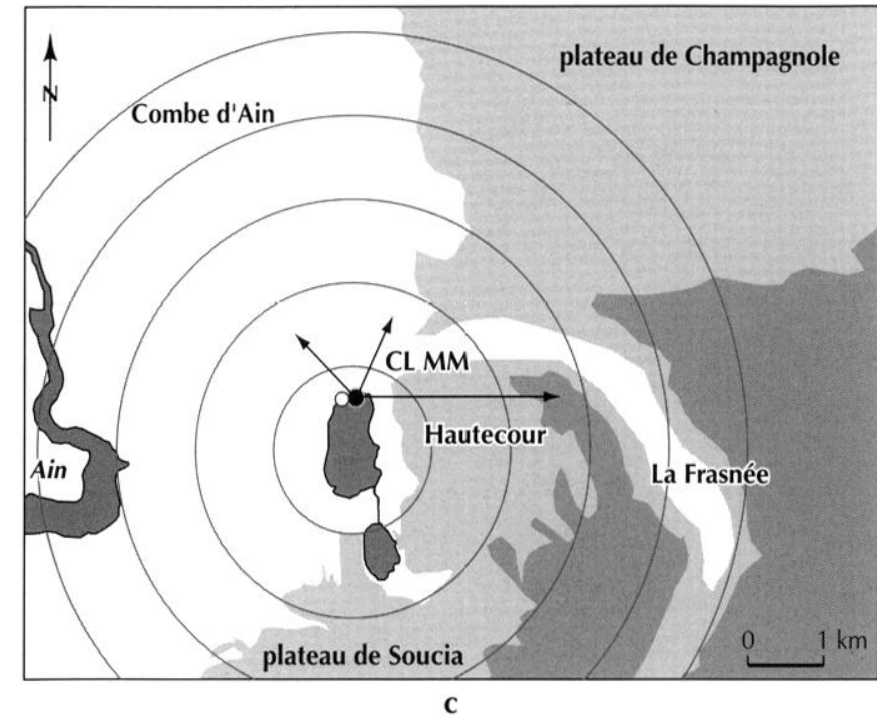

CLAIRVAUX MOYEN

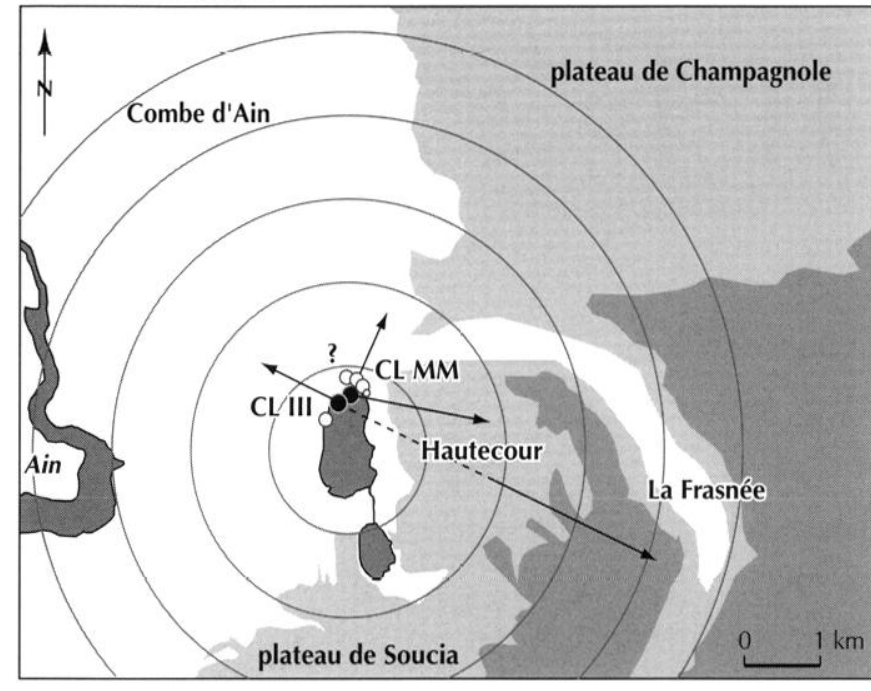

b

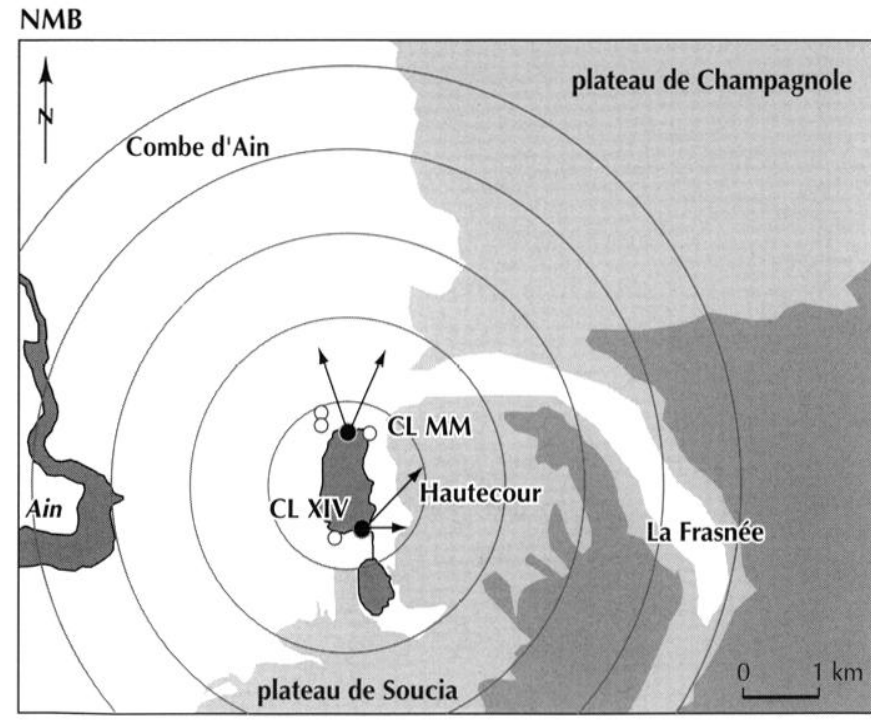

a

$550 \mathrm{~m}$,

terrasses de l'Ain
600-700 m, plateaux calcaires au-dessus de $700 \mathrm{~m}$, plateaux d'altitude
Pendant le Clairvaux moyen, le frêne reste prédominant et le hêtre, accompagné du sapin, augmente. Les essences affiliées à la frênaie sont toujours présentes, mais les arbustes héliophiles et/ou de ripisylve sont moins abondants. Ces résultats pourraient refléter une extension des aires d'exploitation en altitude avec la frênaie sur les terrasses alluviales de l'Ain, d'une part, et la hêtraie sur le deuxième plateau, d'autre part. Dans ce sens, cette extension est accompagnée de diamètres plus importants, ce qui pourrait indiquer l'exploitation de forêts plus âgées (fig. 11b).

$\mathrm{Au}$ Clairvaux récent (contemporain d'une phase de péjoration climatique majeure), l'emprise spatiale des aires d'exploitation semble se maintenir. La présence des essences secondaires à affinités montagnardes est plus marquée, reflétant l'exploitation d'un groupement ligneux à connotations plus fraîches. Dans le même temps, les courbes de croissance diamétrale suggèrent un éclaircissement progressif des peuplements exploités : les diamètres indiquent l'exploitation de peuplements plus jeunes et l'étude de l'état du bois laisse supposer la collecte et l'utilisation de bois vert (fig. 11c).

L'impact sur le couvert forestier reste donc relativement faible, probablement du fait de l'alternance entre des phases d'occupation et des phases d'abandon qui permettent au couvert forestier de se régénérer, ce que conforte d'ailleurs l'étude des ensembles sédimentaires qui démontre que l'essentiel du colluvionnement (résultant de l'érosion provoquée par des défrichements successifs) est postérieur au $\mathrm{I}^{\mathrm{rr}}$ millénaire av. J.-C. (Pétrequin, Pétrequin dir., 2001).

\section{Clairvaux XIV}

La station XIV est localisée à l'extrémité sud du Grand Lac de Clairvaux, à l'opposé de La Motte-aux-Magnins. Au moment des analyses, cette station - repérée lors de l'évaluation archéologique de Clairvaux en 2001 - n'avait pas encore fait l'objet de fouilles. Un seul niveau d'occupation avait été repéré et attribué, selon quelques profils céramiques, au NMB (Pétrequin, Pétrequin dir., 2001).

Fig. 11 - Schéma synthétique des données et interprétations acquises par l'étude des charbons de bois issus des habitats littoraux du bassin de Clairvaux. Les flèches correspondent aux hypothèses sur les zones potentielles d'approvisionnement : $a, N M B$; $b$, Clairvaux moyen ; c, Clairvaux récent. 
Tabl. II - Dénombrements et pourcentages des taxons reconnus par l'identification des charbons de bois de Clairvaux XIV.

\begin{tabular}{|l|r|r|}
\hline \multicolumn{3}{|c|}{ CLAIRVAUX XIV } \\
\hline \multicolumn{1}{|c|}{ Essences } & Nb & \multicolumn{1}{|c|}{$\%$} \\
\hline Abies alba & 2 & 0,2 \\
\hline Acer campestre & 43 & 4,6 \\
\hline Acer platanoides/pseudoplatanus & 29 & 3,1 \\
\hline Acer sp. & 17 & 1,8 \\
\hline Angiospermae & 15 & 1,6 \\
\hline Cornus sanguinea & 1 & 0,1 \\
\hline Corylus avellana & 81 & 8,7 \\
\hline Crataegus sp. & 3 & 0,3 \\
\hline Fabaceae & 1 & 0,1 \\
\hline Fagus sy/vatica & 236 & 25,5 \\
\hline Fraxinus excelsior & 196 & 21,1 \\
\hline Pomoideae & 6 & 0,6 \\
\hline Pomoideae type Sorbus/Crataegus & 33 & 3,6 \\
\hline Populus sp. & 20 & 2,2 \\
\hline Prunus type avium/padus & 1 & 0,1 \\
\hline Quercus f.c. & 189 & 20,4 \\
\hline Rhamnus cathartica & 1 & 0,1 \\
\hline Salix sp. & 13 & 1,4 \\
\hline Salix/Populus & 13 & 1,4 \\
\hline Sorbus sp. & 5 & 0,5 \\
\hline Sorbus type aucupoaria & 1 & 0,1 \\
\hline Tilia cordata & 6 & 0,6 \\
\hline Tilia platyphyllos & 3 & 0,3 \\
\hline Tilia sp. & 27 & 1,1 \\
\hline Ulmus minor & 20 & 0,2 \\
\hline Total & 14 & \\
\hline Nombre de taxons & 9 & \\
\hline Écorce/ Phloème & \\
\hline Indéterminable & \\
\hline
\end{tabular}

Aujourd'hui, plusieurs niveaux d'occupation ont été repérés au cours de deux campagnes de fouilles et les profils céramiques indiquent clairement que Clairvaux XIV est en partie contemporain du niveau $\mathrm{V}$ de Clairvaux La Motteaux-Magnins.

Les sondages, toujours perpendiculaires à la rive du lac, ont permis de restituer une coupe stratigraphique ; l'échantillonnage des charbons de bois a été réalisé dans les secteurs où les couches archéologiques étaient les plus dilatées.

\section{Résultats}

Le spectre anthracologique de Clairvaux XIV (tabl. II ; fig. 12), fondé sur la détermination de 927 charbons et un minimum de 20 taxons, révèle une richesse taxonomique importante et l'abondance relative du hêtre $(25,5 \%)$, des chênes caducifoliés $(20,4 \%)$ et du frêne $(21,1 \%)$ dans des proportions équivalentes. Ces essences sont accompagnées d'un cortège floristique varié composé des érables (9,5\%), des tilleuls (2\%), de l'orme champêtre et du sapin. Les

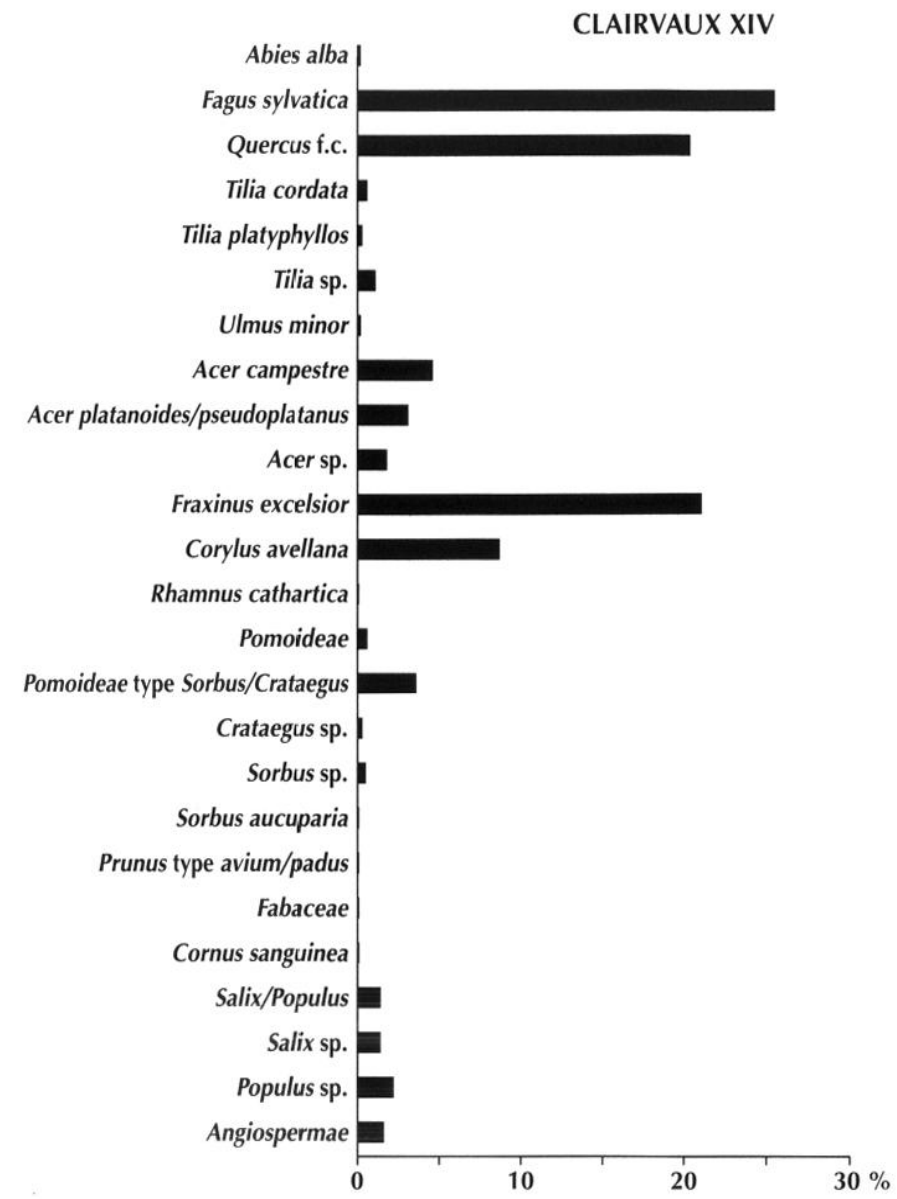

Fig. 12 - Diagramme anthracologique du site de Clairvaux XIV.

espèces postpionnières telles que le noisetier $(8,7 \%)$, les Pomoïdées $(4,2 \%)$ ou encore les saules et les peupliers $(5 \%)$ sont bien représentées. On peut également mentionner la présence du nerprun purgatif et du cornouiller sanguin.

Concernant les courbes de croissance diamétrale, établies sur le hêtre, les chênes, l'érable champêtre, les tilleuls, le frêne, le noisetier, les Pomoïdées, leur interprétation reste délicate étant donné l'absence de référentiel de comparaison (fig. 13). Cependant, on peut remarquer que les taux d'accroissement du hêtre et du frêne sont inférieurs à ceux observés à La Motte-aux-Magnins, niveau V. D'autre part, il est possible de classer ces courbes en deux catégories. La première concerne les courbes de croissance qui augmentent rapidement avec le diamètre ; c'est le cas des essences pionnières ripicoles telles que les saules et peupliers, ce qui indique pour ces essences un développement en milieu ouvert. La seconde catégorie, caractérisée par une diminution rapide de la croissance (à partir de $10 \mathrm{~cm}$ de diamètre) regroupe les autres essences et reflète une compétition 

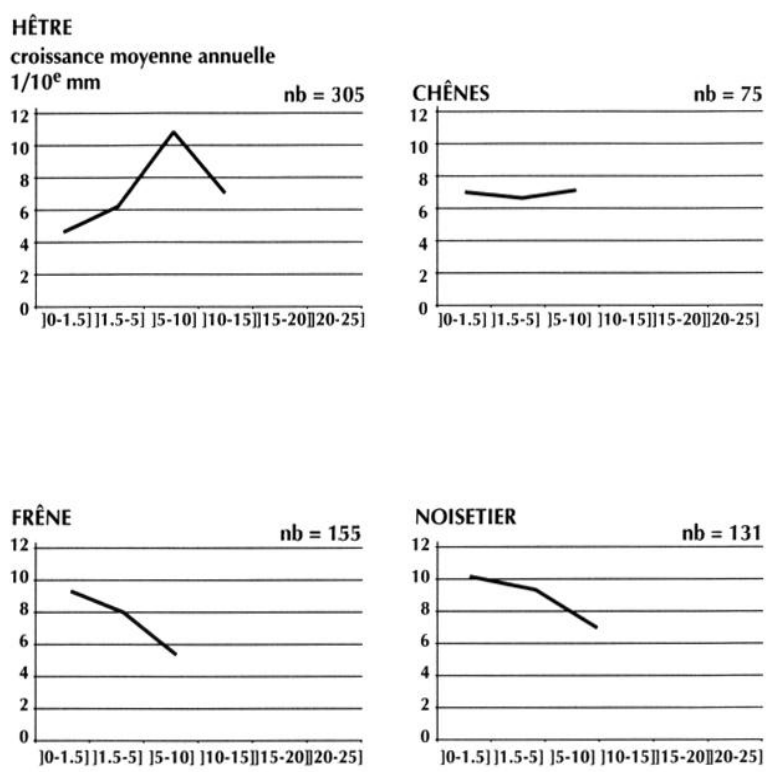
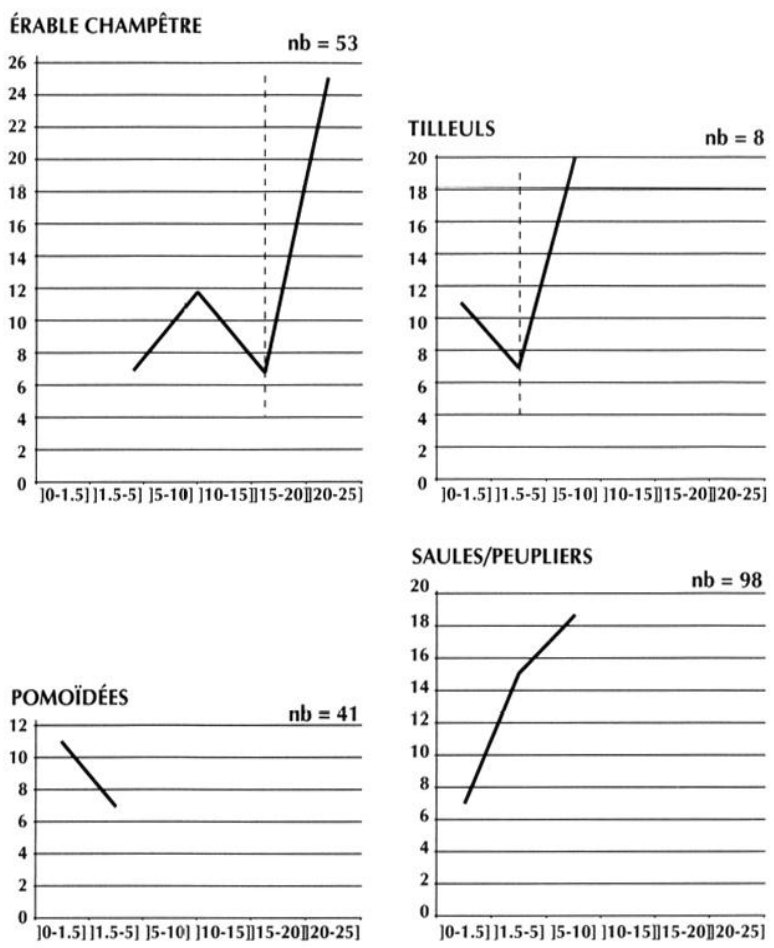

Fig. 13 - Évolution de la croissance moyenne annuelle par classes de diamètres des principaux taxons à Clairvaux XIV.

importante dès le plus jeune âge, ce qui peut être interprété comme l'exploitation d'une strate arbustive dense. Les courbes de croissance de l'érable sont, quant à elles, caractérisées par deux phases de croissance, ce qui laisse supposer l'exploitation de deux strates forestières différentes.

L'étude des courbures de cerne montre justement que les calibres exploités sont inférieurs à $15 \mathrm{~cm}$ de diamètre pour le hêtre, à $10 \mathrm{~cm}$ pour le chêne et à $5 \mathrm{~cm}$ pour les essences arbustives à l'exception de l'érable (fig. 14). Elle permet ainsi de démontrer l'exploitation préférentielle de petits calibres, correspondant probablement à la strate sousarbustive, ce qui ne signifie nullement l'absence d'individus plus gros et donc plus âgés. Enfin, le faible pourcentage de charbons de bois présentant des zones de collapse ne permet de démontrer ni l'utilisation fréquente de bois vert, ni la collecte de bois vert dans le cadre d'un éventuel stockage (Dufraisse, 2002b, p. 160).

\section{Représentativité paléoécologique et zones potentielles d'approvisionnement}

Les résultats en rapport avec le couvert végétal sont en partie cohérents avec les analyses polliniques du Petit Lac de Clairvaux (Richard, 1989a) : le noisetier, le hêtre et le chêne dominent la végétation alors que le frêne est à peine mieux représenté que les tilleuls, les érables, le sapin ou l'orme. L'essai de modélisation palynologique proposé par H. Richard (1989b) indique que les dimensions du lac de Clairvaux permettent un captage étendu des grains de pollen. Le spectre montre donc le reflet pollinique de la région plutôt que de la végétation locale ; c'est pourquoi l'auteur en déduit que les espèces comme le frêne, l'épicéa, les ormes, les érables, le sapin et les tilleuls sont sous-représentées.

Les spectres anthracologiques peuvent donc être interprétés comme résultant de l'exploitation, d'une part, d'une forêt alluviale composée du frêne, du noisetier, des Pomoïdées, des saulcs, dcs peupliers et du cornouiller sanguin et, d'autre part, d'une hêtraie-chênaie à laquelle s'associent les érables, les tilleuls, l'orme champêtre, le sapin. Comme le laisse supposer la végétation potentielle, le frêne se développerait à proximité des rives du lac en raison du degré d'hydromorphie plus élevé du sol, et la hêtraie-chênaie sur les pentes du deuxième plateau, proches des rives du lac et exposées sud - sud-est. L'étude des courbes de croissance diamétrale indique l'exploitation d'un strate arbustive plutôt dense, excepté à proximité des rives du lac où les peuplements semblent plus clairsemés. Les néolithiques ont 

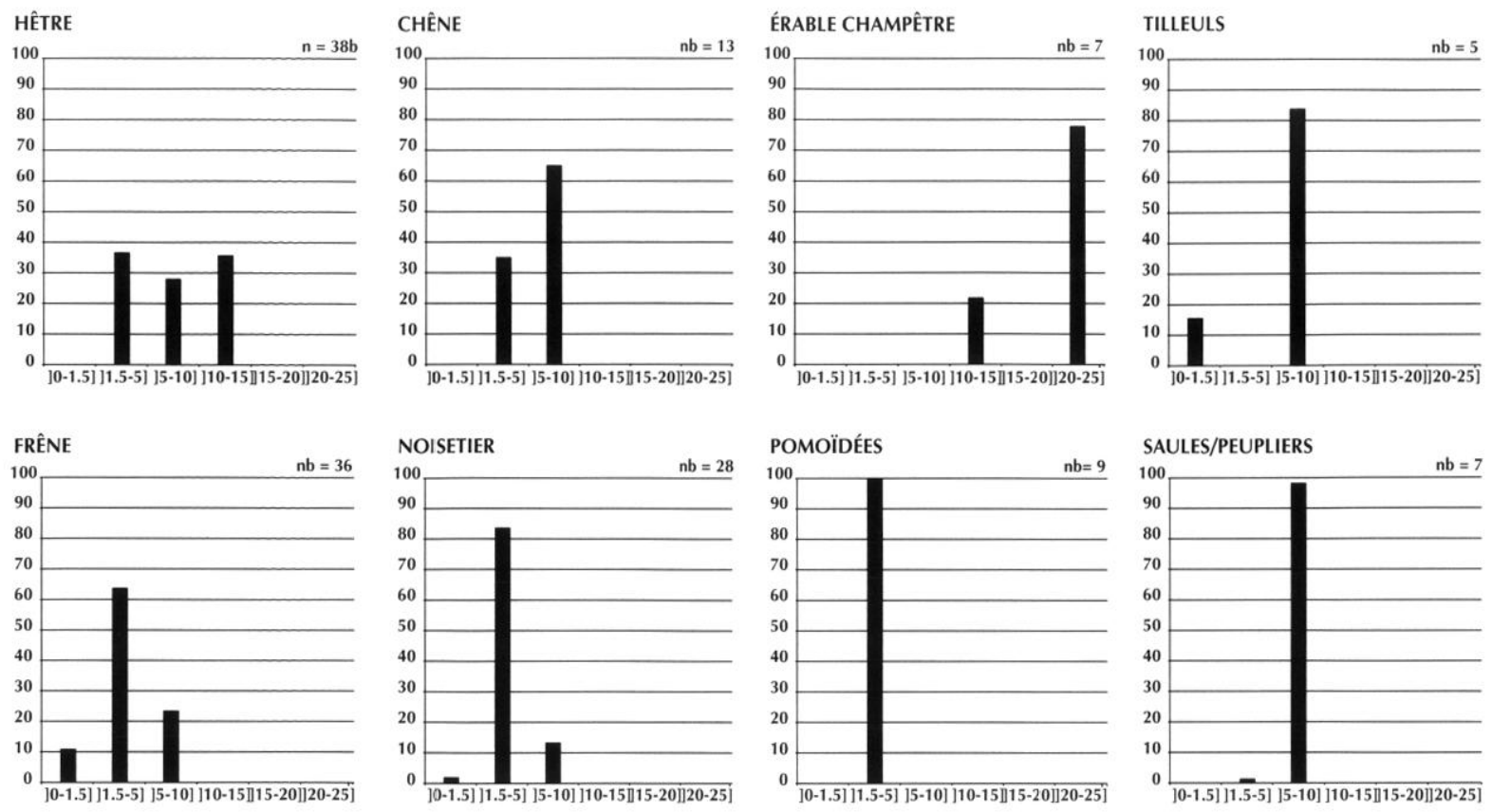

Fig. 14 - Estimations des proportions de diamètres exploités à Clairvaux XIV.

donc tiré parti de ces deux zones situées à la fois à proximité du lac et des pentes du deuxième plateau (fig. l la).

\section{Clatrvaux III}

Clairvaux III est localisé immédiatement au sud-ouest de la presqu'île de La Motte-aux-Magnins. Trois grandes périodes d'occupation, entre le Néolithique final et le début de l'âge du Bronze ont été distinguées. Seuls les niveaux attribués au Clairvaux moyen ont été analysés (niveaux IIe à IIc) (Pétrequin, 1986b). La détermination des charbons de bois de ce site a été réalisée par J.-L. Vernet et par K. Lundström-Baudais (Lundström-Baudais, 1986). L'échantillonnage, réalisé en 1974 lors de la campagne de fouille, représente la totalité des dépôts (naturels ou archéologiques), sur un triangle de $1 \mathrm{~m}$ dc côtć $\left(0,42 \mathrm{~m}^{2}\right)$. L'ensemble des couches a été prélevé par blocs, puis tamisé à une maille de $1 \mathrm{~mm}$ (Pétrequin, 1986c). Pour des raisons que nous ne connaissons pas, les résultats botaniques ont été exprimés tous niveaux confondus malgré une stratigraphie détaillée pour le Clairvaux moyen.

\section{Résultats}

La liste floristique et les proportions identifiées à Clairvaux III (tabl. III ; fig. 15) repose sur 470 fragments de charbons et la détermination de 17 taxons. Les résultats révèlent un environnement dans lequel le frêne $(40,6 \%)$ domine aux côtés d'essences telles que le noisetier (19,4\%), les Pomoïdées $(2,8 \%)$, les chênes à feuillage caduc ( $4 \%)$, le charmc, les tilleuls, les érables et l'orme. Les essences ripicoles telles que les saules et les peupliers $(5,1 \%)$, la bourdaine (Frangula alnus), les bouleaux, le cornouiller ou encore la clématite (Clematis vitalba) sont représentées. Il faut aussi signaler la présence d'un cortège floristique s'apparentant fortement à la hêtraie-sapinière avec des proportions équivalentes de hêtre $(11,5 \%)$ et de sapin $(11,1 \%)$.

\section{Représentativité paléoécologique et zones potentielles d'approvisionnement}

La liste floristique identifiée s'apparente à celle des niveaux contemporains du Clairvaux moyen de La Motte-auxMagnins, notamment par la prédominance du frêne. Il existe néanmoins des différences remarquables telles que les faibles taux de hêtre (11,5\% contre $28 \%$ à La Motte-aux-Magnins) et les taux élevés du sapin (environ $11 \%$ contre $3 \%$ à La Motte-aux-Magnins) et du noisetier (environ $20 \%$ contre $3 \%$ à La Motte-aux-Magnins), le sapin et le noisetier se classant respectivement en quatrième et en deuxième position.

Quoi qu'il en soit, ces résultats sont cohérents avec les analyses polliniques et pourraient refléter deux zones 
Tabl. III - Estimations des dénombrements et pourcentages des taxons de Clairvaux III (d'après Lundström-Baudais, 1986, fig. 16).

\begin{tabular}{|l|r|c|}
\hline \multicolumn{3}{|c|}{ CLAIRVAUX III } \\
\hline \multicolumn{1}{|c|}{ Essences } & $\begin{array}{c}\text { Nb } \\
\text { (estimés) }\end{array}$ & $\begin{array}{c}\% \\
\text { (estimés) }\end{array}$ \\
\hline Abies alba & 52 & 11,1 \\
\hline Acer sp. & 8 & 1,7 \\
\hline Betula sp. & 1 & 0,2 \\
\hline Carpinus betulus & 1 & 0,2 \\
\hline Clematis vitalba & 6 & 1,3 \\
\hline Cornus sp. & 1 & 0,2 \\
\hline Corylus avellana & 91 & 19,4 \\
\hline Fagus sylvatica & 54 & 11,5 \\
\hline Frangula alnus & 1 & 0,2 \\
\hline Fraxinus sp. & 191 & 40,6 \\
\hline Pomoideae & 13 & 2,8 \\
\hline Populus sp. & 23 & 4,9 \\
\hline Prunus sp. & 6 & 1,3 \\
\hline Quercus f.c. & 19 & 4 \\
\hline Salix sp. & 1 & 0,2 \\
\hline Tilia sp. & 1 & 0,2 \\
\hline Ulmus sp. & 1 & 0,2 \\
\hline Total & $\mathbf{4 7 0}$ & \\
\hline
\end{tabular}

d'exploitation distinctes: une première zone située à proximité des rives du lac, sur les terrasses glacio-lacustres de la Combe d'Ain et caractérisée par le frêne et son cortège floristique, et une seconde zone, située sur les plateaux supérieurs où la hêtraie-sapinière domine et/ou dans la vallée de la Frasnée actuellement recouverte par dcs plants naturels de sapin. Il pourrait s'agir là d'un mode d'exploitation de l'espace forestier différent entre les deux sites, peut-être en relation avec les autres activités pratiquées telles que la collecte de bois d'œuvre ou encore l'agriculture, point sur lequel nous reviendrons ultérieurement (fig. 1lb).

\section{LE BASSIN DE CHALAIN}

\section{Chalain 19}

Le site de Chalain 19 est localisé à l'angle sud-ouest de la rive occidentale du lac de Chalain. La séquence stratigraphique a révélé trois phases d'occupation, la première attribuée au Horgen (couche $\mathrm{O}$, datée par dendrochronologie entre 3200 et 3100 av. J.-C.) et les deux autres au Clairvaux ancien (couches $\mathrm{H}$ et $\mathrm{K}$, datées par dendrochronologie entre 3027 et 2960 av. J.-C.). Les campagnes de fouilles ont permis de dégager partiellement le plan du village. Deux aires architecturales se distinguent clairement : la première, située au sud du site, est une zone densément bâtie où des constructions rectangulaires de $8 \mathrm{~m}$ sur $4 \mathrm{~m}$ sont accolées les unes aux autres. Au nord, la

\section{CLAIRVAUX III}

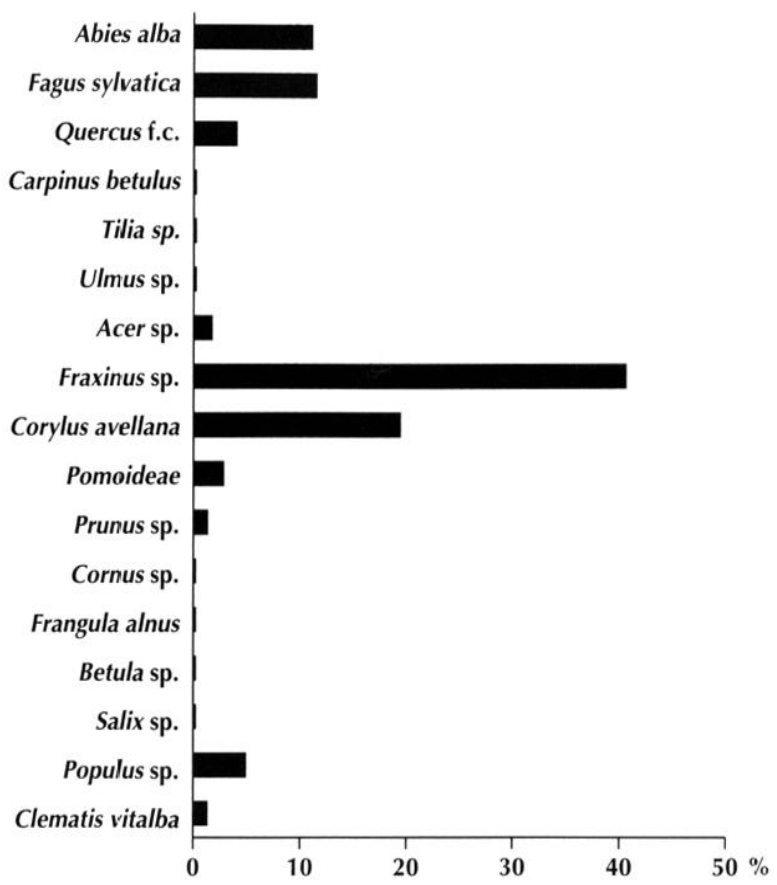

Fig. 15 - Spectre anthracologique de Clairvaux III (d'après Lundström-Baudais, 1986, fig. 16).

seconde est caractérisée par une seule construction isolée, originale par sa position dans le village et reconstruite à plusieurs reprises pendant la première moitié du $30^{\circ}$ siècle av. J.-C. La différence de répartition des artefacts entre ces deux zones dénote une fonction particulière qui semble sortir du cadre domestique strict. Enfin, les zones de rejets sont organisées au moins en deux dépotoirs collectifs en relation avec chacune des zones architecturales (Pétrequin et al., 1999 ; Viellet, 2002 ; Pétrequin dir., à paraître).

Dans la zone densément bâtie, la fouille étant terminée, l'échantillonnage des charbons de bois a été réalisé par une série de sondages à la tarière à main selon un transect perpendiculaire à la rive du lac. Dans le secteur de la maison isolée, lcs prćlc̀vements ont été effectués au moment de la fouille, à la fois au sein de la nappe de flottage et du dépotoir collectif (Dufraisse, 2002b, p. 179, fig. 77).

\section{Résultats}

L'étude de la zone densément bâtie repose sur la détermination de près de 2000 charbons et la présence de 11 à 19 taxons selon les couches (tabl. IV ; fig. 16).

Au Horgen (couche O, 288 fragments, 11 taxons), le frêne $(68,7 \%)$ domine nettement le spectre, accompagné 
Tabl. IV - Dénombrements et pourcentages des taxons reconnus par l'identification de charbons de bois de. Chalain 19.

\begin{tabular}{|c|c|c|c|c|c|c|c|c|c|c|c|c|}
\hline \multicolumn{13}{|c|}{ CHALAIN 19} \\
\hline \multirow{3}{*}{$\begin{array}{|ll|} & \text { Structures } \\
\text { Essences } & \text { Unités stratigraphiques } \\
\end{array}$} & \multicolumn{8}{|c|}{ Zone densément bâtie } & \multirow{2}{*}{\multicolumn{2}{|c|}{$\begin{array}{c}\text { Maison isolée } \\
\text { HK }\end{array}$}} & \multirow{2}{*}{\multicolumn{2}{|c|}{$\begin{array}{c}\text { Dépotoir } \\
\text { HK }\end{array}$}} \\
\hline & \multicolumn{2}{|c|}{$\mathrm{O}$} & \multicolumn{2}{|c|}{$\mathbf{K}$} & \multicolumn{2}{|c|}{ H } & \multicolumn{2}{|c|}{ HK } & & & & \\
\hline & $\mathrm{Nb}$ & $\%$ & $\mathrm{Nb}$ & $\%$ & $\mathrm{Nb}$ & $\%$ & $\mathrm{Nb}$ & $\%$ & $\mathrm{Nb}$ & $\%$ & $\mathrm{Nb}$ & $\%$ \\
\hline Abies alba & & & & & & & 11 & 1,23 & 24 & 0,51 & 5 & 0,11 \\
\hline Acer campestre & 4 & 1,39 & 8 & 2,76 & 13 & 2,88 & 23 & 2,58 & 147 & 3,10 & 77 & 1,68 \\
\hline Acer platanoides/pseudoplatanus & 6 & 2,08 & 9 & 3,10 & 16 & 3,55 & 24 & 2,69 & 222 & 4,68 & 233 & 5,08 \\
\hline Acer sp. & 2 & 0,69 & 11 & 3,79 & 10 & 2,22 & 19 & 2,13 & 29 & 0,61 & 47 & 1,02 \\
\hline Angiospermae & 9 & 3,13 & 7 & 2,41 & 10 & 2,22 & 27 & 3,03 & 6 & 0,13 & 15 & 0,33 \\
\hline Betula sp. & & & & & 2 & 0,44 & 9 & 1,01 & 5 & 0,11 & 4 & 0,09 \\
\hline Carpinus betulus & & & & & & & 1 & 0,11 & & & & \\
\hline Cornus sanguinea & & & & & & & 1 & 0,11 & 15 & 0,32 & 20 & 0,44 \\
\hline Corylaceae & & & & & & & & & & & 1 & 0,02 \\
\hline Corylus avellana & 15 & 5,21 & 22 & 7,59 & 45 & 9,98 & 77 & 8,63 & 387 & 8,16 & 159 & 3,47 \\
\hline Fabaceae & & & & & & & 12 & 1,35 & 1 & 0,02 & & \\
\hline Fagus sylvatica & 20 & 6,94 & 129 & 44,48 & 161 & 35,70 & 209 & 23,43 & 2680 & 56,52 & 2969 & 64,71 \\
\hline Frangula sp. & & & & & & & & & 2 & 0,04 & 1 & 0,02 \\
\hline Fraxinus excelsior & 198 & 68,75 & 67 & 23,10 & 101 & 22,39 & 242 & 27,13 & 637 & 13,43 & 750 & 16,35 \\
\hline Hippophae rhamnoides & & & & & & & & & 2 & 0,04 & & \\
\hline Ilex aquifolium & & & & & & & & & 1 & 0,02 & 1 & 0,02 \\
\hline Larix/Picea & & & & & & & & & 1 & 0,02 & & \\
\hline Monocotyledonae & & & & & & & & & 1 & 0,02 & & \\
\hline Pomoideae & 2 & 0,69 & & & 3 & 0,67 & 8 & 0,90 & 10 & 0,21 & 13 & 0,28 \\
\hline Pomoideae type Pirus & & & & & & & 2 & 0,22 & & & & \\
\hline Pomoideae type Sorbus/Crataegus & 1 & 0,35 & & & 1 & 0,22 & 1 & 0,11 & 17 & 0,36 & & \\
\hline Populus sp. & & & 1 & 0,34 & 5 & 1,11 & 7 & 0,78 & 32 & 0,67 & 12 & 0,26 \\
\hline Prunoideae & & & & & & & & & 1 & 0,02 & & \\
\hline Prunus avium & & & & & & & & & 1 & 0,02 & 1 & 0,02 \\
\hline Prunus type avium/padus & & & 1 & 0,34 & & & 1 & 0,11 & & & & \\
\hline Quercus f.c. & 10 & 3,47 & 12 & 4,14 & 20 & 4,43 & 153 & 17,15 & 232 & 4,89 & 129 & 2,81 \\
\hline Rhamnus cathartica & & & & & & & & & & & 1 & 0,02 \\
\hline Rosaceae & & & & & & & & & 1 & 0,02 & & \\
\hline Salix sp. & 1 & 0,35 & 5 & 1,72 & 31 & 6,87 & 38 & 4,26 & 145 & 3,06 & 42 & 0,92 \\
\hline Salix/Populus & 4 & 1,39 & 1 & 0,34 & 9 & 2,00 & 12 & 1,35 & 13 & 0,27 & 15 & 0,33 \\
\hline Sambucus sp. & & & & & & & & & 1 & 0,02 & & \\
\hline Sorbus sp. & & & & & & & & & 4 & 0,08 & & \\
\hline Taxus baccata & & & & & & & 2 & 0,22 & & & & \\
\hline Tilia cordata & 3 & 1,04 & & & 5 & 1,11 & 3 & 0,34 & 34 & 0,72 & 18 & 0,39 \\
\hline Tilia platyphyllos & 1 & 0,35 & 2 & 0,69 & 3 & 0,67 & & & 11 & 0,23 & 11 & 0,24 \\
\hline Tilia sp. & 5 & 1,74 & 9 & 3,10 & 6 & 1,33 & 5 & 0,56 & 36 & 0,76 & 23 & 0,50 \\
\hline Ulmus minor & & & 1 & 0,34 & 1 & 0,22 & & & 16 & 0,34 & 2 & 0,04 \\
\hline Ulmus montana & 2 & 0,69 & 1 & 0,34 & 2 & 0,44 & & & 15 & 0,32 & 19 & 0,41 \\
\hline Ulmus sp. & 5 & 1,74 & 2 & 0,69 & 6 & 1,33 & 5 & 0,56 & 12 & 0,25 & 20 & 0,44 \\
\hline Viburnum sp. & & & 2 & 0,69 & 1 & 0,22 & & & 1 & 0,02 & & \\
\hline Total & 288 & & 290 & & 451 & & 892 & & 4742 & & 4588 & \\
\hline Écorce/Phloème & 107 & & 9 & & 10 & & 9 & & 128 & & 64 & \\
\hline Nombre de taxons & 11 & & 13 & & 15 & & 19 & & 25 & & 20 & \\
\hline Non identifiés & 2 & & 0 & & 0 & & 0 & & 18 & & 5 & \\
\hline Indéterminables & 2 & & 4 & & 3 & & 2 & & 168 & & 51 & \\
\hline
\end{tabular}

par ordre d'importance du hêtre $(6,9 \%)$, du noisetier $(5,2 \%)$ et des chênes $(3,4 \%)$. Sont également présentes des essences secondaires comme les érables $(4,2 \%)$, les tilleuls $(2,1 \%)$, l'orme des montagnes $(2,4 \%)$, les aubépines et sorbiers $(0,35 \%)$ et des essences de ripisylve telles que les saules $(1,7 \%)$.

$\mathrm{Au}$ Clairvaux ancien (couche $\mathrm{K}, 290$ charbons et 13 taxons), le hêtre $(44,5 \%)$ devient l'essence prédo- minante, mais le frêne se maintient (23\%), accompagné des chênes ( $4 \%$ ), des tilleuls, des ormes et des érables. Puis, au cours du Clairvaux ancien (entre les couches $\mathrm{K}$ et $\mathrm{H}$ ), le hêtre recule $(35,7 \%)$ au profit d'essences postpionnières et pionnières telles que le noisetier $(10 \%)$, les saules $(9 \%)$ et les bouleaux ; le frêne se maintient $(22,4 \%)$.

Dans la zone du bâtiment isolé (tabl. IV; fig. 16), l'analyse a été réalisée uniquement sur le niveau du 
Clairvaux ancien (couche HK, environ 4700 charbons et 25 taxons). Les quatre essences principales sont toujours le hêtre, le frêne, le noisetier et les chênes caducifoliés.

\section{CHALAIN 19}

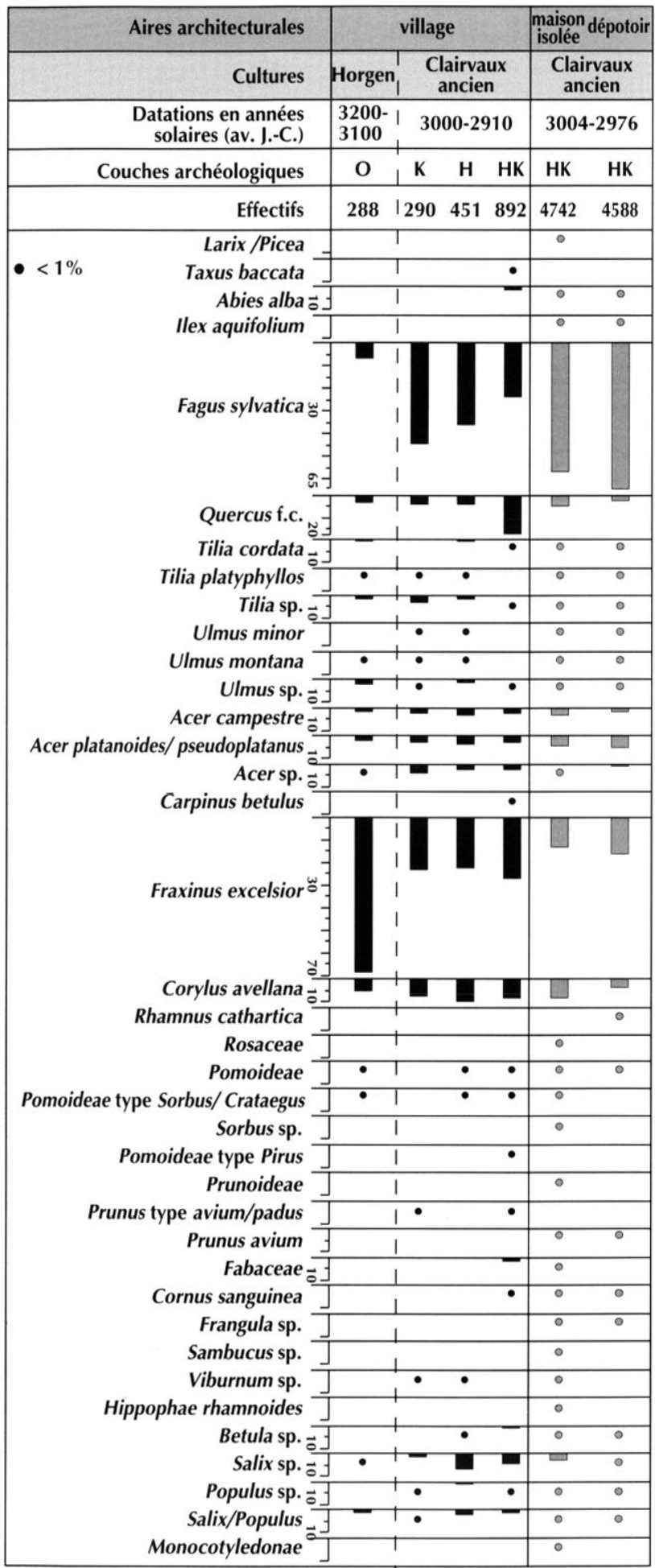

Fig. 16 - Diagramme anthracologique du site de Chalain 19.
Cependant, leur ordre hiérarchique est différent : le hêtre est nettement mieux représenté $(56,5 \%$ contre $23,4 \%$ dans la zone densément bâtie) alors que le frêne l'est moins ( $13,4 \%$ contre $23 \%$ environ dans la zone densément bâtie). Les essences secondaires telles que le noisetier $(8,2 \%)$, les chênes $(4,9 \%)$, la famille des Pomoïdées, les érables, les tilleuls, les ormes, les peupliers et les saules sont présentes dans des proportions équivalentes à celles de la zone densément bâtie, mais la richesse taxonomique est bien plus importante: on note la présence d'essences de ripisylve supplémentaires telles que la bourdaine, le sureau (Sambucus sp.), des essences à affinités montagnardes telles que le sapin, l'épicéa (Picea sp.) et le houx. L'argousier (Hippophae rhamnoides), espèce appréciant les forêts ripicoles et les berges de ruisseau de montagne ou du littoral où il peut constituer des groupements pionniers, peut aussi être rattaché à l'étage montagnard. L'analyse anthracologique du dépotoir rattaché au bâtiment isolé ( 4500 charbons et 20 taxons) montre sur l'ensemble des niveaux (l'échantillonnage a été réalisé selon 9 subdivisions stratigraphiques) un spectre très similaire à celui obtenu à partir des échantillons prélevés au sein de la nappe de flottage, ce qui appuie la cohérence des résultats. Cependant, les subdivisions stratigraphiques du dépotoir permettent de mettre en évidence une dynamique entre le hêtre et le frêne : les fréquences du hêtre diminuent progressivement au profit du frêne. En revanche, les proportions des essences secondaires (chênes à feuillage caduc, érable champêtre et érable sycomore, tilleuls à petites et à grandes feuilles, orme des montagnes) ou encore les essences pionnières (saules, peupliers) et postpionnières (noisetier) restent très stables d'un niveau à l'autre.

Les courbes de croissance diamétrale ont pu être établies pour le frêne et le hêtre (fig. 17). Considérons tout d'abord les courbes du frêne qui sont radicalement différentes entre le niveau $\mathrm{O}$ et l'ensemble $\mathrm{HK}$. Dans le niveau O, la croissance du frêne augmente progressivement avec les classes de diamètre et indique, compte tenu de l'écologie de cette essence, un développement dans un milieu où les besoins en lumière et en humidité sont satisfaisants, peu dense. Dans le niveau $\mathrm{HK}$, le frêne présente un accroissement important et extrêmement rapide jusqu'à $5 \mathrm{~cm}$ de diamètre, puis il diminue progressivement jusqu'à $25 \mathrm{~cm}$ de diamètre ; cette dynamique pourrait correspondre à celle de rejets de souches, au moins pour les diamètres inférieurs à $10 \mathrm{~cm}$, caractérisés par une croissance très rapide dès les premières années de vie (Lundström-Baudais, 1986). 

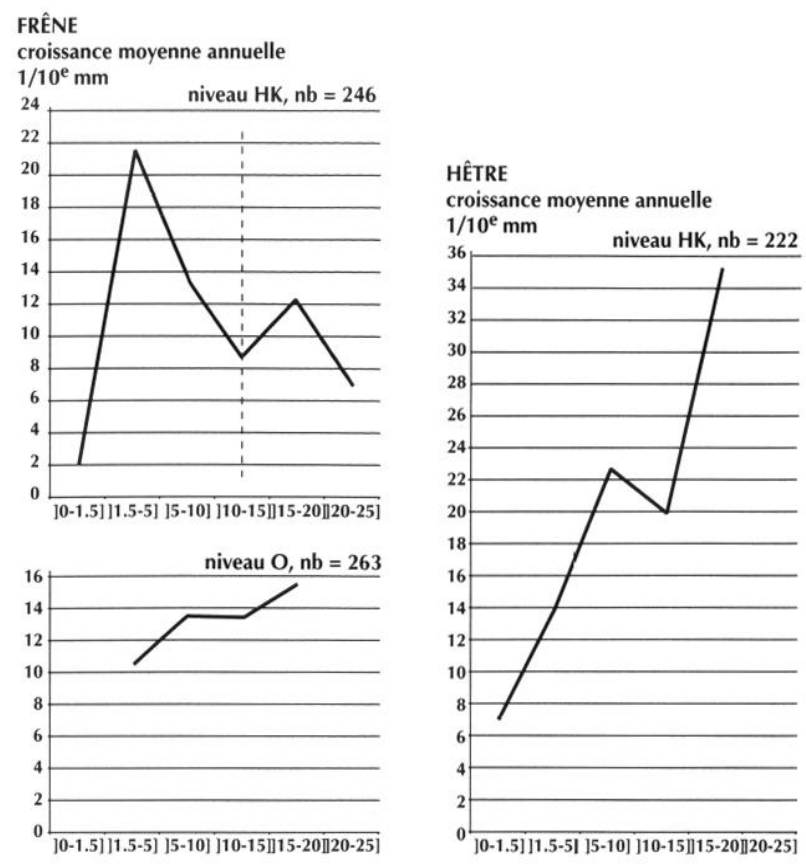

Fig. 17 - Évolution de la croissance moyenne annuelle par classes de diamètres des principaux taxons à Chalain 19.
La croissance des peuplements de hêtre, quant à elle, a pu être établie uniquement pour le niveau HK. Elle est caractérisée par un taux d'accroissement très important comparativement aux autres sites et en constante augmentation. Cette croissance particulièrement élevée est difficilement interprétable en l'absence de référentiel actuel. On peut cependant supposer des conditions de croissance extrêmement favorables où les conditions atmosphériques sont idéales, comme sur le deuxième plateau de Champagnole. Ces courbes peuvent aussi refléter la quasiabsence de compétition intra- et interspécifique, ce qui laisse supposer l'exploitation de peuplements ayant atteint un état d'équilibre.

Enfin, les courbes du noisetier montrent une croissance qui diminue progressivement avec les classes de diamètres. Ce ralentissement de croissance pourrait traduire un milieu relativement dense, limitant la croissance du tronc. Il peut aussi, plus simplement, être lié au diamètre naturel des rejets de cet arbuste. Là encore, un référentiel actuel fait défaut.

La collecte du bois de feu, selon l'étude des calibres, est axée au Horgen comme au Clairvaux ancien, que ce soit pour le frêne ou le hêtre, sur des bois de 5 à $10 \mathrm{~cm}$ et de 15 à $20 \mathrm{~cm}$ de diamètre, ce qui pourrait correspondre à l'exploitation d'une strate forestière du type gaulis et bas perchis (fig. 18). Quant à l'état du bois, les pourcentages de fragments de charbons présentant des zones de collapse ne permettent d'écarter ni l'hypothèse de l'utilisation de bois vert ni sa collecte en vue d'un éventuel stockage (Dufraisse, 2002b, p. 189).

\section{Représentativité paléoécologique et zones potentielles d'approvisionnement}

Totalisant un minimum de 29 taxons, les spectres anthracologiques, aussi bien dans la zone densément bâtie qu'au niveau du bâtiment isolé (fig. 16), montrent une richesse taxonomique considérable. Par analogie avec la végétation actuelle et par comparaison avec le spectre pollinique de Chalain 19, qui indique un milieu clairement dominé par le hêtre (Gauthier, 2001), le diagramme anthracologique présente une grande cohérence paléoécologique.

Ainsi, l'analyse du Horgen et du Clairvaux ancien révèle l'exploitation d'une mosaïque de formations : celle d'une végétation à affinités montagnardes composée du hêtre, du frêne pro parte, des chênes, des tilleuls et des ormes, celle d'une frênaie alluviale accompagnée des chênes, des érables, des Pomoïdées tels le sorbier ou l'aubépine, du noisetier et celle d'une végétation riveraine principalement composée du saule et des peupliers.

$\mathrm{Au}$ Horgen, dans la zone densément bâtie, la prédominance du frêne et les nombreuses essences héliophiles et/ou de ripisylve traduisent l'exploitation d'une forêt alluviale de type frênaie, probablement située sur la terrasse inférieure de l'Ain. Au Clairvaux ancien, le hêtre devient 

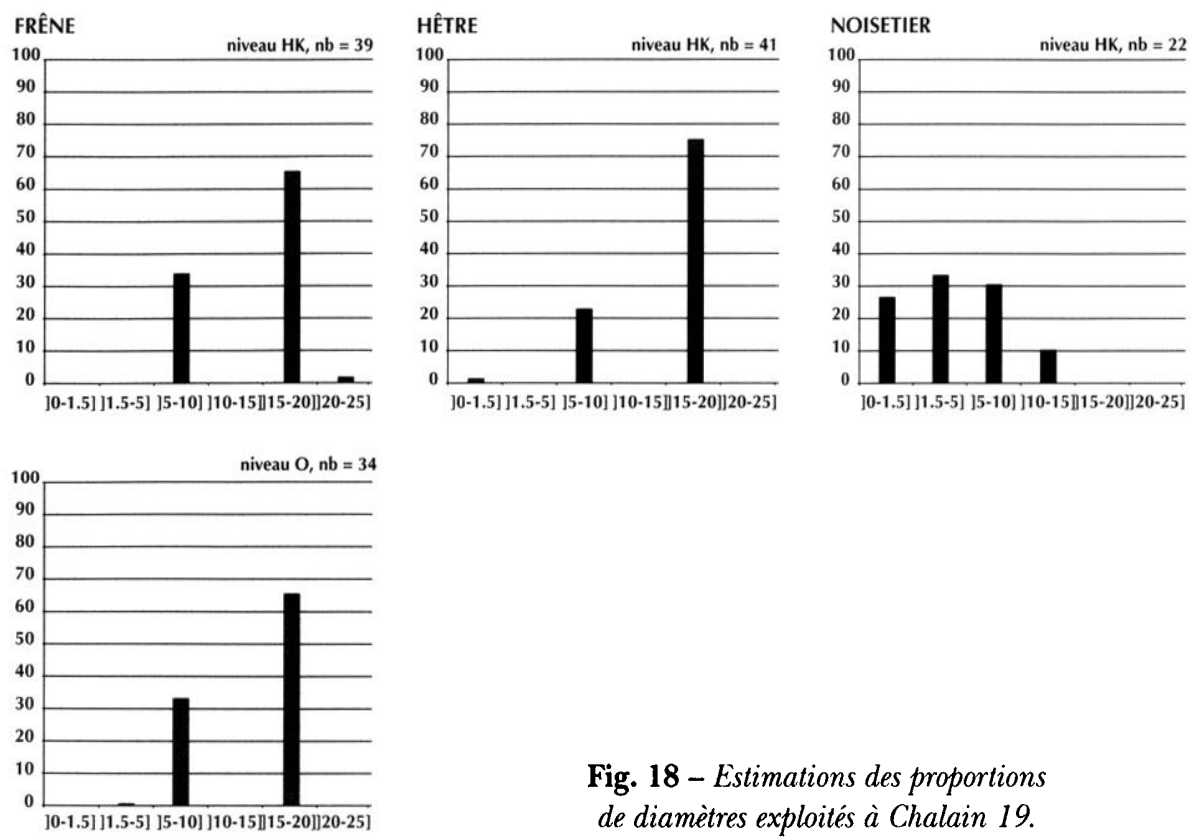

Fig. 18 - Estimations des proportions de diamètres exploités à Chalain 19.

du noisetier, des saules et l'apparition du bouleau conforte cette hypothèse, cohérente, d'une part avec l'augmentation du nombre de villages contemporains sur la rive du lac, et d'autre part avec les courbes de croissance diamétrale du frêne qui suggèrent l'exploitation de rejets de souches au moins pour les diamètres inférieurs à $10 \mathrm{~cm}$.

Enfin, si plusieurs hypothèses peuvent être proposées pour interpréter l'exploitation du hêtre au détriment du frêne au Clairvaux ancien (détérioration climatique, abandon des exploitations, cyclicités naturelles) (Dufraisse, 2002c), nous n'en retiendrons qu'une, la plus probable, celle d'une extension des aires d'approvisionnement vers le

l'essence prédominante, mais le frêne se maintient accompagné des chênes, tilleuls, ormes et érables. Puis, au cours de cette période, le hêtre recule au profit du frêne et d'essences pionnières telles que le noisetier, les saules et les bouleaux. Enfin, le spectre du bâtiment isolé traduit l'exploitation quasi exclusive de la hêtraie, avec des proportions de hêtre plus élevées que dans la zone densément bâtie, et la présence d'essences montagnardes telles que le sapin, l'épicéa, l'if, le houx (qui peut aussi appartenir à la chênaie) ou encore l'argousier. L'étude détaillée du dépotoir collectif attribué à la maison isolée montre un léger retrait du hêtre qui rappelle celui observé au sein de la zone densément bâtie. Cette augmentation des taux de frêne au cours du Clairvaux ancien pourrait refléter les premiers indices d'ouverture du milieu. En effet, les analyses polliniques réalisées sur plusieurs lacs suisses situés à des altitudes proche de celle du lac de Chalain montrent des pics de hêtre et/ou de sapin, alternant avec des pics d'aulne, de bouleau, de noisetier et parfois de peuplier, c'est-à-dire d'espèces pionnières. Ces pics sont interprétés comme des phases de déforestation de 100 à 350 ans, bien séparées dans le temps, et reflétant des " pulses of human activity" (Ammann, 1988; Richoz, Gaillard, 1989; Richoz et al., 1994). Sur le lac de Chalain, les espèces pionnières telles que les aulnes, bouleaux, saules, peupliers et le noisetier sont faiblement représentées voire absentes du diagramme anthracologique mais le frêne, essence postpionnière nomade, opportuniste selon les conditions stationnelles, a pu jouer ce rôle de pionnier. L'augmentation plateau de Champagnole où se développe le hêtre. La prédominance du frêne au Horgen pourrait, en effet, refléter des aires d'exploitation situées à proximité des rives du lac, sur les terrasses alluviales de l'Ain, tandis que l'exploitation du hêtre au Clairvaux ancien pourrait correspondre à des zones d'approvisionnement situées plus en altitude, probablement sur les plateaux supérieurs du Jura. Cette extension a pu être motivée par la raréfaction du frêne, utilisé au Horgen, à la fois en architecture et pour le bois de feu. Cependant, l'abandon des rives lacustres pendant environ 60 ans, entre le Horgen et le Clairvaux ancien, aurait dû permettre la régénération du frêne. L'extension des aires d'exploitation pourrait donc traduire ici un mode de gestion de l'espace forestier différent, point sur lequel nous reviendrons. Enfin, pendant le Clairvaux ancien, les aires d'exploitation entre la zone densément bâtie et la maison isolée sont différentes et pourraient refléter une organisation singulière dans l'approvisionnement en bois de feu, directement liée à la signification sociale de cette construction (fig. 19a et c).

\section{Chalain 3}

Le site de Chalain 3 se trouve au nord de la rive occidentale du lac de Chalain, à l'opposé de Chalain 19. L'ensemble de la séquence sédimentaire, composé de 11 couches, a été subdivisé en trois ensembles présentant des rythmes d'occupation différents (Pétrequin, 1997). L'analyse anthracologique, réalisée par K. Lundström- 


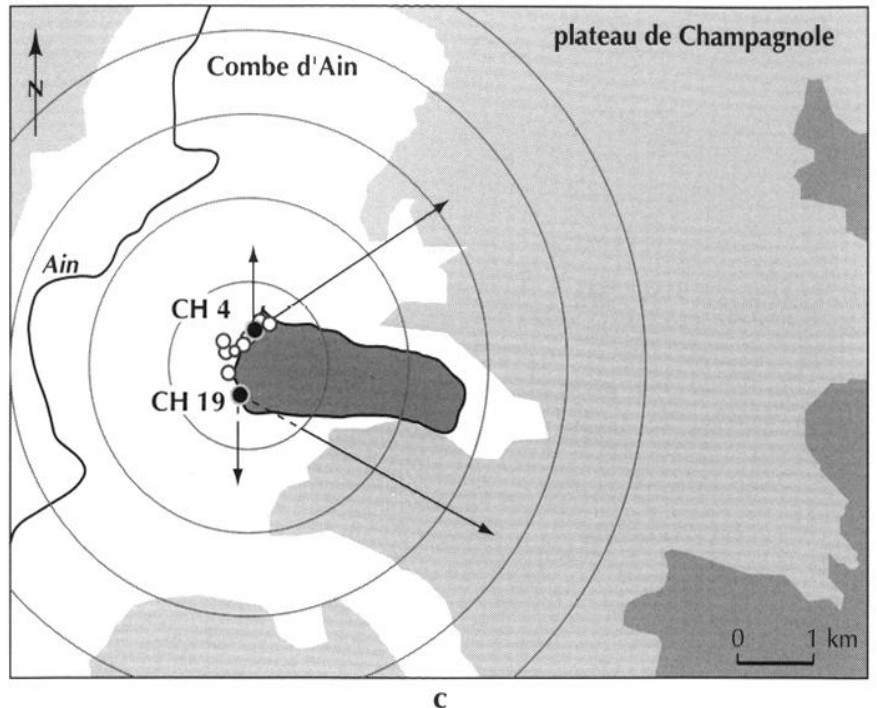

FERRIÈRES-CLAIRVAUX

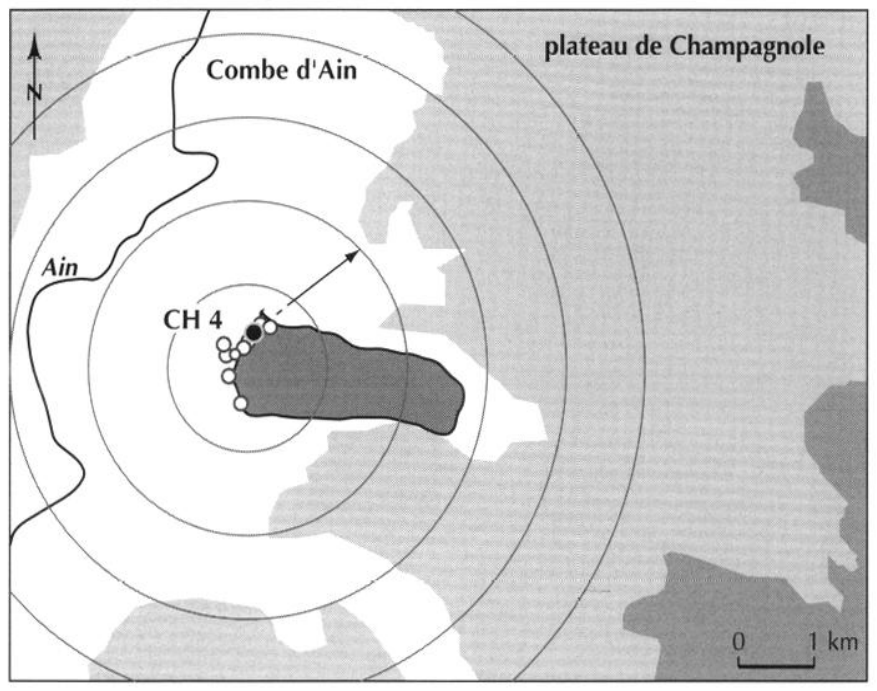

b

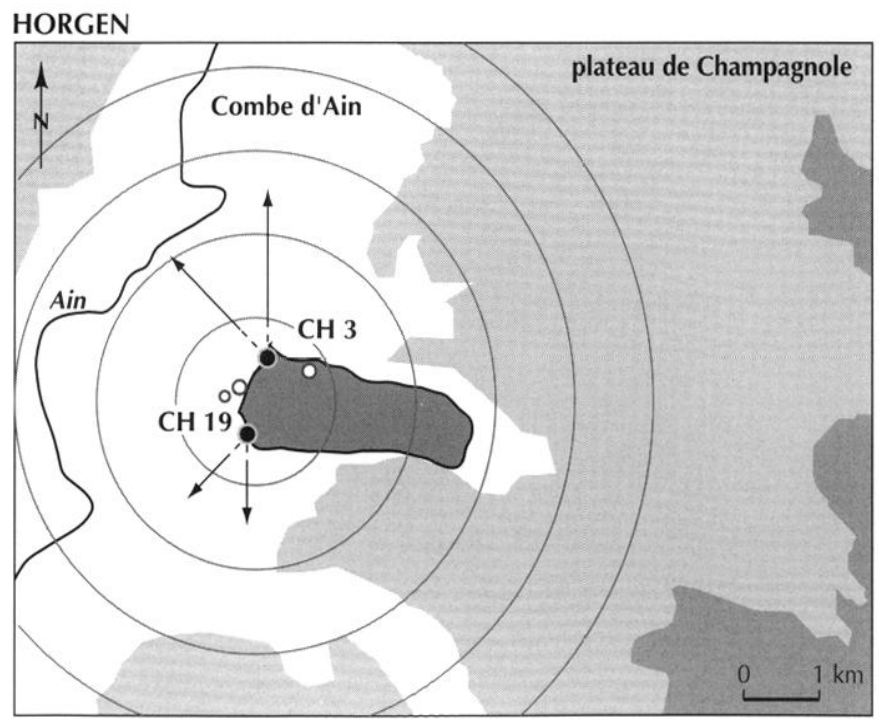

a

$550 \mathrm{~m}$, terrasses de I'Ain

600-700 m, plateaux calcaires au-dessus de $700 \mathrm{~m}$ plateaux d'altitude
Baudais (1997), a porté sur la couche VIII attribuée au Horgen. Cette couche se place dans l'ensemble 1, composé des couches VI (également attribuée au Horgen) et IV (attribuée au Ferrières) (Giligny, 1997).

Les prélèvements, réalisés lors des campagnes de fouille (1989-1991), ont été effectués par tubage tous les quatre mètres de manière à ce que les échantillons soient représentatifs des différents faciès stratigraphiques. Toutefois, seuls les mètres carrés comprenant plus de 50 charbons, soit $23 \mathrm{~m}^{2}$ au total, ont été retenus par le paléobotaniste. Le tamisage a ensuite été réalisé à des mailles de 1 et $2 \mathrm{~mm}$ (Lundström-Baudais, 1997).

\section{Résultats}

Le spectre anthracologique du site de Chalain 3 couche VIII (tabl. V; fig. 20) montre la prédominance du frêne $(43 \%)$, mais aussi celle des érables $(27,5 \%)$ qui se placent directement au deuxième rang. Ces deux essences sont accompagnées du noisetier $(8 \%)$ ainsi que des peupliers, des bouleaux, des saules, du troène (Ligustrum vulgare) et des aulnes. D'autres taxons, représentés dans de plus faibles proportions, sont également présents tels que les chênes à feuillage caduc, le hêtre, les tilleuls ou encore les ormes.

Une étude des diamètres exploités sur les quatre principales essences arborées (frêne, érable, noisetier, chêne) a également été réalisée (Lundström-Baudais, 1997, fig. 3). Les différentes classes de diamètre établies selon l'auteur sont : $1 \mathrm{~cm}, 2 \mathrm{~cm}, 3 \mathrm{~cm}, 4 \mathrm{~cm}, 5 \mathrm{~cm}, 5$ à $10 \mathrm{~cm}, 10$ à $15 \mathrm{~cm}$, 15 à $20 \mathrm{~cm}$ et une classe "gros bois". En regroupant les classes de faible diamètre $(<5 \mathrm{~cm})$ pour raisonner sur des fourchettes de classe équivalentes à celle des analyses des autres sites, il apparait alors que les diamètres de moins de $5 \mathrm{~cm}$ prédominent quelle que soit l'essence considérée.

\section{Représentativité paléoécologique et zones potentielles d'approvisionnement}

Si K. Lundström-Baudais (1997) interprète ces pourcentages comme le résultat d'une collecte sélective du bois de

Fig. 19 - Schéma synthétique des données et interprétations acquises par l'étude des charbons de bois issus des habitats littoraux du bassin de Chalain. Les flèches correspondent aux hypothèses sur les zones potentielles d'approvisionnement : a, Horgen ; b, Ferrières-Clairvaux ; c, Clairvaux ancien. 
Tabl. V - Dénombrements et pourcentages des taxons reconnus par l'identification de charbons de bois de Chalain 3 (d'après LundströmBaudais, 1997).

\begin{tabular}{|l|c|c|}
\hline \multicolumn{3}{|c|}{ CHALAIN 3 } \\
\hline \multicolumn{1}{|c|}{ Essences } & $\begin{array}{c}\text { Nb } \\
\text { (estimés) }\end{array}$ & $\%$ \\
\hline Acer sp. & 371 & 27,5 \\
\hline Alnus sp. & 1 & 0,1 \\
\hline Betula sp. & 10 & 0,7 \\
\hline Corylus avellana & 108 & 8 \\
\hline Fagus sylvatica & 61 & 4,5 \\
\hline Fraxinus sp. & 581 & 43 \\
\hline Ligustrum vulgare & 1 & 0,1 \\
\hline Quercus f.c. & 86 & 6,4 \\
\hline Pomoideae & 49 & 3,6 \\
\hline Populus sp. & 18 & 1,3 \\
\hline Prunus sp. & 1 & 0,1 \\
\hline Salix sp. & 5 & 0,4 \\
\hline Tilia sp. & 55 & 4,1 \\
\hline Ulmus sp. & 3 & 0,2 \\
\hline Total & $\mathbf{1 3 5 0}$ & \\
\hline
\end{tabular}

chauffe en suggérant l'existence d'une relation directe entre les charbons de bois et les éclisses - point que nous discuterons - le cortège floristique représenté à Chalain 3 rappelle fortement, selon nous, le groupement de la frênaieérablaie colonisant les milieux humides tels que les bords de ruisseaux forestiers, en pente ou sur fond plat, sur alluvions et colluvions carbonatées (Beaufils, 1983; Rameau, 1987). Par ailleurs, la comparaison du spectre de Chalain 3 avec celui de Chalain 19 montre une grande cohérence paléoécologique puisque les groupements exploités au Horgen, la frênaie à Chalain 19 et la frênaie-érablaie à Chalain 3 ont des affinités écologiques très proches et sont localisées sur la terrasse inférieure de la Combe d'Ain, probablement à moins d'un kilomètre des rives lacustres. Les analyses polliniques de Chalain 3 indiquent, quant à elles, un milieu globalement dominé par le hêtre, alors que la chênaie mixte est en constante régression et que le frêne se maintient (Richard, 1997). La frênaie ne domine donc pas le milieu, mais elle est suffisamment développée pour être systématiquement exploitée. La faible représentation de l'érable dans les analyses polliniques, excepté dans les prélèvements effectués correspondant aux niveaux archéologiques, laisse aussi supposer que la frênaie-érablaie forme un groupement très local, limité dans l'espace et situé à proximité des rives de l'Ain. Ainsi, l'exploitation de la frênaie à Chalain 19 et de la frênaie-érablaie à Chalain 3 suggère des zones d'exploitation différentes, qui ne sont pas sans rappeler la bipolarité de l'habitat à l'extrémité occidentale du lac de Chalain (Pétrequin et al., 1999) (fig. 19a).

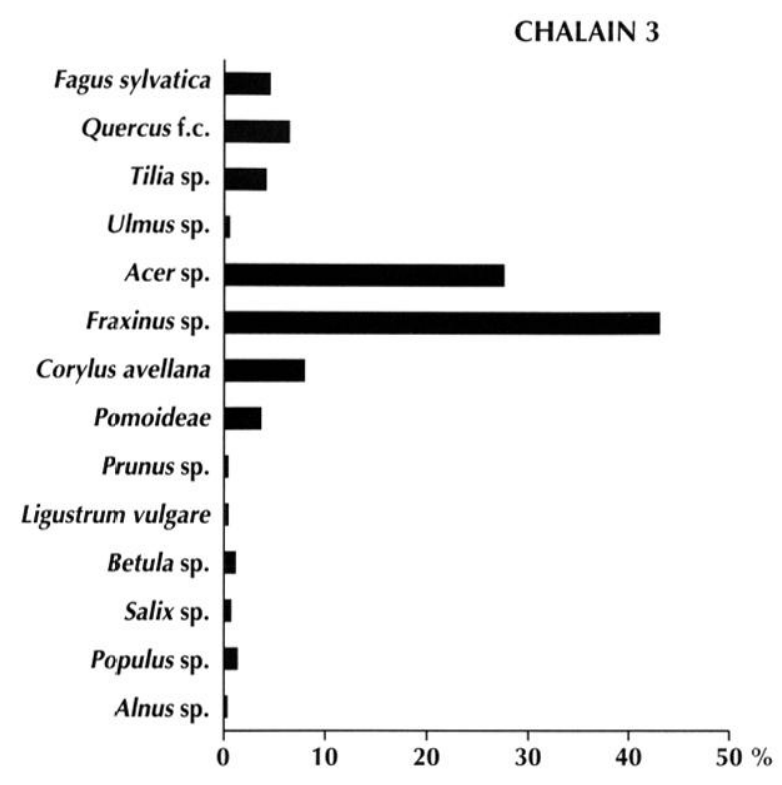

Fig. 20 - Spectre anthracologique du site de Chalain 3.

\section{Chalain 4}

Le site de Chalain 4 forme une presqu'île située au sudouest de Chalain 3. La séquence stratigraphique de ce site est particulièrement dilatée et peut être décomposée en huit couches. Les analyses anthracologiques ont porté sur la couche VII, composée de quatre niveaux organiques (phases 1 à 4) datés par la dendrochronologie entre 3040 et 3000 av. J.-C. (Lavier, 1996). La phase 1 (couche G) est attribuée à la transition Ferrières-Clairvaux, tandis que les phases 2 (couche F), 3 (couche E) et 4 (couches D à A) sont attribuées au Clairvaux ancien. Ces différentes phases d'occupation sont séparées par de courtes périodes d'abandon, relatives à de brèves inondations. Des niveaux d'incendie recouvrent les fumiers des couches G, E et C (phases 1, 3 et 4). La quantité et la qualité des artefacts carbonisés retrouvés dans ces niveaux d'incendie permet de supposer qu'il s'agit de feux accidentels, probablement à l'origine des reconstructions successives (Pétrequin, 1995).

L'échantillonnage des macrorestes végétaux a été systématisé avec un prélèvement tous les huit mètres. Ces prélèvements ont été complétés dans les zones de meilleure conservation ou d'accumulation sous forme de nappes de flottage. Les couches d'incendie ont soigneusement été évitées ainsi que les zones où la présence d'objets lourds a localement mélangé les couches de fumiers aux couches d'incendies (Pétrequin, 1995). 


\section{Résultats}

L'analyse anthracologique de Chalain 4 repose sur 2473 fragments de charbons de bois déterminés, soit 17 taxons, auxquels s'ajoutent 650 fragments d'écorce carbonisée (tabl. VI, fig. 21).

La phase 1 (couche $\mathrm{G}$ ) ne compte que 7 taxons pour 210 charbons déterminés auxquels s'additionnent 133 fragments d'écorce carbonisée, soit environ un tiers de l'échantillon. Les chênes à feuillage caduc $(57,6 \%)$ dominent nettement le spectre, accompagnés du noisetier $(18,1 \%)$ et du frêne $(17,1 \%)$, espèces postpionnières héliophiles. D'autres essences secondaires sont représentées telles que le hêtre $(4,3 \%)$, le cornouiller sanguin, le tilleul à grandes feuilles et les Rosacées.

Les phases 2 et 3 (couches $F$ et $E$ ) présentent des spectres très proches. Ils sont caractérisés par un nombre de taxons deux fois plus important que dans la couche $G$ (respectivement 14 et 12 taxons). L'effectif d'écorce carbonisée est, quant à lui, nettement inférieur à la phase précédente. Le hêtre $(32,3 \%$ et $33,6 \%)$ est l'essence principale dans les deux couches, accompagné du frêne $(20,8 \%$ et $21,8 \%)$, et des chênes à feuillage caduc $(21,8 \%$ et $14,5 \%)$ auparavant dominants. Le cortège floristique qui lui est associé se compose des érables, du noisetier, des Pomoïdées types aubépines et sorbiers, des tilleuls et des ormes. Les essences à affinités ripicoles sont également présentes avec les bouleaux, le cornouiller sanguin, les peupliers et les saules.

La phase 4, regroupant les couches A, B, C et D, présente une liste floristique (9 à 12 taxons) et des proportions comparables d'une couche à l'autre. Le spectre, significativement différent de celui observé dans les phases précédentes, reflète l'exploitation d'un milieu majoritairement dominé par le frêne $(35,5 \%$ à $37,2 \%)$ au détriment du hêtre $(17,4 \%$ à $23,9 \%)$ et des chênes à feuillage caduc $(12,2 \%$ à $21,3 \%)$ dont les fréquences restent pourtant relativement importantes. Corrélativement, le noisetier $(10,3 \%$ à 14,5\%) augmente; certaines espèces secondaires, au contraire, diminuent plus ou moins nettement, telles que les érables. D'autres, enfin, se maintiennent comme les

Tabl. VI - Dénombrements et pourcentages des taxons reconnus par l'identification de charbons de bois de Chalain 4.

\begin{tabular}{|c|c|c|c|c|c|c|c|c|c|c|c|c|c|c|c|c|}
\hline \multicolumn{17}{|c|}{ CHALAIN 4} \\
\hline \multirow{3}{*}{$\begin{array}{ll}\text { Phases } & \\
& \text { Couches } \\
\end{array}$} & \multirow{2}{*}{\multicolumn{2}{|c|}{$\begin{array}{c}\text { Phase } 1 \\
\text { G }\end{array}$}} & \multirow{2}{*}{\multicolumn{2}{|c|}{$\begin{array}{c}\text { Phase } 2 \\
\text { F }\end{array}$}} & \multirow{2}{*}{\multicolumn{2}{|c|}{$\begin{array}{c}\text { Phase } 3 \\
\text { E }\end{array}$}} & \multicolumn{8}{|c|}{ Phase 4} & \multirow{2}{*}{\multicolumn{2}{|c|}{ Total }} \\
\hline & & & & & & & \multicolumn{2}{|c|}{ D } & \multicolumn{2}{|c|}{$\mathrm{C}$} & \multicolumn{2}{|c|}{ B } & \multicolumn{2}{|c|}{ A } & & \\
\hline & $\mathrm{Nb}$ & $\%$ & $\mathrm{Nb}$ & $\%$ & $\mathrm{Nb}$ & $\%$ & $\mathrm{Nb}$ & $\%$ & $\mathrm{Nb}$ & $\%$ & $\mathrm{Nb}$ & $\%$ & $\mathrm{Nb}$ & $\%$ & $\mathrm{Nb}$ & $\%$ \\
\hline Acer campestre & & & 11 & 2,3 & 10 & 2,3 & 4 & 1,2 & 7 & 1,6 & 2 & 0,5 & 3 & 1,9 & 37 & 1,5 \\
\hline Acer platanoides/pseudoplatanus & & & 38 & 8,0 & 59 & 13,4 & 34 & 10,0 & 39 & 9,0 & 21 & 5,0 & 9 & 5,8 & 200 & 8,1 \\
\hline Acer sp. & & & 13 & 2,7 & 6 & 1,4 & 10 & 2,9 & 9 & 2,1 & 6 & 1,4 & 6 & 3,9 & 50 & 2,0 \\
\hline Angiospermae & 2 & 1,0 & 8 & 1,7 & 1 & 0,2 & 4 & 1,2 & & & 1 & 0,2 & 1 & 0,6 & 17 & 0,7 \\
\hline Betula sp. & & & 4 & 0,8 & & & & & & & & & & & 4 & 0,2 \\
\hline Cornus sanguinea & 2 & 1,0 & 1 & 0,2 & 2 & 0,5 & & & & & 1 & 0,2 & & & 6 & 0,2 \\
\hline Corylus avellana & 38 & 18,1 & 30 & 6,3 & 34 & 7,7 & 41 & 12,1 & 63 & 14,5 & 53 & 12,7 & 16 & 10,3 & 275 & 11,1 \\
\hline Fabaceae type Laburnum & & & 1 & 0,2 & & & & & & & & & & & 1 & 0,04 \\
\hline Fagus sy/vatica & 9 & 4,3 & 154 & 32,3 & 148 & 33,6 & 59 & 17,4 & 87 & 20,0 & 76 & 18,2 & 37 & 23,9 & 570 & 23,0 \\
\hline Fraxinus excelsior & 36 & 17,1 & 99 & 20,8 & 96 & 21,8 & 126 & 37,2 & 156 & 35,9 & 149 & 35,6 & 55 & 35,5 & 717 & 29,0 \\
\hline Monocotyledonae & & & & & & & & & 3 & 0,7 & 1 & 0,2 & 1 & 0,6 & 5 & 0,2 \\
\hline Monocotyledonae type Phragmites & & & & & & & 2 & 0,6 & 1 & 0,2 & & & & & 3 & 0,1 \\
\hline Pomoideae & & & 2 & 0,4 & 1 & 0,2 & & & & & 3 & 0,7 & & & 6 & 0,2 \\
\hline Pomoideae type Sorbus/Crataegus & & & 4 & 0,8 & 4 & 0,9 & & & & & & & & & 8 & 0,3 \\
\hline \begin{tabular}{|l} 
Populus sp. \\
\end{tabular} & & & 2 & 0,4 & 4 & 0,9 & 3 & 0,9 & 5 & 1,2 & 3 & 0,7 & & & 17 & 0,7 \\
\hline Quercus f.c. & 121 & 57,6 & 104 & 21,8 & 64 & 14,5 & 45 & 13,3 & 53 & 12,2 & 89 & 21,3 & 22 & 14,2 & 498 & 20,1 \\
\hline Rosaceae & 1 & 0,5 & & & & & & & & & & & & & 1 & 0,04 \\
\hline Salix sp. & & & & & 1 & 0,2 & & & & & & & 2 & 1,3 & 3 & 0,1 \\
\hline Salix/Populus & & & 1 & 0,2 & 1 & 0,2 & & & 2 & 0,5 & 1 & 0,2 & 1 & 0,6 & 6 & 0,2 \\
\hline Tilia cordata & & & 1 & 0,2 & 7 & 1,6 & 6 & 1,8 & 3 & 0,7 & 7 & 1,7 & & & 24 & 1,0 \\
\hline Tilia platyphyllos & 1 & 0,5 & 1 & 0,2 & & & 2 & 0,6 & 2 & 0,5 & & & & & 6 & 0,2 \\
\hline Tilia sp. & & & 2 & 0,4 & 1 & 0,2 & 3 & 0,9 & 2 & 0,5 & 1 & 0,2 & & & 9 & 0,4 \\
\hline Ulmus minor & & & 1 & 0,2 & & & & & & & & & & & 1 & 0,04 \\
\hline Ulmus montana & & & & & & & & & & & 1 & 0,2 & & & 1 & 0,04 \\
\hline Ulmus sp. & & & & & 1 & 0,2 & & & 2 & 0,5 & 3 & 0,7 & 2 & 1,3 & 8 & 0,3 \\
\hline Total & 210 & & 477 & & 440 & & 339 & & 434 & & 418 & & 155 & & 2473 & \\
\hline Nombre de taxons & 7 & & 14 & & 12 & & 10 & & 11 & & 13 & & 9 & & 17 & \\
\hline Écorce/ Phloème & 133 & & 21 & & 73 & & 112 & & 126 & & 146 & & 39 & & 650 & \\
\hline Indéterminables & 7 & & 2 & & 12 & & 9 & & 5 & & 11 & & 2 & & 48 & \\
\hline
\end{tabular}


Pomoïdées, les peupliers, le tilleul à petite feuille et l'orme des montagnes. Pour terminer, les fragments d'écorce carbonisée retrouvent des taux comparables à ceux de la phase 1 (couche G), excepté dans la couche A.

\section{CHALAIN 4}

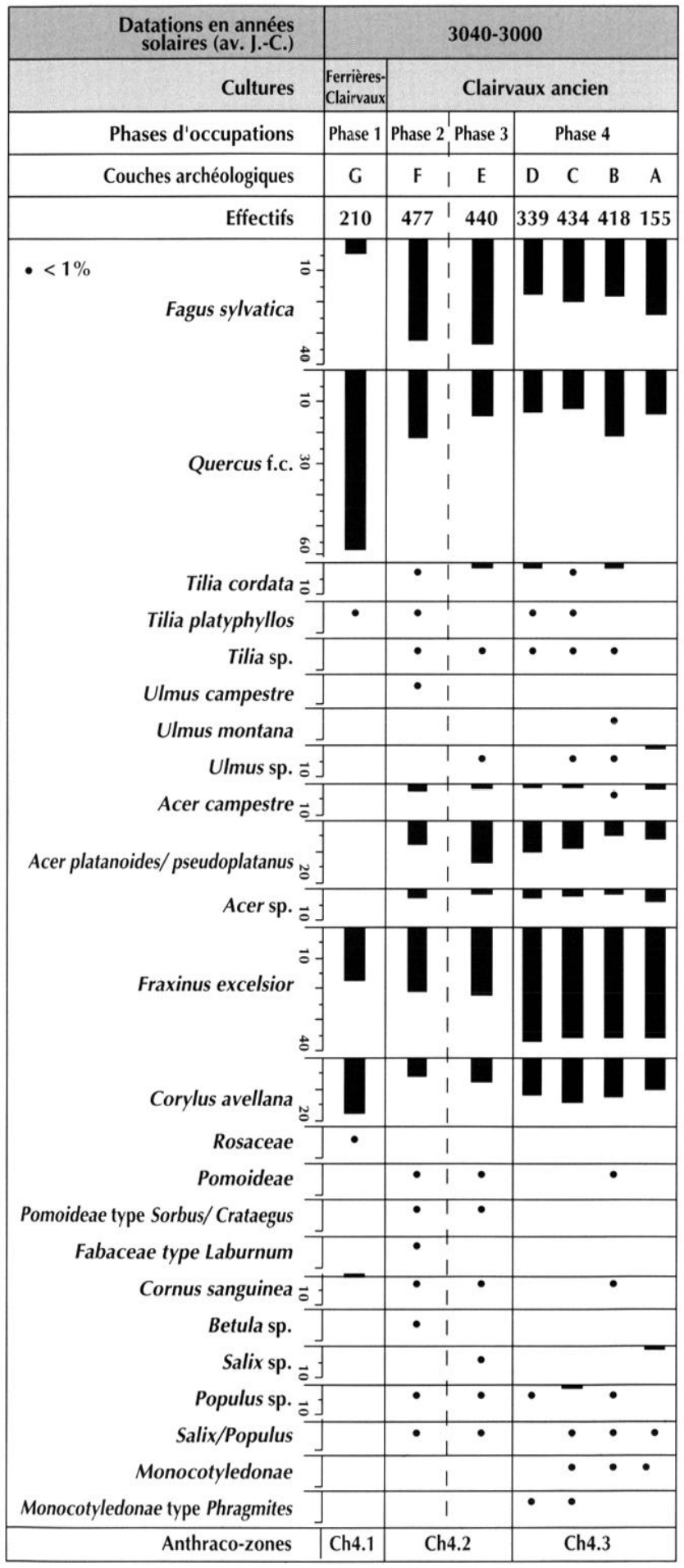

Fig. 21 - Diagramme anthracologique du site de Chalain 4.
Les courbes de croissance diamétrale ont pu être établies pour le chêne, le hêtre, le frêne, l'érable et le noisetier (fig. 22).

La croissance du chêne est caractérisée pendant la première phase par une diminution du taux d'accroissement en fonction des classes de diamètre, ce qui pourrait refléter, compte tenu de son caractère héliophile, un développement du chêne dans des peuplements plutôt dense. Dans les phases suivantes, si on note des taux d'accroissement importants pour les plus grands diamètres, certaines variations restent difficilement interprétables en l'absence de référentiel.

Pour ce qui est du hêtre, une essence dominante pendant les phases 2 et 3 , il présente une croissance qui augmente avec le diamètre, ce qui traduit a priori des conditions de croissance favorables à cette essence, peut-être moins compétitives ou reflétant des peuplements situés plus en altitude comme sur les plateaux supérieurs du Jura.

Les courbes de croissance du frêne peuvent être scindées en deux groupes. Le premier est caractérisé par un taux d'accroissement qui diminue rapidement en fonction du diamètre, qu'il s'agisse de la strate sous-arbustive ou arbustive (couches G, F et E), et le second par un taux d'accroissement qui tend à augmenter ou à se stabiliser en fonction du diamètre. Ainsi, pendant les premières phases, la croissance du frêne est rapidement limitée, ce qui peut signifier un milieu relativement dense, un stress hydrique ou encore un frêne qui se développe sur sol calcaire dans les hêtraies calcicoles ou méso-neutrophiles où sa croissance est lente (Jacamon, 1996, p. 310). Pendant les phases suivantes, les conditions environnementales sont plus propices au développement du frêne ; une ouverture du milieu, comme le laisse suggérer le développement du noisetier, pourrait en être à l'origine. Les courbes de croissance de ce dernier peuvent aussi être divisées en deux groupes, celles qui forment un « $V$ » et celles qui forment un « $V$ » inversé, mais leur interprétation reste délicate en l'absence de référentiel. Enfin, pour ce qui est de l'érable, les taux de croissance se maintiennent tout au long de la séquence et ne montre pas de variations particulières.

En ce qui concerne les diamètres de bois exploités (fig. 23), la collecte est axée dans la phase 1 (couche G) sur des bois d'un diamètre pouvant atteindre $20 \mathrm{~cm}$ pour le chêne. Les autres essences, à savoir le frêne, les érables et le noisetier sont en revanche représentées par des diamètres inférieurs à $10 \mathrm{~cm}$. 
CHÊNE

croissance moyenne annuelle
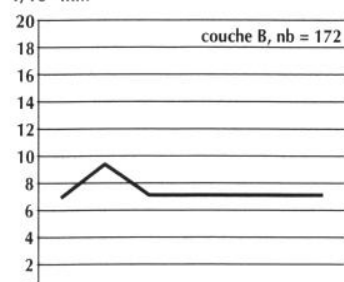

0 [0-1.5][1.5-5]15-10][10-15]15-20]20-25]25-3

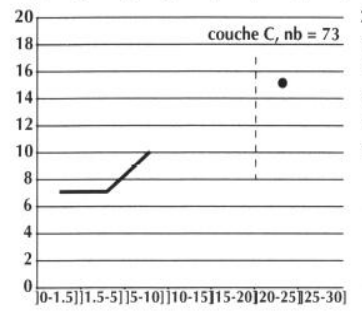

$\sqrt[20]{18}$ couche $\mathrm{D}, \mathrm{nb}=\mathbf{5 0}$
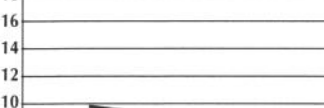

10

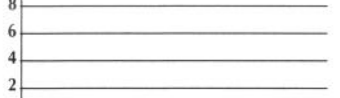

0 [0-1.5]11.5-5][5-10]]10-15]15-20]20-25]25-30]
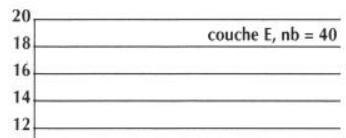

10

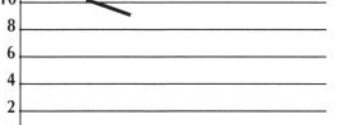

0 [0-1.5]]1.5-5]]5-10]]10-15]15-20]20-25]25-30]
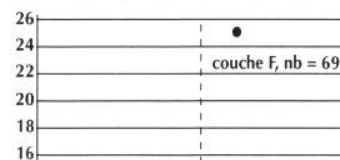

\begin{tabular}{l|l}
16 & \\
\hline 14 & \\
\hline
\end{tabular}
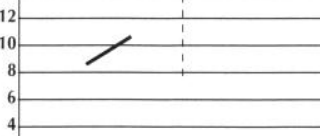

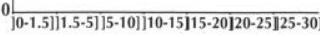

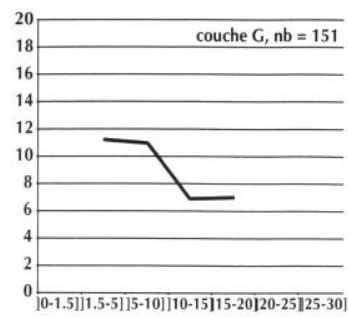

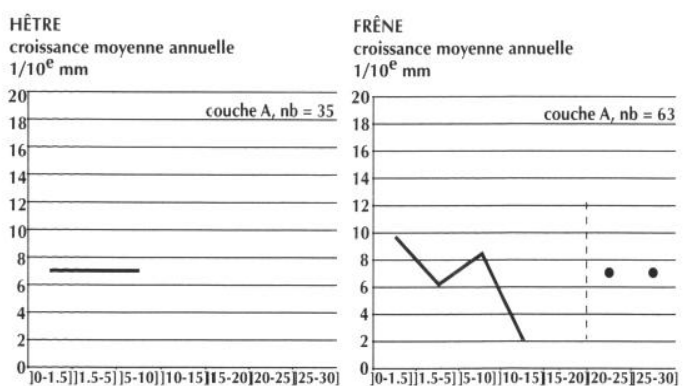

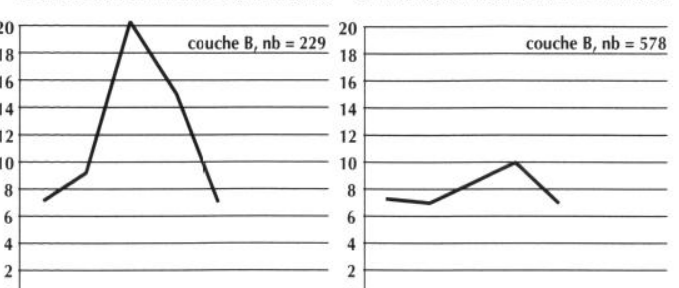

0 [0-1.5][1.5-5]]5-10]]10-15]15-20]20-25]25-30] $0 \frac{}{[0-1.5] \mid 1.5-5][5-10] \mid 10-15] 15-20] 20-25] 25-30]}$
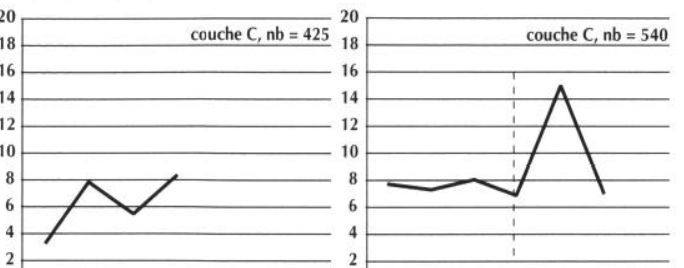

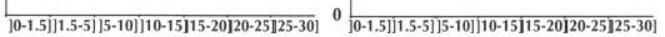

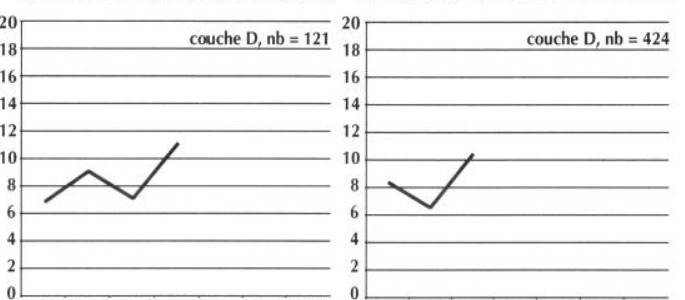

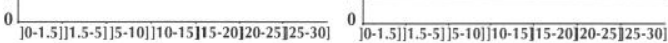
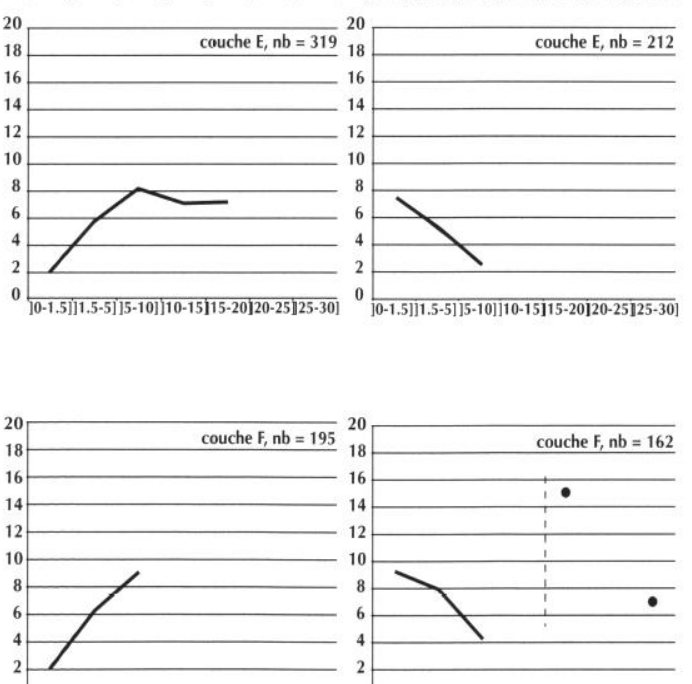

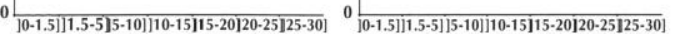

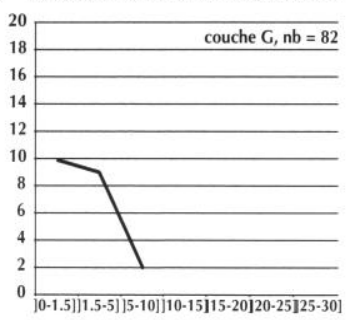

ÉRABLE PLANE/SYCOMORE

$1 / 10^{\mathrm{e}} \mathrm{mm}$

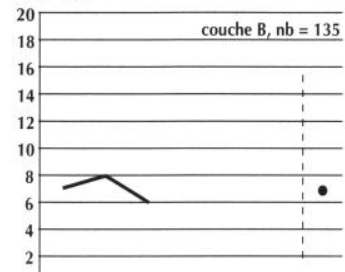

0 [0-1.5]]1.5-5] [5-10][10-15]15-20]20-25]25-30
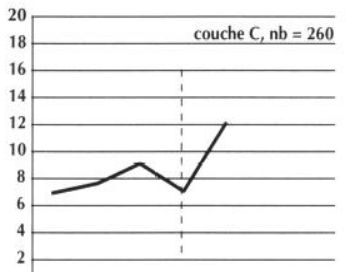

00
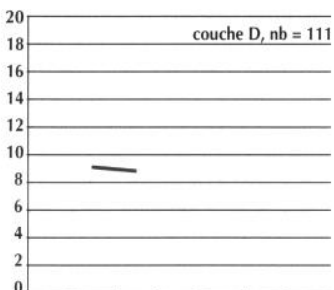

0 [0-1.5]11.5-5][5-10][10-15]15-20j20-25]25-30]
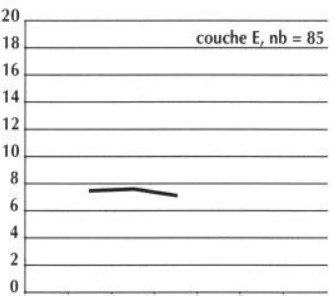

$0 0 \longdiv { [ 0 - 1 . 5 ] ] 1 . 5 - 5 ] [ 5 - 1 0 ] ] 1 0 - 1 5 ] 1 5 - 2 0 ] 2 0 - 2 5 ] 2 5 - 3 0 ] }$
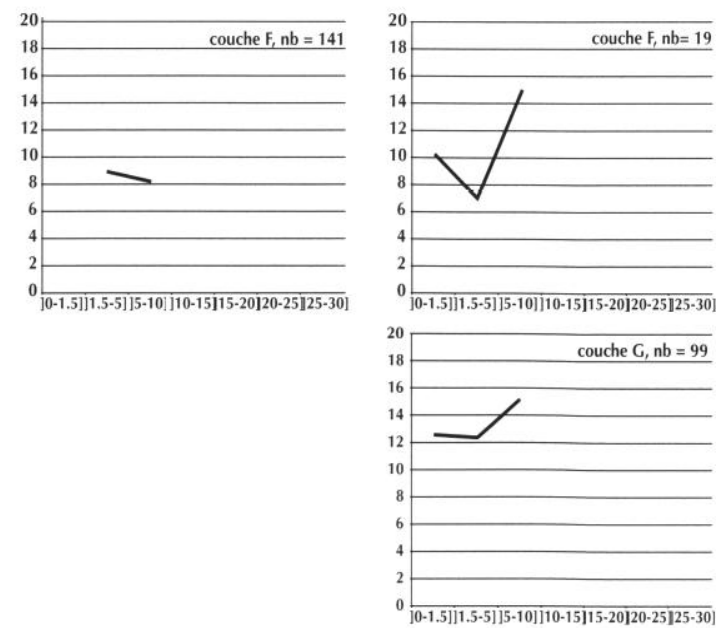

Fig. 22 - Évolution de la croissance moyenne annuelle par classes de diamètres des principaux taxons à Chalain 4. 

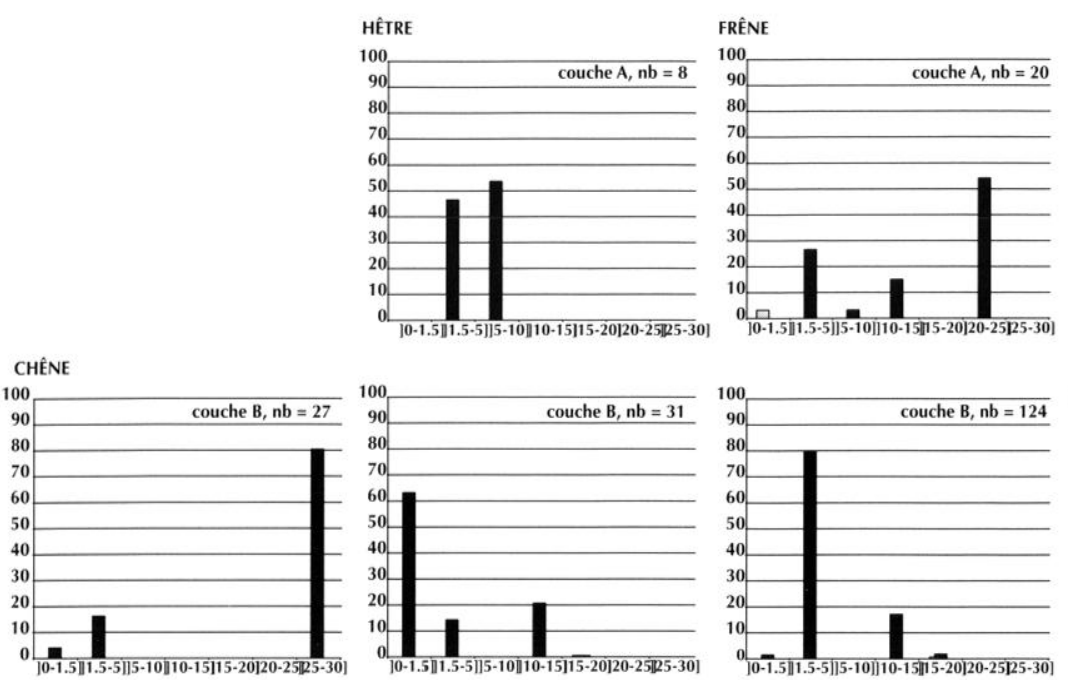

ÉRABLE PLANE/SYCOMORE
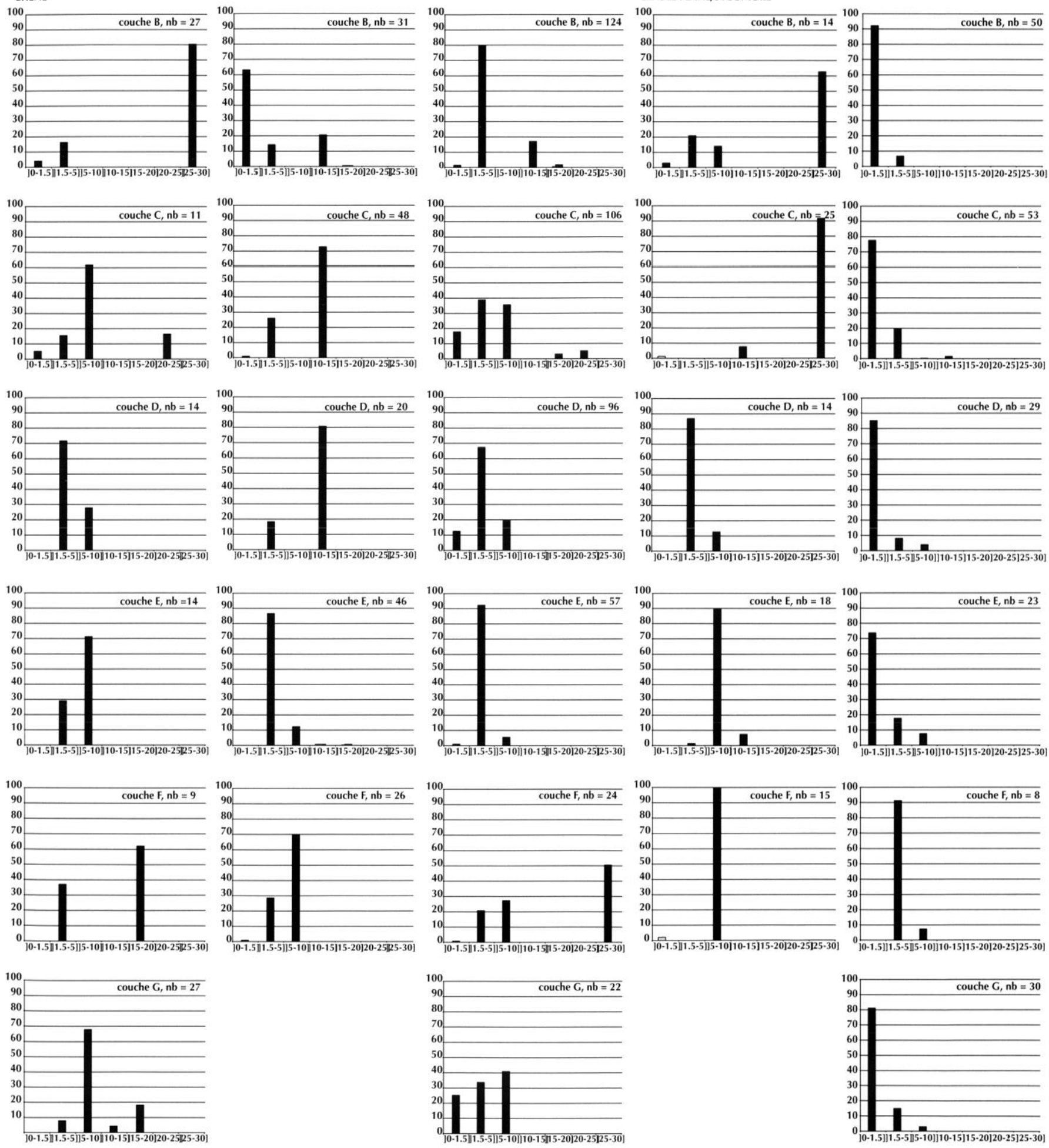

Fig. 23 - Estimations des proportions de diamètres exploités à Chalain 4. 
Pendant les phases 2 et 3 (couches F et E), l'exploitation du hêtre, essence dominante, est caractérisée par des diamètres inférieurs à $10 \mathrm{~cm}$ comme pour les érables et le noisetier. À la même période, les diamètres du frêne sont en revanche plus importants, pouvant atteindre $30 \mathrm{~cm}$ pendant la phase 2 (couche F). Dans la phase 3 (couche E), on observe un retour vers l'exploitation de petits calibres de frêne.

Pendant la phase 4, l'exploitation de petits calibres semble dans un premier temps se prolonger (couche D) puis, à partir de la couche $\mathrm{C}$, il y a un élargissement des gammes de diamètre, notamment pour le chêne et l'érable. Pour le frêne, cette augmentation est beaucoup plus marquée dans la couche $\mathrm{A}$.

Enfin, le pourcentage de charbons présentant des zones de collapse varie peu d'une phase à l'autre et ne permet pas de rejeter la collecte et l'utilisation de bois vert (Dufraisse, $2002 b$, p. 225). En revanche, le nombre de fragments d'écorce est bien plus important que dans les autres sites. Or, l'écorce du bois a un pouvoir calorifique supérieur à celui du bois lui-même. Les écorces sont en revanche difficiles à enflammer, c'est pourquoi elles n'ont probablement pas servi à l'allumage du feu, mais elles permettent d'obtenir un feu avec peu de flammes (Théry-Parisot, 2001, p. 158).

\section{Représentativité paléoécologique et zones potentielles d'approvisionnement}

Les analyses polliniques de Chalain 4 réalisées par P. Ruffaldi (Pétrequin dir., 2000, p. 44), qui témoignent d'un milieu nettement dominé par le hêtre, le noisetier et le chêne, appuient la qualité et la validité paléoécologique des échantillons anthracologiques de Chalain 4. Ainsi, les résultats peuvent être interprétés comme résultant de l'exploitation d'au moins trois biotopes différents : celui de la ripisylve, principalement composée des saules et peupliers, celui de la chênaie caducifoliée accompagnée des tilleuls, érables, d'espèces postpionnières telles que le frêne et telles que le noisetier. Enfin, un troisième biotope pourrait être exploité, la hêtraie puisque le hêtre (taxon "chef de file") est présent. Il faut néanmoins souligner que les essences qui lui sont habituellement affiliées, telles que le sapin, sont peu ou pas représentées.

Les variations de pourcentages observées dans le diagramme (fig. 21) reflètent une dynamique de végétation que nous avons scindée en trois périodes nommées : Ch4.1 pour la phase $1, \mathrm{Ch} 4.2$ pour les phases 2 et 3 et Ch4.3 pour la phase 4.

La première période (Ch4.1) est précédée d'un hiatus complet de l'habitat sur les rives du lac d'environ 60 ans. Attribuée à la transition Ferrières-Clairvaux, elle correspond à la première occupation du village. Elle est caractérisée par l'exploitation de la chênaie caducifoliée accompagnée de deux essences postpionnières caractéristiques : le noisetier et le frêne. Les proportions exceptionnellement élevées de chêne pourraient refléter l'exploitation d'un espace réduit, peu représentatif de la région, par exemple sur un versant exposé au sud et situé dans une zone où le degré d'hydromorphie est relativement faible pour permettre le développement du chêne, ce qui limite de ce fait le développement du frêne, comme le laisse supposer les courbes de croissance de cette essence.

Dix années plus tard, pendant la première partie du Clairvaux ancien (Ch4.2, phases culturelles 2 et 3), l'augmentation du hêtre (alors sans essence compagne) pourrait résulter de l'exploitation du chêne pendant la première phase, aboutissant à la formation d'une hêtraie-chênaie. Dans ce sens, rappelons le faible nombre de taxons (7) dans la phase Ch4.1, suggérant une disparition de la chênaie caducifoliée. Les calibres du hêtre, systématiquement inférieurs à $10 \mathrm{~cm}$ puis à $5 \mathrm{~cm}$ de diamètre, sont de plus cohérents avec une telle interprétation. Cependant, l'augmentation des taux de hêtre dans le diagramme anthracologique pourrait aussi être interprétée, comme à Chalain 19, dans le sens d'une extension des aires d'approvisionnement vers les hauteurs puisque le nombre de villages contemporains sur les rives du lac de Chalain augmente progressivement. Les diamètres du frêne, reflétant l'exploitation de peuplements plus âgés, vont dans ce sens. Toutefois, l'étude des courbes de croissance diamétrale n'indique pas d'ouverture du milieu qui aurait pu motiver l'éloignement des aires d'approvisionnement. Il pourrait donc s'agir là d'une réorganisation de l'cspacc forestier en réponse à l'augmentation progressive du nombre de maisons au sein du village (P. Pétrequin, comm. pers.).

La dernière phase (Ch4.3) se place pendant la seconde partie du Clairvaux ancien (la phase 4). Elle voit le passage de l'exploitation du hêtre à celle du frêne qui devient majoritaire. Le chêne et le hêtre restent présents mais dans des proportions plus discrètes. De nombreuses essences secondaires accompagnent le frêne, notamment les érables, les tilleuls, les ormes, etc. Enfin, il faut noter l'augmentation significative du noisetier au cours de cette phase qui permet 
de suggérer une ouverture progressive du milieu. L'éclaircissement des peuplements forestiers, lié à l'exploitation du hêtre pendant les vingt années précédentes, a pu, comme à Chalain 19, favoriser le développement du frêne et du noisetier. Cette progression du frêne n'apparaît pas dans les analyses polliniques correspondant aux niveaux d'occupation, d'une part parce que les prélèvements ont été réalisés en contexte intra-site, ce qui réduit la perception du couvert arboréen et, d'autre part, parce que le frêne, alors présent sous forme de jeunes peuplements, a certainement une production pollinique réduite. En revanche, dans les dépôts de craie supérieurs, les taux de frêne ont sensiblement augmenté par rapport aux niveaux de craie qui précèdent les premières occupations. Si l'on se rapporte à la liste floristique et ses proportions, il semble donc, à cette période, que les territoires exploités ne soient pas davantage étendus. Cependant, l'exploitation de plus gros diamètres, pouvant refléter l'exploitation de forêts plus âgées, notamment pendant la phase 4 couche $\mathrm{C}$, pourrait indiquer une seconde phase d'extension comme pour les épisodes précédents (fig. 19b et c).

\section{CONCLUSIONS}

Au cours de cette première phase d'analyse, nous avons pu démontrer la qualité et la validité paléoécologique des charbons de bois prélevés en milieu lacustre, moyennant une méthode d'échantillonnage rigoureuse qui diffère parfois de celle appliquée en milieu terrestre sec.

Les résultats de l'analyse anthracologique mettent ainsi en avant l'exploitation de plusieurs groupements végétaux ligneux, avec la hêtraie accompagnée du sapin - groupement à affinités montagnardes et à connotations humides -, la chênaie caducifoliée associée à son cortège floristique et où le frêne peut jouer un rôle majeur. D'autres associations telles la hêtraie-chênaie ou la frênaie-érablaie ont également été mises en ćvidence. Le dernicr groupement est celui de la ripisylve, principalement composé des saules, des peupliers et du tremble.

Ces associations végétales ne sont pas toujours représentées dans les mêmes proportions entre deux sites contemporains ou entre deux occupations successives. Pendant le NMB, par exemple, c'est la frênaie qui domine pour les stations localisées au nord du lac de Clairvaux (Clairvaux La Motte-aux-Magnins) et la hêtraie-chênaie sur la rive sud (Clairvaux XIV). Parfois, certains groupements sont propres à un site ; citons les exemples de la hêtraie-sapinière à Clairvaux III et de la chênaie caducifoliée à Chalain 4 (phase 1). Enfin, certaines évolutions sont perceptibles d'une période à une autre. Ainsi, le Horgen se caractérise à Chalain 3 et Chalain 19 par l'exploitation d'une frênaie. Puis, au Clairvaux ancien, on observe le passage de l'exploitation du hêtre à celle du frêne sur les sites de Chalain 19 et de Chalain 4.

Ces différences, synchroniques et/ou diachroniques, peuvent refléter l'évolution du milieu sous l'effet de facteurs naturels et/ou anthropiques, mais aussi des changements dans les modes d'exploitation, comme l'extension ou le partage de zones d'approvisionnement qui semble en étroite corrélation avec la densité de village sur les rives des lacs de Chalain et de Clairvaux.

\section{SYNTHÈSE ET DISCUSSION}

\section{BILAN DIACHRONIQUE DES PRINCIPAUX GROUPEMENTS VÉGÉTAUX EXPLOITÉS}

Le NMB (3700-3600 av. J.-C.) est documenté par les sites de Clairvaux La Motte-aux-Magnins et Clairvaux XIV. À La Motte-aux-Magnins, cette période se caractérise par l'exploitation prédominante de la frênaie associée à son cortège floristique composé des chênes à feuillage caduc, du noisetier, des érables, des tilleuls et des Pomoïdées. Les essences de ripisylve, saules et peupliers notamment, ainsi que la hêtraie sont peu représentées. À Clairvaux XIV, à l'autre extrémité du lac, sur la rive sud, le spectre anthracologique révèle, d'une part, l'exploitation d'une frênaie accompagnée par le noisetier et, d'autre part, celle d'une hêtraie-chênaie accompagnée du sapin, des érables et des tilleuls. La ripisylve est, comme à La Motte-aux-Magnins, faiblement représentée.

Cette période est suivie d'une péjoration climatique importante et d'un abandon des rives lacustres pendant les $31^{\circ}$ et $33^{\circ}$ siècles (Magny, 1995; Arbogast ot al. 1995).

Au Horgen (3200-3100 av. J.-(.), période qui coincide avec une amélioration du climat (Magny, 1997), l'analyse anthracologique révèle l'exploitation d'une frênaieérablaie à Chalain 3 et d'une frênaie à Chalain 19. Le hêtre, le chêne et le noisetier ainsi que la ripisylve sont peu représentés.

Cette période est suivie d'une courte phase de transgression lacustre dont la durée peut être estimée à une soixantaine d'années; les rives du lac de Chalain sont à nouveau complètement désertées, ce que le diagramme pollinique 
de Chalain 19 conforte par l'absence quasi totale de marqueurs anthropiques.

Le groupe de Clairvaux (3040-2700 av. J.-C.) correspond à un changement culturel important et peut être subdivisé en trois phases.

Le Clairvaux ancien (entre 3040-2990 av. J.-C.) est caractérisé à Chalain 19 par l'exploitation de la hêtraie, tandis que le frêne se maintient par rapport au Horgen, accompagné du chêne, des tilleuls, des ormes et des érables. Progressivement, le hêtre perd de l'importance, au profit d'essences préforestières telles que le noisetier, le bouleau, le saule et le frêne qui joue ici un rôle pionnier. Le frêne est, en effet, une essence ubiquiste, de lumière ou de demiombre, poussant sur sol humide ou sur sol sec, pouvant être rattachée à l'étage collinéen ou montagnard. À Chalain 4, la chênaie est tout d'abord exploitée (transition FerrièresClairvaux), puis on assiste à l'exploitation du hêtre tandis que le chêne se maintient. Ensuite, le frêne se développe au détriment du hêtre, accompagné d'une augmentation significative du noisetier. Il existe donc une convergence des dynamiques de végétation entre Chalain 19 et Chalain 4, caractérisées par le développement du frêne et d'essences héliophiles au détriment du hêtre.

Le Clairvaux moyen (2990-2900 av. J.-C.) est caractérisé par l'exploitation prédominante d'une frênaie, accompagnée de celle de la hêtraie à Clairvaux La Motte-auxMagnins et de celle de la hêtraie-sapinière à Clairvaux III. Il faut également noter des différences importantes dans les proportions du noisetier, bien mieux représenté à Clairvaux III qu'à La Motte-aux-Magnins.

Enfin, au Clairvaux récent (2900-2700 av. J.-C.), période contemporaine d'une péjoration climatique majeure (Magny, 1995), on assiste à La Motte-aux-Magnins à une augmentation des essences secondaires à affinités montagnardes (sapin, houx, orme des montagnes, érable plane/sycomore) traduisant l'exploitation d'un milieu végétal qui s'est développé sous un climat plus frais et plus humide.

\section{ESSAI DE RECONSTITUTION DYNAMIQUE DU PAYSAGE FORESTIER AU NÉOLITHIQUE}

L'analyse anthracologique montre l'exploitation de groupements végétaux aux affinités écologiques différentes (ripisylve, frênaie, chênaie caducifoliée et hêtraie) qui se répartissent dans la Combe d'Ain principalement en fonction du degré d'hydromorphie du sol et de l'altitude.

\section{LES BORDURES DE LACS ET COURS D'EAU}

La ripisylve, groupement qui se développe sur les sols à forte rétention d'eau, à proximité des rives des lacs ou des cours d'eau, est principalement composée des saules et des peupliers auxquels peuvent se mêler la viorne, la bourdaine, le cornouiller pro parte, le noisetier pro parte, le bouleau pro parte et le frêne pro parte.

Tout au long de la séquence étudiée, ce groupement est faiblement représenté avec des pourcentages inférieurs à $5 \%$. Les courbes de croissance indiquent des conditions de croissance particulièrement propices, probablement en milieu humide et clairsemé ; en effet, ces essences exigent la pleine lumière et préfèrent les sols profonds et frais. L'étude des assemblages de coléoptères prélevés dans les niveaux d'habitats de Chalain 3 (couches VIII, VI, IV, IIc///+++ et IIc) confirme cette tendance clairsemée, au moins entre le Horgen et le groupe Clairvaux : les résultats ont révélé très peu d'espèces ripicoles, " pas plus en nombre d'espèces qu'en nombre d'individus" (Ponel, 1997).

Deux hypothèses sont envisageables. La première est liée à la construction des villages à proximité des rives du lac, ce qui suppose un dégagement et un entretien de l'espace littoral où est située la ripisylve. Cependant, cette hypothèse n'est pas cohérente avec les taux importants de la ripisylve qui atteignent plus de $20 \%$ vers 2700 av. J.-C. sur les sites de Chalain 2 et Chalain 21 (Dufraisse, 2002b). La seconde hypothèse est en relation avec l'apport de colluvions et pourrait en outre expliquer les fortes proportions de cette association végétale à partir du III $^{\mathrm{e}}$ millénaire av. J.-C. Les colluvions se mettent, en effet, en place à partir du III $^{e}$ millénaire av. J.-C. sur le bassin de Chalain et à partir du I ${ }^{\text {er }}$ millénaire av. J.-C. sur le bassin de Clairvaux. La formation des tourbes commence, quant à elle, vers le $I^{\text {er }}$ millénaire av. J.-C. sur le bassin de Chalain et vers le III $^{\mathrm{e}}$ millénaire av. J.-C. sur le bassin de Clairvaux. Par conséquent, avant le III $^{\mathrm{c}}$ millénaire, que ce soit à Chalain ou à Clairvaux, les rives du lac sont dénuées de toute couverture pédologique (Pétrequin dir., 2000; Pétrequin, Pétrequin, 2001). Or, l'étude phytosociologique réalisée sur les rives du lac de Chalain indique que la végétation est réduite à une couverture herbacée dans les zones où la craie affleure (Trivaudey, Bailly, 1991). C'est ensuite l'arrivée des colluvions à Chalain à partir du III ${ }^{\mathrm{e}}$ millénaire av. J.-C., en relation avec les mises en culture, qui a favorisé, semble-t-il, le développement d'essences arbustives et arborescentes ripicoles à proximité des rives du lac. Il faut probablement attendre le $\mathrm{I}^{\mathrm{er}}$ millénaire 
av. J.-C. sur le lac de Clairvaux pour que la ripisylve se développe à moins que le processus de formation des tourbes, beaucoup plus rapide dans le bassin lacustre de Clairvaux en raison de la faible amplitude des variations du niveau d'eau (vers le III' millénaire av. J.-C.), ait accéléré le phénomène.

En définitive, la végétation riveraine de bord de lac est très peu développée, avec quelques arbustes ça et là sur une ceinture d'environ $200 \mathrm{~m}$ de large. Les faibles taux de ripisylve caractérisant les périodes précédentes sont donc très certainement en relation avec l'exploitation d'un sol gorgé d'eau comme les terrasses glacio-lacustres de l'Ain.

\section{LES TERRASSES GLACIO-LACUSTRES DE L'AIN}

Le frêne représenté à la fois au Néolithique moyen (entre 3700 et 3600 av. J.-C.) et final (entre 3200 et 2700 av. J.-C.) est l'une des principales essences exploitées.

Les analyses anthracologiques montrent cette essence, aux valences écologiques larges, dans deux situations bien distinctes. Dans la première, le frêne apparaît en début de chaque cycle, lors des phases de faible densité de village, comme au NMB (Clairvaux La Motte-aux-Magnins et Clairvaux XIV) et au Horgen (Chalain 3 et Chalain 19). Associé au chêne et/ou à l'érable, il reflète alors l'exploitation d'une végétation sur sol humide, qui trouve son équivalence potentielle sur les terrasses glacio-lacustres. Dans la seconde situation, le frêne apparaît en fin de cycle, lors des phases de forte densité d'habitat comme au Clairvaux ancien (Chalain 4, phase 4 et Chalain 19, couche $H$ ), où il se développe accompagné du noisetier (essence postpionnière). Il profite alors de l'éclaircissement de la hêtraie et de ses capacités de régénération rapide pour se développer; l'exploitation de rejets de souche a en effet pu être évoquée par l'étude des courbes de croissance diamétrale du frêne (Chalain 19). Cette hypothèse est d'autant plus cohérente que le noisetier est, d'une part, favorisé par les activités agricoles et, d'autre part, supporte mal la concurrence du hêtre (Aaby, 1986). L'extrême dilation de la séquence de Chalain 4 permet d'évaluer à 20 ans le temps nécessaire à un tel changement. Cette même dynamique a déjà été décrite dans le sud-ouest de l'Allemagne près du lac de Constance (Clark et al., 1989).

En définitive, pendant les phases de fortes activités humaines, le frêne réussit à se maintenir dans le milieu comme le soulignent les analyses polliniques, mais il n'appartient plus aux associations locales développées sur sol humide et pousse dans des zones plus éloignées, où domine normalement le hêtre, c'est-à-dire en partie sur les plateaux supérieurs du Jura.

\section{LES PLATEAUX SUPÉRIEURS}

Le hêtre est également l'une des principales essences exploitées. Il est souvent accompagné du sapin, de l'orme des montages, de l'épicéa, du houx, de l'argousier ou encore de l'if (Chalain 19 maison isolée, Clairvaux La Motte-aux-Magnins niveaux $\mathrm{ABC}, \mathrm{D}$ à $\mathrm{G}$, Clairvaux III). Ce cortège floristique, aux affinités submontagnarde et montagnarde trouve son équivalent actuel sur les plateaux supérieurs occupés par des hêtraies accompagnées des chênes et du charme.

Cependant, les proportions des essences qui lui sont affiliées fluctuent en fonction de plusieurs facteurs tels que l'altitude ou encore l'exposition. Il est ainsi possible d'identifier la hêtraie-chênaie (Clairvaux XIV), probablement située sur un versant exposé au soleil, ou encore la hêtraiesapinière (Clairvaux III), située plus en altitude.

Parfois, les essences affiliées à la hêtraie sont quasiment absentes, notamment à Chalain 4 pendant la phase Ch4.2 (couches $\mathrm{E}$ et $\mathrm{F}$ ) où le développement du hêtre suit l'exploitation de la chênaie caducifoliée. Cette dynamique rappelle fortement les hypothèses, souvent contradictoires, avancées pour expliquer l'évolution du hêtre dans le nord de l'Europe. Si tout le monde s'accorde à dire qu'un climat plus frais et plus humide favorise le développement du hêtre, il n'en va pas de même quant à l'impact des exploitations humaines sur l'essor de cette essence. Selon certains auteurs, le hêtre serait favorisé lors des phases de déprise agricole (Ammann, 1988 ; Burga, 1988 ; Richoz et al., 1994 ; Jahns, 2001). Pour d'autres, il serait au contraire favorisé par les activités humaines. De plus, les avis divergent quant aux causes explicatives : selon les uns, c'est l'ouverture du milieu qui permet la régénération du hêtre ; il est alors accompagné d'essences pionnières telles que le bouleau ou le noisetier (Lowe et al., 1994). Selon J. Clark (Clark et al.1989), l'augmentation du hêtre ne peut pas être mise en relation avec l'agriculture sur brûlis ; cet auteur n'exclut cependant pas la possibilité d'autres activités agricoles qui auraient pu favoriser l'expansion du hêtre. Selon L. Björkman (1999), ce sont le pâturage (les graines se logent dans les empreintes laissées par les porcs qui forment des « nids " favorables à leur germination), l'ouverture du 
milieu (qui favorise la production de faines et la régénération du hêtre) et le feu qui facilitent le développement du hêtre ; Björkman a pu établir une bonne corrélation entre les indicateurs d'activités humaines (prairies, pâturages, et cultures) et l'expansion du hêtre. Enfin, une dernière hypothèse, déjà avancée à Chalain, est celle de l'exploitation du chêne qui permettrait au hêtre de se développer, la compétition étant moins forte (Richard, 1999). Cependant, à Chalain 4, le hêtre s'est développé en 10 ans. Cette période paraît a priori très courte, mais l'exploitation de très petits calibres (moyenne de la couche $\mathrm{F}: 6,2 \mathrm{~cm}$ de diamètre et moyenne de la couche $\mathrm{E}: 3,7 \mathrm{~cm}$ de diamètre), permet de maintenir cette hypothèse. En outre, on peut noter qu'actuellement les coupes d'ensemencement, où l'on conserve une certaine proportion de vieux arbres dits semenciers, sont suivies du développement de fourrés de hêtre en quelques années (Collectif, 1999, p. 701). Pour Chalain, l'hypothèse déjà évoquée par $\mathrm{H}$. Richard, celle de l'exploitation du chêne qui permettrait au hêtre de se développer, semble donc se confirmer.

L'étude du comportement des différents groupements végétaux permet donc de souligner la complexité des successions de végétation et la diversité des causes qui en sont à l'origine.

Ces dynamiques correspondent à des stades évolutifs différents. Les causes sont d'ordre climatique et anthropique; elles ont un impact différent, mais il semble que l'alternance hêtre/frêne (et plus tardivement hêtre/chêne) dépende davantage de l'intensité et des durées d'exploitation. On comprend alors aisément comment ces différentes modifications, parfois très rapides (entre 10 et 20 ans), peuvent créer un paysage complexe formé d'une mosaique de formations ligneuses.

\section{ORGANISATION ET GESTION DE L'ESPACE FORESTIER}

Il n'est pas dans notre intention de restituer précisément l'étendue des surfaces exploitées. Les moyens d'estimation sont, en effet, basés sur des paramètres accessibles tels que la biomasse forestière actuelle ou la productivité annuelle des forêts, mais il reste des paramètres inconnus tels que la quantité de bois utilisée (rappelons que l'anthracologie ne permet pas de restituer la masse de bois mise au feu). En outre, certains de ces paramètres varient d'une communauté humaine à l'autre selon des facteurs sociaux, de résistance au froid ou encore de distance aux sources. Nous préférons donc fonder notre raisonnement sur l'écologie des groupements végétaux exploités, la Combe d'Ain se prêtant fort bien à ce type d'approche.

\section{LES ZONES POTENTIELLES D'EXPLOITATION}

Sur le lac de Clairvaux, au NMB, les sites de Clairvaux La Motte-aux-Magnins et Clairvaux XIV, situés sur des rives opposées, sont respectivement caractérisés par l'exploitation d'une frênaie et celle d'une hêtraie-chênaie. Tandis que le frêne pousse sur les terrasses glacio-lacustres, la hêtraie-chênaie se développe probablement sur les pentes du deuxième plateau d'exposition sud - sud-est, proches des rives du lac et actuellement occupées par la hêtraie-chênaie (fig. 11a).

Au Clairvaux moyen et récent, l'analyse des sites de La Motte-aux-Magnins et de Clairvaux III, proches l'un de l'autre, présente l'exploitation en commun de la frênaie; tandis que ce groupement est accompagné de l'exploitation de la hêtraie à La Motte-aux-Magnins, c'est la hêtraiesapinière qui est représentée à Clairvaux III. Si la frênaie se développe sur les terrasses glacio-lacustres, la hêtraie trouve son équivalence actuelle dans l'étage montagnard inférieur, sur les plateaux supérieurs du Jura, ici sur le plateau de Soucia. Enfin, il est possible que la hêtraie-sapinière, groupement caractéristique de l'étage montagnard supéricur (entre 800 et $900 \mathrm{~m}$ d'altitude) soit localisée sur les versants de la reculée de Clairvaux, mais aussi sur ceux de la vallée de la Frasnée, située à proximité du lac (reculée du Drouvenant), actuellement recouverts par des plants naturels de sapin dont la dispersion des semis a certainement été favorisée par l'inclinaison importante des versants et par une exposition ombragée (fig. 11b, c).

Sur le lac de Chalain, l'analyse des sites de Chalain 3 et de Chalain 19 - situés aux extrémités opposées nord et sud de la rive occidentale - indique pour le Horgen l'exploitation d'une frênaie-érablaie à Chalain 3 et d'une frênaie à Chalain 19. Ces deux groupements sont caractéristiques des sols à forte rétention d'eau et se situent probablement sur la terrasse glacio-lacustre ou sur la moraine terminale. L'exploitation de groupements végétaux différents, d'une part, et la situation des villages de Chalain 3 et Chalain 19 au nord et au sud de la rive occidentale, d'autre part, ne sont pas sans rappeler la bipolarité de l'habitat (Pétrequin et al., 1999) et permettent de proposer des aires d'exploitation également situées au nord et au sud de la rive occidentale du lac de Chalain (fig. 19a). 
Au Clairvaux ancien, l'analyse des sites de Chalain 4 et de Chalain 19 montre également l'exploitation de deux groupements différents, avec respectivement la chênaie caducifoliée et la hêtraie. Or, ces deux habitats sont aussi situés au nord et au sud de la rive occidentale. Il est donc envisageable que les aires d'exploitation soient, comme au Horgen, partagées entre le nord et le sud de la rive occidentale. Pour étayer cette hypothèse, rappelons que nous avons interprété l'exploitation de la chênaie à Chalain 4 comme un groupement très localisé, certainement situé sur une zone exposée au sud, probablement aux alentours de Marigny (fig. 19b et c).

En définitive, il apparaît que la localisation des villages sur les rives des lacs, notamment leur opposition, est un élément déterminant dans le choix des zones d'exploitation. Ces conclusions permettent de suggérer un partage de l'espace forestier au moins en fonction des principaux pôles d'habitat, ce qui n'est pas sans rappeler les droits d'usage des terres à vocation agricole ou non. Toutefois, lorsque le nombre de villages est restreint, comme au Horgen entre Chalain 3 et Chalain 19, rien ne permet de préciser s'il y a recouvrement entre deux territoires. En ce qui concerne les sites de Clairvaux III et Clairvaux La Motteaux-Magnins pour le Clairvaux moyen (période à partir de laquelle on assiste à une ouverture progressive du milieu), les résultats peuvent être interprétés comme l'exploitation de deux zones pour chaque village, l'une à proximité du village et l'autre plus éloignée. Cette image rappelle fortement l'organisation actuelle de certains territoires, où les boisements se raréfient, avec à proximité du village les champs cultivés en permanence et à distance les champs cultivés plus ou moins temporairement (Bergeret, Ribot, 1990). S'il paraît ici difficile d'envisager des cultures à $700 \mathrm{~m}$ d'altitude (en considérant que la hêtraie-sapinière est bien à cette altitude et non dans la vallée de la Frasnée), ces aires ont pu être fréquentées pour l'exploitation de ressources végétales destinées à d'autres usages ; en effet, à cette même période, le fourrage du bétail ou encore les planchers des maisons sont en sapin (Pétrequin et al., 1998).

\section{ÉVOLUTION DE L'EMPRISE SPATIALE DES ZONES D'EXPLOITATION}

Pendant le NMB (Clairvaux La Motte-aux-Magnins et Clairvaux XIV), les groupements exploités (frênaie et hêtraie-chênaie) sont limités aux terrasses inférieure et supérieure de l'Ain (soit dans un rayon de $2 \mathrm{~km}$ ), ce qui est cohérent en regard du faible nombre de villages contemporains pendant cette période où les communautés seraient engagées dans des cycles d'agriculture itinérante en forêt d'où une faible sédentarité de l'habitat (Pétrequin et al., 1999). Dans ce sens, les courbes de croissance diamétrale indiquent l'exploitation de strates sous-arbustive et arbustive denses, la phase de croissance juvénile étant rapidement bloquée. Il en va de même au Horgen, une période également marquée par une faible densité d'habitat et pour laquelle les groupements exploités (frênaie et frênaieérablaie) sont situés sur la terrasse inférieure de l'Ain.

Pendant le Clairvaux, en revanche, les aires d'exploitation sont plus étendues aussi bien sur le bassin de Clairvaux (pendant le Clairvaux moyen) que sur celui de Chalain (pendant le Clairvaux ancien). Ainsi, sur Clairvaux, la frênaie est accompagnée de la hêtraie à La Motte-auxMagnins et de la hêtraie-sapinière à Clairvaux III, groupements dont les affinités plus montagnardes permettent de proposer une localisation plus en altitude, sur le deuxième plateau du Jura. Sur Chalain, on assiste à l'exploitation de la hêtraie à Chalain 19 et à Chalain 4. Rappelons que la période du Clairvaux, datée entre 3040 et 2900 av. J.-C., est précédée d'une phase de détérioration climatique mineure et d'un abandon complet des rives du lac. Cette extension des aires d'approvisionnement ne résulte donc pas d'un éclaircissement progressif des forêts et, donc, d'un épuisement des ressources, la désertion des rives pendant 60 ans ayant certainement permis une régénération du couvert forestier.

À ce propos et à titre d'indication, on peut donner une évaluation de la surface nécessaire à l'approvisionnement en bois de feu, à partir de quelques chiffres approximatifs donnés pour une période de 10 ans et une communauté de 12 maisons (Pétrequin, Pétrequin, 1988, p. 143-145). Ces chiffres, évalués à 264 stères annuelles, permettent d'évaluer la surface boisée nécessaire à l'approvisionnement en bois de feù à environ 24 ha en ne comptant que sur la productivité forestière annuelle de la frênaie et de la hêtraie (c'est-à-dire sans " entamer " cette surface), ce qui représente une surface de $500 \mathrm{~m}$ de côté. Ces chiffres, extrapolés à environ 10 villages (nombre maximum de villages contemporains sur les rives du lac de Chalain) et à une durée d'occupation de 20 ans mènent aux mêmes conclusions : la surface boisée totale nécessaire pour les besoins en bois de feu est d'environ 480 ha, soit une surface d'environ $2,2 \mathrm{~km}$ de côté, toujours en ne comptant que sur la productivité annuelle de la forêt. 
Quoiqu'il en soit, il semble, en revanche, bien exister un lien étroit entre ce phénomène d'extension des aires d'approvisionnement et le nombre de villages contemporains sur les rives des lacs, ce qui dans lc cadre d'un partage des territoires par village ou par groupe de villages (voir p. 38), pourrait refléter une réorganisation des aires d'exploitation. Ces phases d'extension correspondent, en effet, aux périodes de forte densité de villages sur chacun des bassins lacustres. Ainsi, sur le lac de Clairvaux, la plus forte densité de village correspond au Clairvaux moyen, phase d'extension des aires d'acquisition par rapport au NMB ; au Clairvaux récent, les aires d'exploitation ne sont pas davantage étendues, le nombre de villages contemporains étant plus réduit. Sur le bassin de Chalain, la phase de forte densité d'habitat correspond au Clairvaux ancien. Cette phase, caractérisée par une augmentation progressive du nombre de villages contemporains, voit ainsi une phase d'extension des aires d'approvisionnement pendant la première partie du Clairvaux ancien. Puis, pendant la deuxième partie du Clairvaux ancien, alors que le nombre de villages continue d'augmenter, les aires d'exploitation sont maintenues. La présence d'autres groupes humains sur le plateau aurait pu être un facteur limitant mais, à cette même période, l'étude de la répartition spatiale et chronologique des habitats néolithiques de la région indique l'abscncc de toutc autrc communauté agricole entre les $32^{\circ}$ et $30^{\circ}$ siècles av. J.-C. (Arbogast et al., 2000). Dans le cadre d'une collecte fréquente et répétée, ce qui est le cas pour le bois de feu, ce maintien pourrait être déterminé par un équilibre entre la fréquence de l'activité de collecte et les distances parcourues. On assiste alors à un éclaircissement progressif des forêts de hêtre, qui voient le développement du frêne et du noisetier.

Pour conclure, dynamiques de végétation et contraintes territoriales ont en partie conditionné l'économie du bois de feu qui ne semble pas avoir été sélectionné en fonction des essences, les spectres anthracologiques présentant un grand nombre d'essences ligneuses (jusqu'à 30 taxons, un chiffre considérable en milieu tempéré). Reste à démontrer que toutes les essences alors présentes dans le milieu ont été exploitées ou encore que la collecte du bois a bien fait l'objet d'une activité spécifique et appartient à un système fonctionnel qui lui est propre, indépendant des autres systèmes d'exploitation.

\section{LES MODALITÉS D'ACQUISITION DU BOIS DE FEU AU SEIN DU TERRITOIRE}

\section{LE BOIS DE FEU, UNE COLLECTE SPÉCIFIQUE ?}

Il s'agit en premier lieu de se demander si le bois de feu est issu d'une collecte spécifique et/ou des éclisses de bois elles-mêmes issues du façonnage des bois d'œuvre. L'utilisation des éclisses pour alimenter un feu permet, en effet, un bon contrôle de la chauffe et des températures de cuisson des céramiques (Bocquet et al., 1986). Cette hypothèse de réutilisation des chutes de bois doit être prise en compte car si la collecte du bois de feu ne fait pas l'objet d'une sélection particulière en fonction de l'essence, celle des bois d'architecture ou encore des brindilles pour le fourrage du bétail a été clairement démontrée (Billard et al., 1997).

C'est tout d'abord la surreprésentation du sapin et du noisetier à Clairvaux III qui nous a amenée à discuter de l'hypothèse d'une réutilisation des chutes issues du travail du bois. Le sapin représente en effet $12 \%$ des copeaux de bois, mais le noisetier n'y est pas représenté. La réutilisation des copeaux pour le bois de feu est donc plausible pour le sapin mais n'explique en rien les forts taux de noisetier. Par ailleurs, comment expliquer que les autres essences représentées dans les copeaux ne le soient pas dans les charbons de bois ? S'agit-il d'une réutilisation sélective?

À Chalain 3, K. Lundström-Baudais (1997) a interprété les taux de frêne et d'érable comme étant le résultat d'une collecte sélective en suggérant l'existence d'une relation directe entre les charbons et les éclisses. Il existe, en effet, des ressemblances à Chalain 3 entre ces deux éléments puisque les essences les plus abondantes dans le milieu sont représentées dans chacun des spectres; les spectres des pieux circulaires et des éclisses se caractérisent par des taux importants de frêne (respectivement $38,7 \%$ et $36,3 \%$ ), de chêne (respectivement $22,8 \%$ et $23 \%$ ) et d'érable (respectivement $14,3 \%$ et $15,7 \%$ ). Si cette hypothèse est vraie, on peut se demander pourquoi les autres chutes telles celles du chêne (environ $23 \%$ des éclisses) n'ont pas été utilisées comme le frêne et l'érable pour le bois de feu ?

À Chalain 4 (phase Ch4.1), c'est cette fois-ci la proportion exceptionnellement élevée de chêne (57,6\%) en comparaison avec les résultats de Chalain 19 qui a permis de soulever la question d'un réemploi des chutes de travail du bois, notamment du bois de construction, les pieux étant 
principalement en chêne. De plus, l'étude des calibres montre l'emploi de diamètres supérieurs à $10 \mathrm{~cm}$ pour le chêne, même s'ils sont loin d'être majoritaires. Cette hypothèse cst donc plausible mais, au vu de la durée d'occupation estimée à environ 10 ans (peut-être moins), elle n'explique pas à elle seule des taux aussi élevés.

Enfin, à La Motte-aux-Magnins, si l'on considère le spectre des copeaux, il n'offre cette fois-ci aucun équivalent ni avec les autres bois (pieux, perches et baguettes) ni avec les charbons de bois.

En définitive, si rien ne permet d'accepter ou de rejeter cette hypothèse du réemploi des chutes de bois pour alimenter le feu, nous pensons que l'utilisation des éclisses, produites pour une grande part lors de la construction d'un village et des quelques réfections qui ont lieu pendant l'occupation, n'a pas d'impact significatif sur un spectre anthracologique résultant d'un approvisionnement fréquent et répété sur une période de 10 et 15 ans. De plus, si on admet cette hypothèse de réutilisation des chutes de bois, que représente la part restante de copeaux et/ou d'éclisses non carbonisés dans les couches de fumiers? Enfin, il faut garder à l'esprit que plus l'habitat est rapidement abandonné (accidentellement ou volontairement), plus ces chutes de bois participeront aux pourcentages observés dans les charbons de bois, raison pour laquelle il faut tester celle hypothèse au cas par cas.

Si une grande part de la collecte du bois de feu fait l'objet d'une collecte spécifique, on peut maintenant se demander s'il existe une préservation de certaines essences, notamment celles dont le choix est démontré pour d'autres usages. Autrement dit, est-ce que les essences sélectionnées pour des usages spécifiques, notamment le bois d'œuvre, l'alimentation des hommes et du bétail, sont également employées pour le combustible?

\section{UNE SÉLECTION DU BOIS DE FEU EN FONCTION DES ESPÈCES?}

Il est démontré que le bois d'œuvre fait l'objet d'une sélection rigoureuse (Billard $\ell$ al., 1997) ; ainsi, les pieux porteurs des maisons sont en règle générale en frêne et en chêne, tandis que les clayonnages sont habituellement en noisetier. Concernant le chêne, les analyses polliniques révèlent des taux importants pendant le Subboréal (Richard, 1997) et suggèrent son abondance dans le milieu. Or, entre 3700 et 2700 av. J.-C., les analyses anthracologiques indiquent que l'exploitation du chêne est rare, excepté à Chalain 4 (phase 1). On peut donc se demander si le chêne n'a pas fait l'objet d'une certaine protection, de même que le noisetier dont les taux sont souvent faibles dans les diagrammes anthracologiques alors qu'ils sont importants dans les diagrammes polliniques.

De la même manière, la comparaison des spectres anthracologiques avec celui des brindilles, utilisées comme litières végétales ou pour le fourrage du bétail, indique que les espèces les plus utilisées comme le gui, le lierre ou l'orme, espèces peu abondantes dans le milieu, sont rares ou absentes des spectres anthracologiques. Il en va de même pour les objets en bois. Citons les exemples du buis consacré à la fabrication des peignes ou de l'if exclusivement utilisé pour le façonnage des arcs.

Il apparait donc que, si les essences prédominantes dans lc milicu sont fréquemment employées pour divers usages (c'est notamment le cas du frêne, utilisé à la fois pour le combustible, les pieux porteurs des maisons, la fabrication des manches de hache ou encore le fourrage du bétail), les essences moins abondantes dans le milieu et particulièrement appropriées à certains usages (comme l'orme pour le fourrage du bétail, le chêne pour les pieux porteurs ou l'if pour les arcs) sont strictement réservées à ces usages spécifiques.

La question de la préservation de certaines essences se pose également pour les arbres et arbustes fruitiers dont les graines et/ou les fruits potentiellemcnt comcstibles ont été retrouvés sur les sites. À Chalain et à Clairvaux, la cueillette (comme la chasse) est, en effet, une activité qui continue à jouer un rôle important tout au long du Néolithique.

C'est en partie les fortes distorsions qui existent entre les taux de noisetier représentés dans l'ensemble des analyses polliniques et ceux représentés dans les spectres anthracologiques qui nous ont conduite vers cette piste, d'autant plus qu'aucune corrélation n'a pu être établie entre les taux élevés de noisetier dans les analyses polliniques et les phases d'ouverture du milieu repérées par les analyses anthracologiques.

Il est possible de tester cette hypothèse de préservation en comparant les spectres carpologiques (LundströmBaudais, 1986, 1989) et anthracologiques. Précisons que l'étude des graines ne permet pas, pour le moment, de distinguer si les fruits ou graines proviennent de plantes sauvages, protégées ou plantées. Globalement, on constate que le prunellier, l'églantier, le framboisier, le mûrier sauvage ou encore le pommier sont absents des spectres anthracologiques alors que leurs fruits et/ou graines sont présents dans les sites étudiés. D'autres espèces sont, elles, 
représentées dans les spectres anthracologiques, mais dans des proportions certainement inférieures à la réalité. Il s'agit notamment du noisetier et des chênes à feuillage caduc qui pourraient avoir bénéficié d'une protection pour leurs fruits, dont la consommation est démontrée ; on peut également citer l'aubépine, la viorne obier et le cornouiller sanguin.

En ce qui concerne les arbustes fruitiers, on pourrait rétorquer à ces observations que la combustion de tiges de petits calibres est tellement rapide que ces essences sont très vites réduites en cendres et n'apparaissent donc pas dans les diagrammes anthracologiques. Il ne s'agit pas d'un bon argument puisque, outre les essences d'arbres et arbustes, on trouve fréquemment dans les spectres anthracologiques des ligneux d'assez faible calibre tels que les lianes, les arbrisseaux ainsi que des épineux (Chabal et al., 1999, p. 89).

Deux hypothèses sont donc envisageables : il s'agit soit d'un désintérêt pour ces essences soit d'une préservation (au moins partielle) des arbres et arbustes fruitiers, la notion de préservation devant encore faire l'objet d'une démonstration claire. En effet, ces ressources pouvaient être récoltées dans des zones différentes de celles de la collecte du bois de feu. Cette possibilité expliquerait d'ailleurs l'importance des taux de noisetier dans les analyses polliniques et la cohérence des proportions et des variations du noisetier (par rapport à l'état du milieu) dans les spectres anthracologiques : si le noisetier est protégé par l'homme et favorisé par l'apport de lumière (qui permet une meilleure production de noisettes), sa production pollinique s'en trouve augmentée et serait à l'origine des taux élevés de pollen dans les diagrammes.

Cette dernière hypothèse évoque un modèle d'exploitation proposé par A. Kreuz (1992) sur des sites terrestres allemands et autrichiens datant de $7500 \mathrm{BP}$, à savoir la mise en place volontaire et l'exploitation de haies et de lisières. Nous préférons cependant le concept de "lisières mobiles ", plus nuancé : les hommes ont pu favoriser cet effet de lisière par le biais d'une rotation entre les lisières présentes dans le milieu, en fonction des différents stades de vieillissement et des saisons, c'est-à-dire en fonction de la production de fruits et de graines.

Pour conclure, toutes les essences présentes dans le milieu n'ont pas été exploitées, notamment lorsque ces essences sont destinées à des usages bien spécifiques. Le bois de feu ne semble pas pour autant faire l'objet d'une sélection en fonction des propriétés combustibles du bois, propriétés qui varient d'ailleurs davantage en fonction de l'état du bois et de sa morphologie qu'en fonction de l'espèce (Théry-Parisot, 2001). Or, les résultats concernant l'état du bois nous laissent dans l'ambiguïté : scul un nivcau à La Motte-aux-Magnins ( $\mathrm{D}$ à $\mathrm{G}$ ) permet de certifier pour la plupart des essences l'utilisation et donc la collecte de bois vert. Un autre niveau, à Clairvaux La Motte-aux-Magnins $(A B C)$, suggère une utilisation mixte entre bois sec et bois vert. Pour le reste, on ne peut qu'évoquer l'utilisation de bois sec sans aucune certitude. Il est paraît donc plus pertinent et moins hasardeux de s'intéresser aux diamètres des bois exploités, d'autant qu'il s'agit d'un critère de sélection déjà reconnu à Chalain et à Clairvaux (voir p. 42)

\section{LE DIAMÈTRE, UN CRITÈRE DE SÉLECTION DU BOIS DE FEU ?}

$\mathrm{Au}$ NMB, les calibres exploités sont inférieurs à $15 \mathrm{~cm}$ quelles que soient les essences. Le plus souvent compris entre 5 et $10 \mathrm{~cm}$ de diamètre, il existe quelques exceptions, notamment à Clairvaux XIV où les diamètres de l'érable peuvent atteindre $25 \mathrm{~cm}$. Au Horgen, les diamètres exploités sont inférieurs à $5 \mathrm{~cm}$ à Chalain 3 et compris entre $5-10 \mathrm{~cm}$ et $10-20 \mathrm{~cm}$ à Chalain 19. Le site de Chalain 4 montre pour la transition Ferrières-Clairvaux, une collecte du bois principalement axée sur des diamc̀trcs inférieurs à $10 \mathrm{~cm}$, qui peuvent cependant atteindre $20 \mathrm{~cm}$ pour le chêne, alors essence prédominante. Puis, pendant la première partie du Clairvaux ancien, on assiste à l'utilisation du hêtre dont les diamètres sont inférieurs à $10 \mathrm{~cm}$ tandis que le frêne est exploité dans une gamme de calibres beaucoup plus large, jusqu'à $30 \mathrm{~cm}$. Pendant la dernière phase du Clairvaux ancien, également caractérisée par l'exploitation de petits calibres, on assiste progressivement à l'utilisation de diamètres de plus en plus gros. Enfin, le Clairvaux moyen et le Clairvaux récent voient aussi un élargissement des gammcs de diamètres exploités (Clairvaux La Motte-aux-Magnins).

Par comparaison avec les différentes strates arbustives et arborescentes que l'on peut observer actuellement, les diamètres suggèrent dans l'ensemble l'exploitation des strates sous-arbustive et arbustive qui correspondent dans les forêts actuelles au fourré $(<5 \mathrm{~cm}$ de diamètre), au gaulis ( $<8 \mathrm{~cm}$ de diamètre) et au bas perchis (entre 10 et $20 \mathrm{~cm}$ de diamètre). Ces variations ne reflètent en aucun cas un état du milieu et ne sont donc certainement pas régies par des contraintes environnementales; il est en effet peu 
vraisemblable que les forêts jurassiennes du Néolithique soient toutes au stade de gaulis ou de bas perchis. Il ne s'agit pas non plus d'une contrainte technique puisque, dès le NMB, l'étude du bois d'œuvre montre que toutes les gammes de calibres sont exploitées en fonction de leur place dans l'architecture (pieux, plancher, clayonnage, etc.) (Billard et al., 1997).

L'exploitation des petits calibres du NMB au Horgen est, selon nous, le résultat d'un choix en équilibre avec les systèmes techniques et économiques. L'utilisation de petits bois est particulièrement bien adaptée dans ces constructions en bois où le foyer domestique, essentiellement destiné à la cuisson des aliments et au chauffage, doit répondre à certaines exigences; ainsi, l'ajout progressif de pctits bois permet de contrôler facilement la hauteur des flammes, la chaleur du foyer, l'éclatement de braises ou les projections d'escarbilles. Cette technique évite le développement des hautes flammes, mais permet l'accumulation de braises, propice au rayonnement de chaleur pour le chauffage de l'habitat ou des pierres de chauffe (Bocquet et al., 1986). Par ailleurs, la fabrication d'un manche de hache ou d'herminette nécessite techniquement plusieurs heures de travail. Ainsi, les exemples ethnographiques montrent qu'on utilise la hache ou l'herminette lorsqu'il n'est pas possible de faire autrement (Pétrequin, Pétrequin, 1993). La collectc du bois de feu par le bris des arbustes et des buissons est donc cohérent et pourrait même expliquer l'exploitation importante du hêtre; on pensait en effet jusqu'à présent qu'il n'était pas ou peu exploité en raison de sa dureté et de la faible résistance mécanique du tranchant de hache (Pétrequin, comm. pers.). Enfin, ce choix, qui consiste à exploiter les jeunes peuplements est cohérent avec la préservation partielle pour leurs fruits. Citons notamment le chêne et le hêtre, espèces dont la maturité sexuelle (et la production de glands et de faines) est tardive, vers l'âge de 40 ou 60 ans.

Pendant le Clairvaux, on assistc à l'utilisation de diamètres de plus en plus gros (Chalain 4, Clairvaux La Motte-aux-Magnins) qui pourrait être le reflet de l'exploitation de forêts plus âgées, probablement moins touchées par les activités humaines comme le suggèrent les phases d'extension des aires d'approvisionnement, elles-mêmes en relation avec les phases de densité d'habitat (voir p. 38). Ce nouveau mode d'acquisition, moins adapté aux exigences d'un foyer dans des constructions en matériaux végétaux, est donc probablement le résultat d'une pression de collecte plus forte : il requiert plus de temps et d'effort aussi bien pour l'abattage des troncs que pour la refente du bois. On constate d'ailleurs à ces périodes une augmentation significative du nombre de merlins à fendre (Y. Maigrot, $2003 \mathrm{et}$ comm. pers.). Si l'on considère en outre les outils d'abattage du bois, notamment les haches de pierre polie dont les lames en roches tenaces proviennent des Alpes (jadéitite, éclogite, serpentinite, etc.), on peut observer un passage progressif, à partir de 3200 av. J.-C., des lames de pierre de forme triangulaire pour un emmanchement direct vers des lames de pierre rectangulaire pour un emmanchement indirect (présence d'une gaine en bois de cerf). Ces modifications techniques, qui permettent une durée de vie plus longue du manche de hache mais également une économie de la matière première (Jeudy et al. 1997), pourraient donc être une réponse à l'exploitation de forêts plus âgées.

Enfin, le retour vers l'exploitation de petits diamètres à la fin du Clairvaux pourrait correspondre au maintien délibéré des zones d'approvisionnement et refléter dans une certaine mesure l'éclaircissement des zones d'exploitation; dans ce sens, rappelons le développement d'essences pionnières et postpionnières comme le noisetier et le frêne, ainsi que l'évolution des courbes de croissance diamétrale, qui suggèrent une ouverture du milieu et, probablement, l'exploitation de rejets de souche.

\section{LE BOIS DE FEU, UN SYSTÈME D'EXPLOITATION INDÉPENDANT ?}

Les populations néolithiques de Chalain et de Clairvaux sont des agriculteurs-éleveurs même si la chasse et la cueillette continuent à jouer un rôle important. De nombreux éléments, comme la mobilité des villages ou encore l'exploitation du bois d'œuvre, montrent des évolutions qui ne sont pas sans rappeler certains modèles actuels de gestion du milieu et permettent de supposer que ces communautés jurassiennes pratiquaient un système de culture extensif, l'agriculture cyclique, telle que la jachèreforêt (Arbogast et al., 1995).

Au cours des IV" et III" millénaires av. J.-C., ces communautés recherchent, dans la mesure du possible, le bois de feu dans les zones les plus proches des villages, dans un rayon de $2 \mathrm{~km}$. L'implantation des villages sur les rives du lac et leur position les uns par rapport aux autres semblent par ailleurs déterminants dans la localisation des zones d'exploitation. Si les analyses ne permettent pas, pour l'instant, de préciser s'il y a recouvrement ou non entre les aires d'acquisition de plusieurs villages, ces observations 


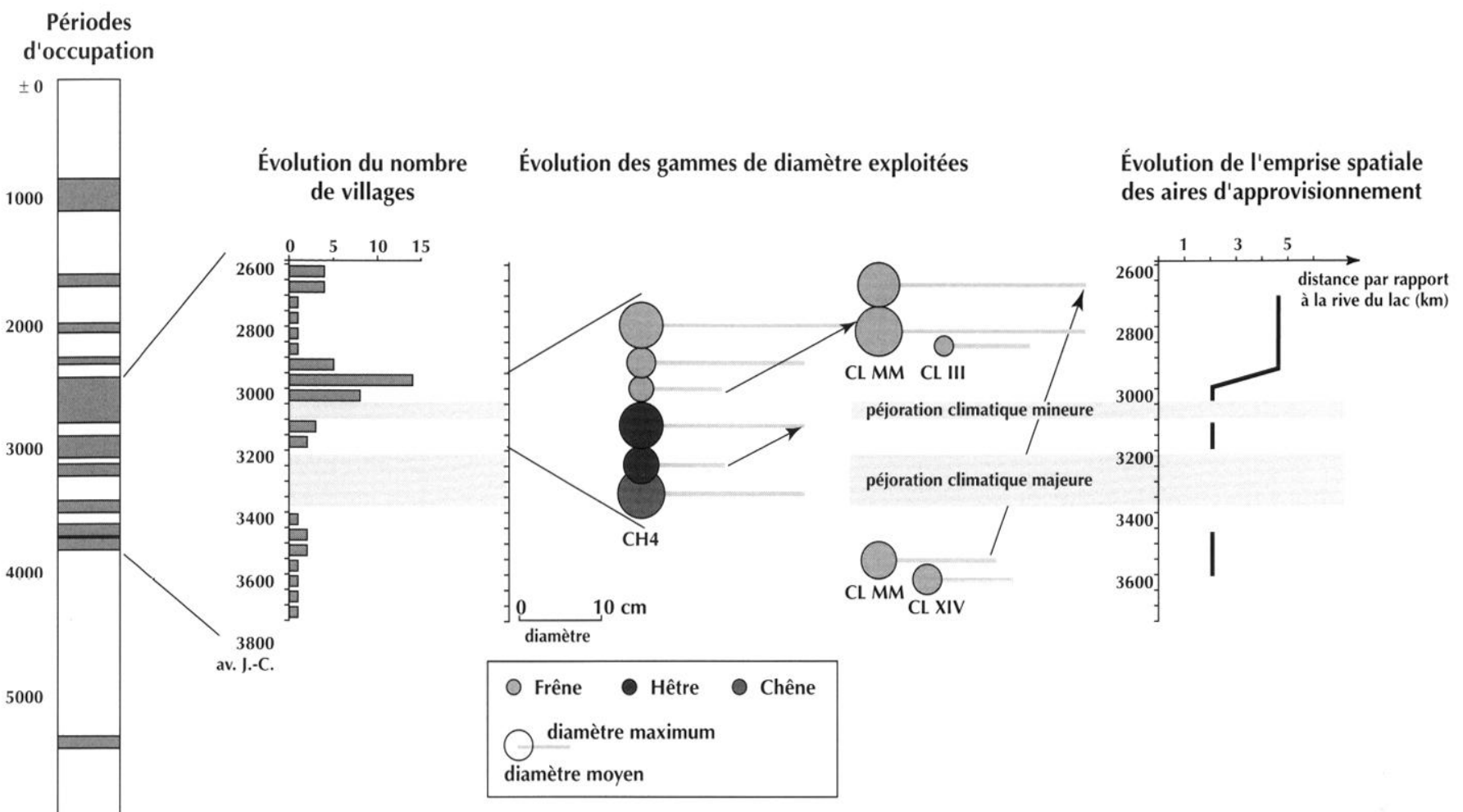

Fig. 24 - Évolution de l'économie du bois de feu entre 3700 et 2800 av. J.-C. sur les lacs de Chalain et de (ilairvaux et corrélation avec le nombre de villages contemporains.

évoquent les notions de partage de l'espace forestier et de territoire, qui ne sont pas sans rappeler le droit d'usage des terres à vocation agricoles ou non.

Au sein de ce territoire, la collecte du bois de feu, caractérisée par un grand nombre d'essences et axée sur des petits diamètres, est à première vue une collecte opportuniste (fig. 24). Mais l'étude de l'exploitation des autres ressources végétales ligneuses permet de démontrer que toutes les essences présentes dans le milieu ne sont pas exploitées pour le bois de feu. Si les essences les plus abondantes dans le milieu sont destinées à des usages divers, les essences moins abondantes et convenant à des usages spécifiques sont en revanche réservées à ces usages. C'est notamment le cas du chêne pour les pieux maîtres des maisons, de l'orme, du lierre ou du gui pour le fourrage du bétail, de l'if pour la fabrication des arcs ou encore des arbres et arbustes dont les fruits et/ou graines sont comestibles et consommés. En outre, l'exploitation de petits calibres, pouvant a priori être interprétée comme une loi du moindre effort, s'avère réfléchie et en accord avec les systèmes techniques et économiques.
Cette sélection " négative " pour le bois de feu explique pourquoi, dans le cadre d'une véritable économie du bois de feu et d'une gestion des ressources forestières, les spectres anthracologiques reflètent correctement un état de la végétation dont certaines espèces sont absentes ou sousreprésentées, sans que cela tronque la représentation de l'association végétale.

À partir du début du III" millénaire av. J.-C., l'économie $\mathrm{du}$ bois de feu, alors bien établie, subit des modifications importantes tant du point de vue des modes de collecte, axés cette fois-ci sur de gros diamètres, que des distances parcourues, jusque dans un rayon de $5 \mathrm{~km}$. La haute résolution chronologique - de l'ordre de la génération permet de corréler ces changements avec l'évolution globale du nombre de villages contemporains sur les rives des lacs, interprétée en termes de densité relative de population. Ainsi, entre 3040 et 2910 av. J.-C., on assiste à une forte densification de l'habitat, résultant d'une véritable colonisation d'origine méridionale (qui correspond à la mise en place du groupe de Clairvaux) et à une sédentarisation croissante (Pétrequin et al., 1999). La 
dilatation des séquences sédimentaires, notamment à Chalain 4 , et les quelques estimations chiffrées ont permis de montrer que cette extension des territoires n'était pas liée à un épuisement des ressources forestières, mais correspondait plutôt à une réorganisation des aires d'exploitation en fonction du nombre de villages, voire en fonction du nombre de maisons au sein d'un village (Chalain 4). Or, dans un système d'agriculture itinérante, deux solutions sont possibles face à la pression démographique : étendre les champs cultivés vers des forêts encore non exploitées ou entrer dans un système de culture plus intensif. Au vu de la productivité par heure de travail, il est préférable d'étendre les zones cultivables en défrichant des forêts âgées encore non exploitées plutôt que de rentrer dans un système de culture plus intensif (Boserup, 1970). C'est cette solution qui semble avoir été choisie par les communautés de Chalain et de Clairvaux, comme le suggère l'examen des bois d'architecture en chêne et issus de peuplements âgés (Arbogast et al., 1995). L'utilisation de gros bois pour le combustible domestique pourrait donc aussi refléter l'exploitation de forêts plus âgées. On peut alors se demander pourquoi obéir à de telles contraintes (rappelons que ce mode de collecte demande plus de temps et d'effort pour l'abattage et la refente du bois, et nécessite l'adaptation des outils d'abattage) alors que l'environnement ne l'y force pas (fig. 24).

Une hypothèse est envisageable : celle que le bois de feu soit récolté dans les champs abandonnés à la forêt et/ou provienne des terres en cours de défrichement. Il existe en effet une convergence spatiale entre les zones d'approvisionnement pour le bois et les zones potentiellement cultivables. Ce lien peut aussi exister avec les terres vouées à d'autres activités telles que l'abattage de bois d'œuvre, la cueillette ou la récolte du fourrage pour le bétail comme nous avons pu l'évoquer pour les sites de (lairvaux III et Clairvaux La Motte-aux-Magnins (niveau ABC). La collecte du bois de feu pourrait donc s'effectuer le long des trajets quotidiens en fonction des activités pratiquées au sein du territoire, un mode d'exploitation largement reconnu et exercé par des populations actuelles (Carlstein, 1980).

En définitive, ces résultats mettent clairement en évidence des interactions complexes entre la collecte du bois de feu et les systèmes sociaux, techniques et économiques, interactions qui interviennent apparemment aussi bien sur les modes de collecte que sur la gestion du territoire.

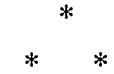

De par la dilatation des séquences stratigraphiques et la haute résolution chronologique, les analyses anthracologiques en milieu humide permettent pour la première fois d'accéder à un niveau d'interprétation d'ordre environnemental et social encore jamais atteint pour le ramassage du bois de feu, une activité ancrée dans la vie quotidienne des populations.

L'analyse de grandes séries de charbons de bois issus de sites d'ambiance humide a montré, contrairement à toute attente, que le système d'exploitation du bois de feu est étroitement lié aux autres systèmes d'acquisition. Parce que le feu joue un rôle fondamental dans la vie quotidienne, les sociétés ont mis en place une véritable économie du bois de feu dès les périodes préhistoriques. L'exploitation du bois comme combustible se trouve ainsi conditionnée par un certain nombre de variables telles que la société et ses modes de vie, les usages auxquels le bois est destiné, le contexte économique et le milieu.

L'économie du bois de feu doit donc aujourd'hui être appréhendée selon une approche systémique, intégrant l'ensemble des composantes qui structurent un territoire, ce que seule l'anthracologie appliquée au milieu humide peut apporter.

\section{Remerciements}

Cette étude, en partie issue d'une thèse de doctorat ${ }^{4}$, a été réalisée sous la direction de Pierre Pétrequin et Stéphanie Thiébault que je tiens tout particulièrement à remercier pour leur confiance, leur patience, leur disponibilité et les conseils qu'ils m'ont chacun apportés dans leur domaine. Je tiens aussi à remercier Hervé Richard pour m'avoir accueillie au laboratoire de Chrono-Écologie à Besançon. Un grand merci ćgalcment à Christinc BourquinMignot pour ses discussions fructueuses et à Lucie Chabal pour ses conseils, ses critiques constructives et ses nombreuses explications qui m'ont apporté toute la réflexion nécessaire à l'élaboration de ce travail.

4. Thèse soutenue à l'université de Franche-Comté à Besançon (décembre 2002) et financée par une allocation de recherche. 


\section{BIBLIOGRAPHIE}

AABY $B$.

1986 : " Trees as anthropegenic indicators in regional pollen diagrams from eastern Denmark ", in Behre K. E. (ÉD.), Anthropogenic Indicators in Pollen Diagrams, Rotterdam/Boston, Balkema, p. 73-93.

\section{Ammann B.}

1988 : " Palynological evidence of prehistoric anthropogenic forest changes on the swiss plateau ", in BiRks H. H., BIRKS H. J. B., Kaland P. E., MOE: D. (DIR.), The Cultural Landscape Past, Present and Future, Cambridge University Press, p. 279-298.

Arbogast R.-M., Beugnier V., Delattre N., Giligny F., Maitre A., Pétrequin A.-M., Pétrequin P.

1997 : "La répartition des témoins et le fonctionnement de la cellule domestique ", in Pítrequin P. (DIR.), Les Sites littoraux néolithiques de Clairvaux-les-Lacs et de Chalain (Jura) -III- Chalain station 3: 3200-2900 at. J.-C., Paris, éd. de la Maison des sciences de l'Homme, p. 583-639.

\section{Arbogast R.-M., Magny M., Pétrequin P.}

1995 : «Expansions et déprises agricoles au Néolithique : populations, cultures céréalières et climat dans la Combe d'Ain (Jura, France) de 3700 à 2500 av. J.-C. " in VAN DER LeEuw' S.-E. (E.l.), L'Homme et la dégradation de l'environnement, Actes des $\mathrm{XV}^{\mathrm{V}}$ rencontres internationales d'archéologie et d'histoire d'Antibes, 20-22 oct. 1994, Sophia Antipolis, éd. APDCA, p. 19-41.

\section{ARbogast R.-M., MARÉchal D., Pétrequin A.-M., Pétrequin P., SAINTOT S.}

1998 : «Parures et flèches du Néolithique final à Chalain et à Clairvaux (Jura). Une approche culturelle et environnementale ", Gallia Préhistoire, 40, p. 133-247.

\section{Arbogast R.-M., Pétrequin P., Affolter J.}

2000 : «Écologie de la chasse du cerf dans le cadre des occupations lacustres du Jura au Néolithique ", Anthropozoologica, 31, p. 85-98.

\section{BEAUfILS T.}

1983 : "Végétation et sols des forêts de la Combe d'Ain et des reliefs environnants ", in L'Homme et la forêt en FrancheComté. Structures et dynamisme de l'écosystème. forêt en rapport avec les activités humaines passées et actuelles, Besançon, Centre universitaire d'études régionales, p. $325-383$.

\section{Bergeret A., Rubot J.-C.}

1990 : L'Arbre nourricier en pays sahélien, Paris, éd. de la Maison des sciences de l'Homme, $237 \mathrm{p}$.

Billard M., Joly F., Lundström-BaUdais K. Maitre A., Mignot C., Monnier J.-L., PÉTRequin P.

1997 : " Environnement végétal et sélection des bois d'oeuvre ", in PÉTREQUIN P. (DIR.), les Sites littoraux néolithiques de Clairvauxles-Lacs et de Chalain (Jura) -III- Chalain station 3 : 3200-2900 av. J.-C., Paris, éd. de la Maison des sciences de l'Homme, p. 171-185.

\section{BJÖRKMAN L.}

1999 : « The establishment of Fagus sylvalica at the stand-scale in southern Sweden ", The Holocene, 9, 2, p. 237-245.

Boceuet A., Caillat R., LundströmBaudaIS $\mathbf{K}$.

1986 : "Alimentation et techniques de cuisson dans le village néolithique de Charavines. Isère ", in DFmoul.F. J.-P., GuILAINE J. (DIR.), Le Néolithique de la France: hommage à Gérard Bailloud, Paris, Picard, p. 319-329.

\section{BOSERUP E.}

1970 : Évolution agraire et pression démographique, Paris, Flammarion (coll. Nouvelle bibliothèque scientifique), $218 \mathrm{p}$.

\section{BURGa C. A.}

1988: "Swiss vegetation history during the last 18000 years ", New Phytologist, 110, p. $581-602$.

\section{CAMPY M.}

1982 : Le Quaternaire franc-comtois. Essai chronologique et paléoclimatique, thèse de $3^{\mathrm{e}}$ cycle, univ. de Franche-Comté, 575 p.

\section{Caristein T.}

1980 : Time Resources, Society and Ecology, on the Capacity for Human Interaction in Spare and Time -I- Preindustrial Societies, Lund, Royal University, $302 \mathrm{p}$.

\section{Chabal L.}

1997 : Forêts et sociétés en Languedoc (Néolithique final, Antiquité tardive). L'anthracologie, méthode et patéoécologie, Paris, éd. de la Maison des sciences de l'Homme (coll. Documents d'archéologie française, 63), $189 \mathrm{p}$.

Chabal L., Fabre L., Terral J.F., ThéryParisot I.

1999 : " L'anthracologie ", in BoLRQUINMignot C., Brochier J.-E., Chabal. L., Crotat S., fabre L., Guibal. F., Marinval. P., Richard H., Terral. J.-F, Théry-Parisot I., La Botanique, Paris, Errance (coll. Archéologiques), p. 43-104.

Clark J. S., Merkt J., Müller H.

1989 : "Post-Glacial fire, vegetation, and human history on the northern alpine forelands, south-western Germany ", Journal of Ecology, 77, p. 897-925.

\section{Collectif}

1999 : Dictionnaire de l'écologie, Paris, Encyclopaedia Universalis/Albin Michel, $1400 \mathrm{p}$.

\section{DUFRAISSE A.}

2002a : "Charcoal analysis in a lake-dwelling site (Chalain 19, Jura) : a sampling model in a neolithic lacustrine context ", in Thif́BAcit S. (ÉI).), Nouvelles approches méthodologiques, histoire de la végétation et des usages du bois depuis la Préhistoire, Second colloque international d'anthracologie, Paris, 13-16 sept. 2000, Oxford, BAR, International Series, 1063, p. 17-24.

2002b : Les Habitats littoraux néolithiques des lacs de Chalain et Clairvaux (Jura, France): collecte du bois de feu, gestion de l'espace forestier et impact sur le couvert arboréen entre 3700 et 2500 ar. J.-C. Analyses anthracologiques, thèse de doctorat, univ. de Franche-Comté, $349 \mathrm{p}$.

2002c : "Combustible et espace forestier à Chalain, station 19 (Jura) ", in Richard H., VigivoT A. (ÉD).), Équilibres et ruptures dans les écosystèmes depuis 20000 ans en Europe de l'Ouest, Besanson, 18-22 sept. 2000, Besançon, Presses universitaires franc-comtoises, p. 413-422.

\section{Dufraisse A., Gauthier E.}

2002 : "Exploitation des sources salées en Franche-Comté : impact sur l'espace forestier du Néolithique à la période médiévale ", in WELI.t.R O. (ÉD.), 
Archéologie du sel: techniques et sociétés dans la Pré- et Protohistoire européenne, Actes du colloque 12.2 du XIV congress de UISPP, 4 sept. 2001, Liege, et de la Table ronde du Comité des salines de France, 18 mai 1998 , Paris, Rahden, Westf., M. Leidorf (coll. Internationale Archäologie, Arbeitsgemeinschaft, Symposium, Tagung, Kongress, 3), p. 243-257.

\section{GaUTHIER E.}

2001 : Evolution de l'impact de l'homme sur la végétation du massif jurassien au cours des quatre derniers millénaires. Nouvelles données palynologiques, thèse de doctorat, univ. de Franche-Comté, $250 \mathrm{p}$.

\section{GILIGNY F}

1997 : "La céramique de Chalain 3 ", in PítreQuiN P. (DIR.), Les Sites littoraux néolithiques de Clairvaux-les-Lacs et de Chalain (Jura) -III- Chalain station 3: 3200-2900 av. J.-C., Paris, éd. de la Maison des sciences de l'Homme, p. 27-370.

\section{Higgs E. S., Vita-Finzi C.}

1972 : "Prehistoric economies : a territorial approach ", in HIGcis E. S. (DIR.), P'apers in Economic Prehistory. Studies by Members and Associates of the British Academy Major Research Projet in the Larly History of Agriculture, Cambridge, University Press, p. $27-36$.

\section{JACAMON M.}

1996 : (inide de dendrologie. Arbres, arbustes, arbrisseaux des forêts françaises, Nancy, ENGREF (1'réd. 1979, réed. 1992), 349 p.

\section{Jacomet S., Brombacher C., Dick M.}

1989 : Archäobotanik am Zürichsee. Ackerbau, Sammelwirtschaft und Umwelt von neolithischen und bronzezeitlichen Seeufersiedlungen im Raum Zürich: Ergebnisse von Untersuchungen pflanzischer Makroreste der Jahre 1979-1988, Zürich, Orell Füssli (coll. Berichte der Zürcher Denkmalpflege, Monographien 7), $363 \mathrm{p}$.

\section{Jacevat C.}

1989 : Les Plantes de l'Âge du Bronze : contribution a l'histoire de l'environnement et de l'alimentation, Saint-Blaise (Suisse), Saint-Blaise, éd. du Ruau, Hauterives-Champréveyres 2 (coll. Archéologie neuchâteloise, 8), $112 \mathrm{p}$.

JAHNS S.

2001 : "On the late pleistocene and holocene history of vegetation and human impact

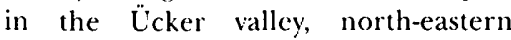

Germany ", Vegetation History and Archaeobotany, 10, p. 97-104.

Jeudy F., Maître A., Praud I., Pétrequin A.-M.

1997 : “Les lames de pierre polie ", in Ṕ́trequin P. (ÉD.) Les Sites littoraux néolithiques de Clairvaux-les-Lacs et de Chalain (Jura) -III-Chalain station 3 : 3200-2900 at. J.-C., Paris, éd. de la Maison des sciences de l'Homme, p. 455-465.

\section{Kreuz A.}

1992 : " Charcoal from ten early settlements in Central Europe and its interpretation in terms of woodland management and wildwood resources ", in VERNET J.-L. (ED).) Les charbons de bois, les anciens écosystèmes et le rôle de l'Homme, colloque organisé à Montpellier du 10 au 13 sept. 1991, Actualités botaniques, 2, 3, 4, Bulletin de la Société botanique fransaise, 139, p. 383-394.

\section{LAVIER C.}

1996 : Dendrochronologie appliquée à l'Archéologie : élaboration d'une chronologie du chêne (Quercus sp.) pour le Néolithique à partir des sites lacustres de Clairvaux-les-Lacs et de Chalain (Jura, France), mém. de DEA, univ. de Franche-Comté, 87 p.

\section{Lowe J.-J., Branch N., Watson C.}

1994 : "The chronology of human disturbances of the vegetation of the northern Apennines during the Holocene ", in Highland zone exploitation in southern Europe, Bergame, Museo Civico di Sciebze Naturali, p. 169-187.

\section{Ludemann T., Nelle $\boldsymbol{O}$.}

2002 : Die Wälder am Schauinsland und ihre Nutzung durch Bergbau und Köhlerei, Freiburg, Forstwissenschatliche Fakultät der Universität Freiburg und Forstlische Versuchs- und Forschungsanstalt BadenWürttemberg (coll. Schriftenreihe Freiburger Forstliche Forschung, 15), $139 \mathrm{p}$.

\section{LUNDSTRÖM-BAUDAIS $\mathrm{K}$.}

1986 : "Étude paléoethnobotanique de la station III de Clairvaux ", in Ṕ́trl:Quin P. (DIR.), Les Sites littoraux néolithiques de Clairvaux-les-Lacs (Jura) -I- Problematique générale : l'exemple de la station III, Paris, éd. de la Maison des sciences de l'Homme, p. 311-391.

1989 : «Les macrorestes végétaux du niveau $\mathrm{V}$ de la Motte-aux-Magnins à Clairvaux ", in Pétrequin P. (DIR.), Les Sites littoraux néolithiques de Clairvaux-les-Lacs (Jura) -II- Le
Néolithique moyen, Paris, éd. de la Maison des sciences de l'Homme, p. 417-439.

1997 : " Les foyers et la forêt au travers des charbons de bois de Chalain 3 ", in Pítre:Quin P. (DIr.), Les Sites littoraux néolithiques de Clairvaux-les-Lacs et de Chalain (Jura) -III- Chalain station 3, 3200-2900 av. J.-C., Paris, éd. de la Maison des sciences de l'Homme, p. 295-298.

\section{MAGNY M.}

1995 : Une histoire du climat: des derniers mammouths au siècle de l'automobile, Paris, Errance (coll. des Hespérides), $176 \mathrm{p}$.

1997 : « Chalain de 6000 à 4500 BP. L.'histoire du lac, du climat et du soleil ", in PÉtre.oun P. (DIR.), les Sites littoraux néolithiques de Clairvaux-les-Lacs et de Chalain (Jura) -III-Chalain station 3: 3200-2900 av. J.-C., Paris, éd. de la Maison des sciences de l'Homme, p. 65-85.

\section{MAIGROT Y.}

2003 : Etude technologique et fonctionnelle de l'outillage en matieres dures animales. I.a station 4 de Chalain (Néolithique final, Jura, France), thèse de doctorat, univ. Paris-I, 284 p.

\section{MARguerie D.}

1992 : « Le bois : évolution, structure et détermination ", in Dossier AGORA Les bois archéologiques, 2, p. 3-8.

\section{Nicoud C.}

1992 : Habitats littoraux présents et passés : confrontation entre un modèle ethnoarchéologique et une analyse de site archéologique, in kithnoarchéologie, justification, problemes, limiles, Actes des XIT rencontres internationales d'archéologie et d'histoire d'Antibes, 17-19 oct. 1990, Juan-les-Pins, éd. APDCA, p. 239-256.

\section{Pétrequin A.-M., Pétrequin P.}

1984 : Habitat lacustre du Bénin : une approche ethnoarchéologique, Paris, éd. Recherche sur les civilisations (coll. Mémoire, 39), 209 p., 75 fig., $110 \mathrm{pl}$.

1989 : « (.L. MM V. La répartition des témoins archéologiques", in Pि.TRE.QUIN P. (DIR.), Les Sites littoraux néolithiques de Clairvauxles-Lacs (Jura) -II- Le Néolithique moyen, Paris, éd. de la Maison des sciences de l'Homme, p. 253-263.

\section{PÉtrequin P.}

1986a : "La répartition du matériel archéologique (témoins lithiques, céramiques et osseux) ", in Pétrequin P. (dir.), Les Sites littoraux néolithiques de Clairvaux-les-Lacs (Jura) -I- Problématique générale : l'exemple de 
la station III, Paris, éd. de la Maison des sciences de l'Homme, p. 249-262.

1986b : "La stratigraphie et la dynamique de sédimentation: le point de vue de l'archéologue ", in Pítreqlis P. (DIR.), I.es Sites littoraux néolithiques de Cilairvaux-lesLacs (Jura) -I- Problématique générale. l'exemple de la station III, Paris, éd. de la Maison des sciences de l'Homme. p. 107-127.

1986c: "La fouille subaquatique de la station III ", in Pítri.QliN P. (DIR.), Les Sites littoraux néolithiques de Clairvaux-lesLacs (Jura) -I- Problématique générale: l'exemple de la station III, Paris, éd. de la Maison des sciences de l'Homme. p. 95-106.

1995 : Fontenu (Jura). Lac de Chalain. Fouille de Chalain 4, 1993-1995. Rapport de synthèse, Besançon, Laboratoire de chronoécologie/Centre de recherche archéologique de la vallée de l'Ain, $298 \mathrm{p}$.

1997 : "Stratigraphie et stratégie de fouille ", in PÉtrr.ol IN P. (DIR.), Les Sites littoraux néolithiques de Clairvaux-les-Lacs et de Chalain (Jura) -III- Chalain station 3: 32002900 av. J.-C., Paris, éd. de la Maison des sciences de l'Homme, p. 37-54.

\section{Pétrequin P. (DIR.)}

1989 : Les Sites littoraux néolithiques de Clairvaux-les-Lacs (Jura) -II- Le Néolithique moyen, Paris, éd. de la Maison des sciences dc l'Hommc, $508 \mathrm{p}$.

2000 : Chalain 2000. Quatre millénaires d'habitat lacustre mis en question, Besançon/Doucier, Laboratoire de chrono-écologie/Centre de recherche archéologique de la vallée de l'Ain, $303 \mathrm{p}$.

À paraître: Les Sites néolithiques de Clairvaux-lesLacs et de Chalain (Jura) -IV- Du Ferrières au groupe de Clairvaux (31 et $30^{\circ}$ siècles av. J.-C.), Paris, éd. de la Maison des sciences de l'Homme.

\section{Pétrequin P., Pétrequin A.-M.}

1988 : Le Néolithique des Lacs. Préhistoire des lacs de Chalain et de Clairvaux 14000-2000 av. J.-C.), Paris, éd. Errance (coll. des Hespérides), $288 \mathrm{p}$.

1993 : Ecologie d'un outil: la hache de pierre en Irian Jaya (Indonésie), Paris, CNRS Éditions (Monographie du CRA, 12), $461 \mathrm{p}$.

\section{Pétrequin P., Pétrequin A.-M. (Dir.)}

2001 : Clairvaux 2001. Trois millénaires d'habitai lacustre, Besançon/Doucier. Laboratoire de chrono-écologie/Centre de recherche archéologique de la vallée de l'Ain, $331 \mathrm{p}$.
Pétrequin P., Arbogast R.-M., BourquinMignot C., LaVier C., Viellet A.

1998 : « Demographic growth, environmental changes and technical adaptations: responses of an agricultural community from the $32^{\text {nd }}$ to the $30^{\text {th }}$ centuries $\mathrm{BC}$ ", World Archaeology, 30, 2, p. 181-192.

\section{Pétrequin P., Viellet A., Illert N.}

1999 : "Le Néolithique au nord-ouest des Alpes : rythmes lents de l'habitat, rythmes rapides des techniques et des styles ?" in Brafmer F., Cifuziol S., Coudart A. (ÉD.), Habital et société, Actes des XIX'rencontres internationales d'archéologie et d'histoire d'Antibes, oct. 1998, Antibes, éd. APDCA, p. 297-323.

\section{Ponel P.}

1997 : "Succession des assemblages de coléoptères à Chalain 3 ", in PÉtrelocin P. (DIR.), Les Sites littoraux néolithiques de Clairvaux-les-Iars et de Chalain (Jura) -IIIChalain station 3 : 3200-2900 av. J.-C., Paris, éd. de la Maison des sciences de l'Homme, p. 113-118.

\section{RAMEAU J.-C.}

1987 : Contribution phytoécologique et dynamique à l'étude des écosystèmes forestiers. Applications aux forêts du nord-est de la France, thèse d'État, univ. de Franche-Comté, $344 \mathrm{p}$.

Rameau J.-C., Schmitt A., Bidault M., GAIFFE M. (ÉD.)

1980 : Végétation et écologie des forêts comtoises, Besançon, $\mathrm{n}^{\circ}$ spécial du Bulletin de la Société d'histoire naturelle du Doubs et du Bulletin de l'Association UNTVERS, p. 80-116.

\section{RICHARD H.}

1989a : L'analyse pollinique du Petit Lac: les six mètres supérieurs, in Pétrequin $P$. (DIR.) Les Sites littoraux néolithiques de Clairvaux-les-Lacs (Jura) -II- Le Néolithique moyen, Paris, éd. de la Maison des sciences de l'Homme, p. 45-49.

$1989 \mathrm{~b}$ : « Essai de modélisation palynologique sur le Grand Lac ", in PéTrequiN P. (DIR.), Les Sites littoraux néolithiques de Clairvauxles-Lacs (Jura) III-Le Néolithique moyen, Paris, éd. de la Maison des sciences de l'Homme, p. 39-43.

1997 : "Analyse pollinique d'un sondage de $7,5 \mathrm{~m}$ ", in Pŕtrfolcix P. (DIR.), Les Siles littoraux néolithiques de Clairvaux-les-Lats et de Chalain (Jura) -III- Chalain station 3:
3200-2900 av. J.-C., Paris, éd. de la Maison des sciences de l'Homme, p. 101-112.

1999 : Interface milieux naturels sociétés et techniques, Besançon, Laboratoire de chronoécologie, p. 11-21.

\section{Richoz I., Gaillard M.J.}

1989 : "Histoire de la végétation neuchâteloise de l'époque néolithique à nos jours. Analyse pollinique d'une colonne sédimentaire prélevée dans le lac de Neuchâtel (Suisse) ", Bulletin de la Société vaudoise des sciences naturelles, 79,4 , p. 355-377.

\section{Richoz I., Gaullard M.J., MagnY M.}

1994 : " The Influence of human activities and climate on the development of vegetation at Seedorf, Southern Swiss Plateau, during the Holocene: a case study ", Dissertationes Botanicae, 234, p. 423-445.

\section{SCHWEINGRUBER F.-H.}

1990 : Anatomie europaïscher Hölzer: ein Atlas zur Bestimmung europaïscher Baum-, Strauchund Zwergstrauchhölzer, Bern/Stuttgart, Haupt, $800 \mathrm{p}$.

SMART T. L., HofFMan E. S.

1987 : " Environnemental interpretation of archaeological charcoal ", in Hastorf C.-A., Popper V. S. (DIR.), Current Paleothnobotany: Analytical Methods and Cultural Interpretation of Archaeological Plant Remains, Chicago/London, The University of Chicago Press, p. 167-205.

\section{THÉRY-ParISOT I.}

2001 : Économie des combustibles au Paléolithique: expérimentation, taphonomie, anthracologie, Paris, CNRS Éditions, Centre d'études Préhistoire, Antiquité, Moyen Âge (Dossier de documentation archéologique, 20), $195 \mathrm{p}$.

Trivaudey M.-J., Bailly G.

1991 : Étude phytosociologique de l'abord occidental du lar de Chalain (carte de la végétation au $\left.1 / 2500^{\circ}\right)$, Rapport du SIVOM de la région de Clairvaux-les-Lacs et Association pour la promotion de l'archéologie dans le Jura, 29 p.

\section{VIELLET A.}

2002 : " The isolated structure of the Neolithic site 19, Lake Chalain (Jura, France) : dendrochronological study of oak pilings (Quercus sp.) ", Dendrochronologia, 20, 3, p. $301-312$. 